\title{
Multi-Mechanism Flood Hazard Assessment: Critical Review of Current Practice and Approaches
}

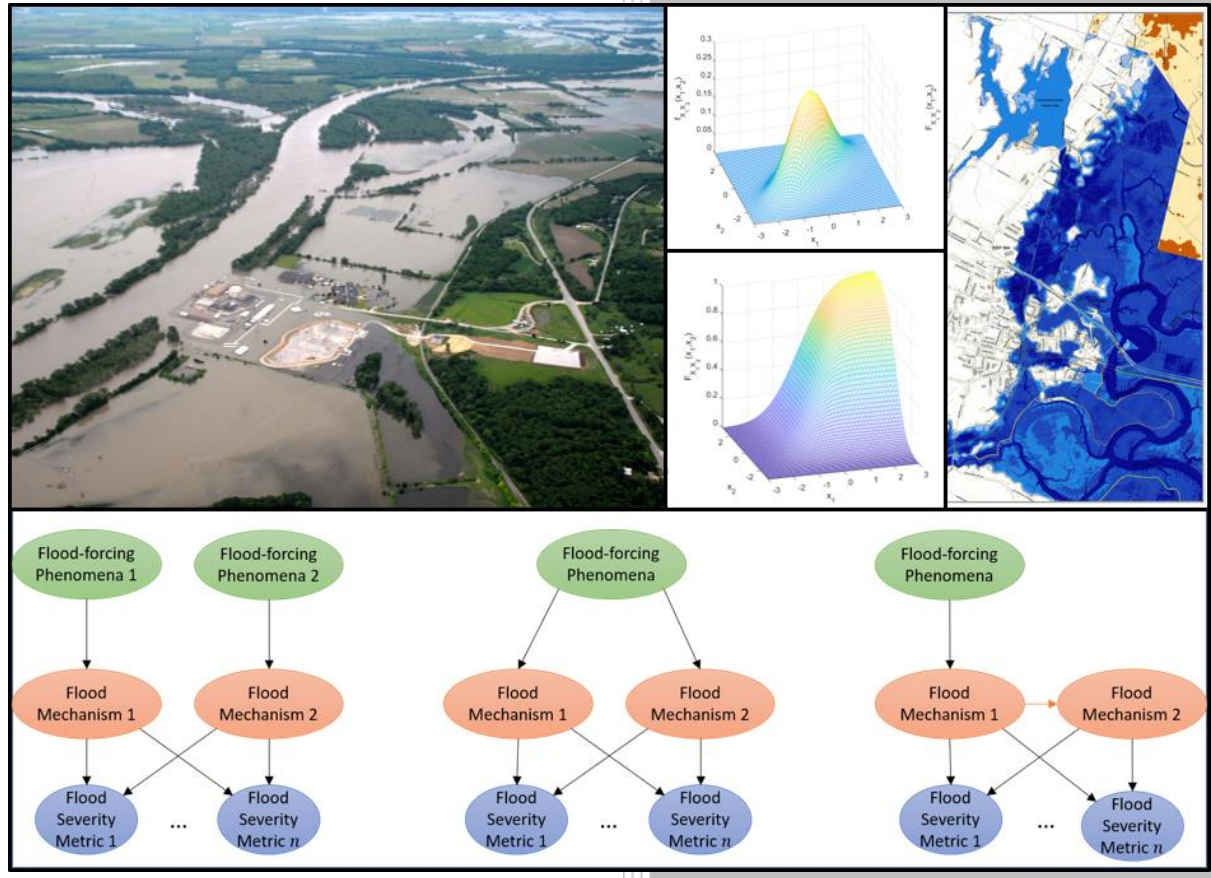

Approved for public release. Distribution is unlimited.
Michelle Bensi

Somayeh Mohammadi Shih-Chieh Kao Scott T. DeNeale July 2020 


\section{DOCUMENT AVAILABILITY}

Reports produced after January 1, 1996, are generally available free via US Department of Energy (DOE) SciTech Connect.

Website www.osti.gov

Reports produced before January 1,1996, may be purchased by members of the public from the following source:

National Technical Information Service

5285 Port Royal Road

Springfield, VA 22161

Telephone 703-605-6000 (1-800-553-6847)

TDD 703-487-4639

Fax 703-605-6900

E-mailinfo@ntis.gov

Website http://classic.ntis.gov/

Reports are available to DOE employees, DOE contractors, Energy Technology Data Exchange representatives, and International Nuclear Information System representatives from the following source:

Office of Scientific and Technical Information

PO Box 62

Oak Ridge, TN 37831

Telephone 865-576-8401

Fax 865-576-5728

E-mail reports@osti.gov

Website http://www.osti.gov/contact.html

This report was prepared as an account of work sponsored by an
agency of the United States Government. Neither the United States
Government nor any agency thereof, nor any of their employees, makes
any warranty, express or implied, or assumes any legal liability or
responsibility for the accuracy, completeness, or usefulness of any
information, apparatus, product, or process disclosed, or represents that
its use would not infringe privately owned rights. Reference herein to
any specific commercial product, process, or service by trade name,
trademark, manufacturer, or otherwise, does not necessarily constitute
or imply its endorsement, recommendation, or favoring by the United
States Government or any agency thereof. The views and opinions of
authors expressed herein do not necessarily state or reflect those of the
United States Government or any agency thereof.

Cover credits: Photograph (top-left) of Missouri River flooding at Fort Calhoun Nuclear Power Plant reprinted from Unknown Author and made available under a Creative Commons Attribution 3.0 Unported license. Map (top-right) of estimated flood depth reprinted from Unknown Author and made available under a Creative Commons Attribution 3.0 Unported license. 
Environmental Sciences Division

\title{
MULTI-MECHANISM FLOOD HAZARD ASSESSMENT: CRITICAL REVIEW OF CURRENT PRACTICE AND APPROACHES
}

\author{
University of Maryland, College Park \\ Michelle Bensi \\ Somayeh Mohammadi
}

\section{Oak Ridge National Laboratory \\ Shih-Chieh Kao \\ Scott T. DeNeale}

July 2020

\author{
Prepared for \\ US Nuclear Regulatory Commission \\ Rockville, MD
}

\author{
Prepared by \\ OAK RIDGE NATIONAL LABORATORY \\ Oak Ridge, TN 37831-6283 \\ managed by \\ UT-BATTELLE, LLC \\ for the \\ US DEPARTMENT OF ENERGY \\ under contract DE-AC05-00OR22725
}





\section{CONTENTS}

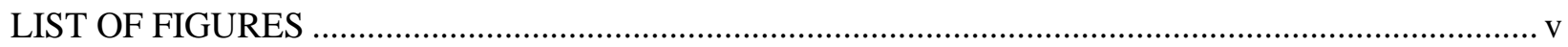

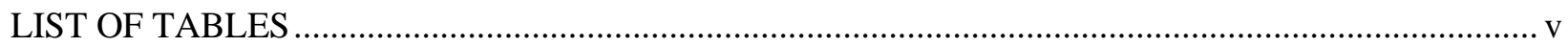

ABBREVIATIONS, ACRONYMS, AND INITIALISMS ….................................................... vii

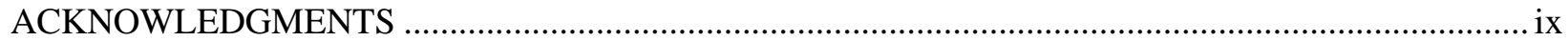

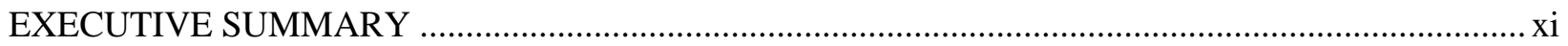

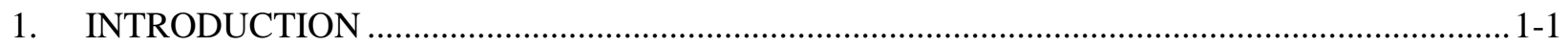

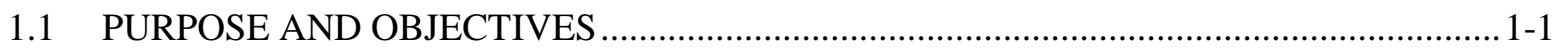

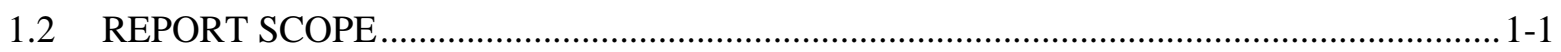

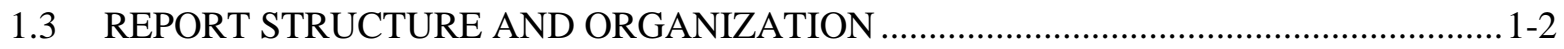

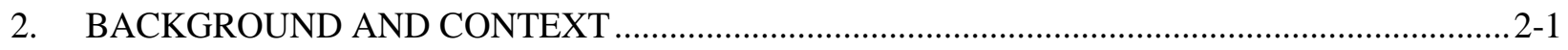

2.1 HAZARDS OF RELEVANCE TO US NUCLEAR POWER PLANTS .............................. 2-1

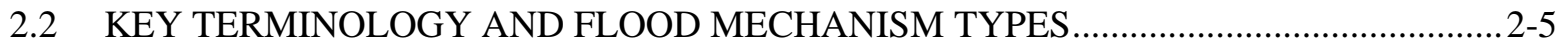

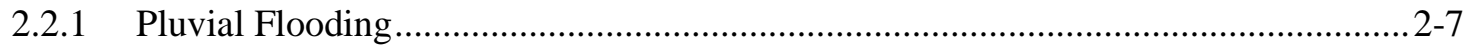

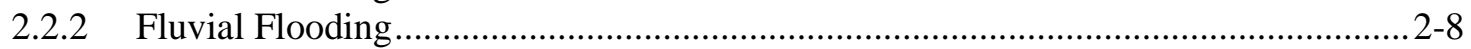

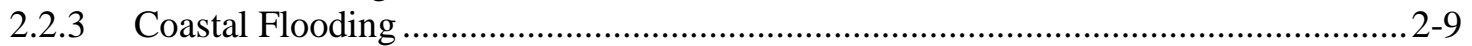

2.3 MULTI-MECHANISM FLOOD HAZARD FRAMEWORK …................................... 2-10

3. OVERVIEW OF PROBABILISTIC FLOOD HAZARD ASSESSMENT …................................. 3-1

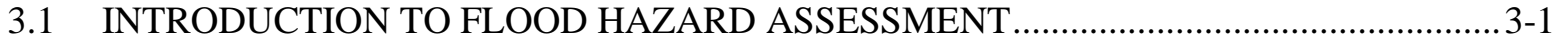

3.2 INTRODUCTION TO RANDOM VARIABLES AND DISTRIBUTIONS ........................ 3-2

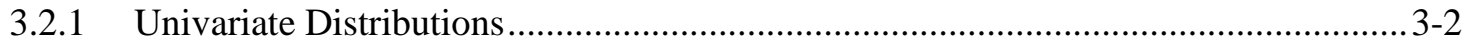

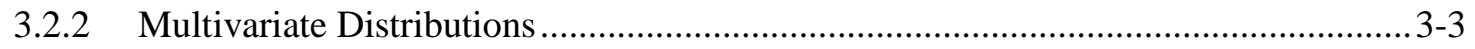

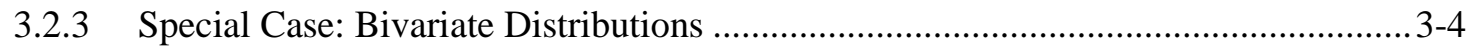

3.3 SUMMARY OF APPROACHES TO DEVELOP JOINT DISTRIBUTIONS ..................... 3-6

3.3.1 Direct Estimation of Joint Distributions .................................................................

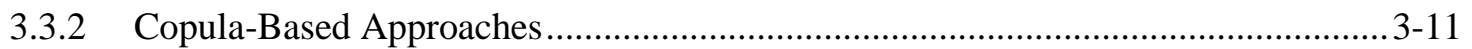

3.3.3 Bayesian-Motivated Approaches …................................................................... 3-13

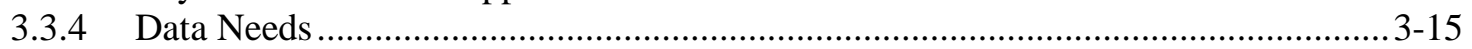

3.4 DEVELOPMENT OF HAZARD CURVES AND SURFACES …..................................... 3-16

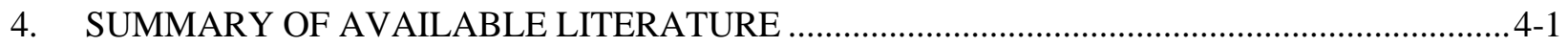

4.1 OVERVIEW OF AVAILABLE LITERATURE .........................................................

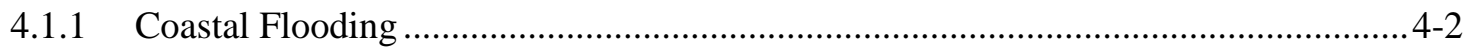

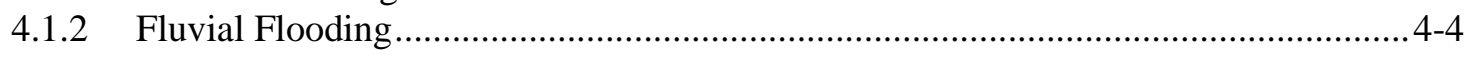

4.1.3 Coastal and Fluvial Joint Flooding ...................................................................... 4-6

4.1.4 Coastal and Pluvial Joint Flooding ................................................................ 4-11

4.1.5 Coastal and Precipitation (Pluvial or Fluvial) .................................................... 4-11

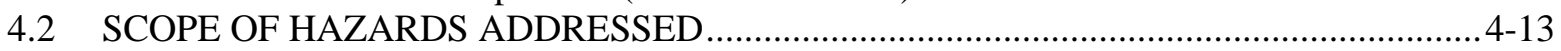

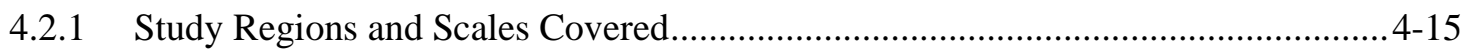

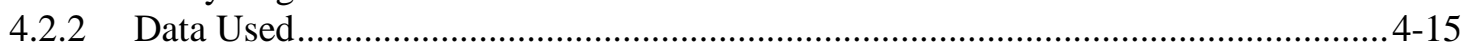

5. CRITICAL REVIEW OF EXISTING PRACTICE AND RESEARCH ….............................. $5-1$

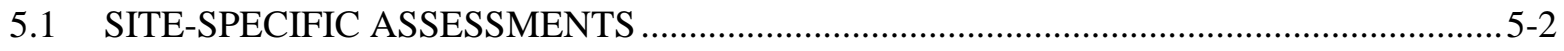

5.2 DEFINITION OF FLOOD SEVERITY METRICS .............................................. $5-2$

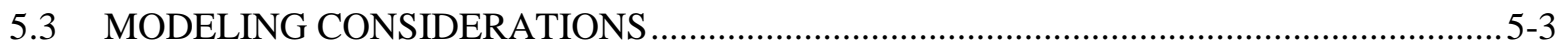

5.3.1 Return Periods Considered in Existing Assessments............................................. 5-3

5.3.2 Length of Record and Characteristics of Available Data Series ................................. 5-3

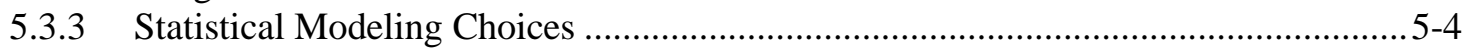

5.3.4 Assumptions Regarding Concurrence of Extrema ..................................................5-6

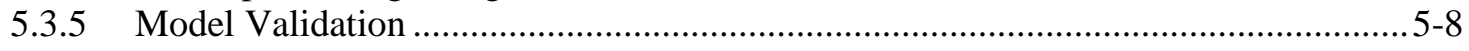

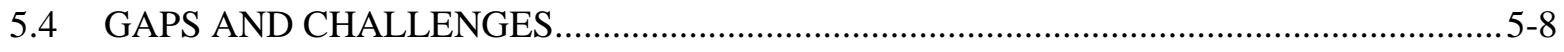




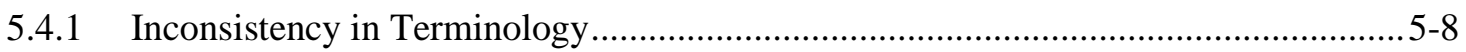

5.4.2 Presentation of Results......................................................................................... $5-9$

5.4.3 Lack of a Comprehensive Framework for Analyzing Dependence among Variables

5.4.4 Limited Scope of Variables Included in Existing Models ....................................... 5-10

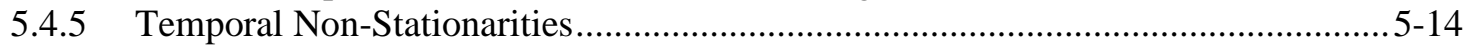

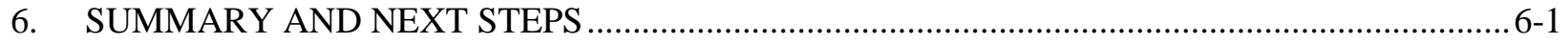

6.1 CONSIDERATIONS FOR PROBABILISTIC FLOOD HAZARD ASSESSMENT

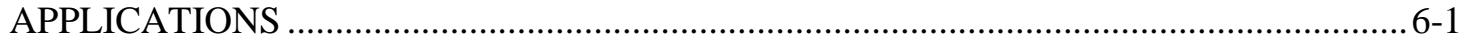

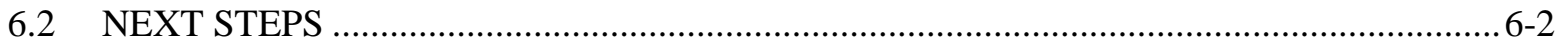

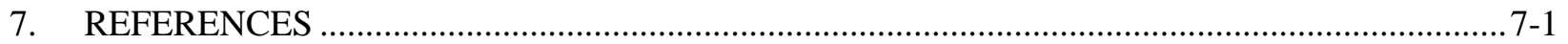

APPENDIX A. SUMMARY OF CURRENT US AND INTERNATIONAL MULTI-

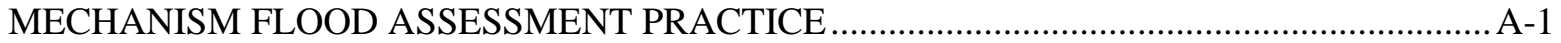

APPENDIX B. KEY COASTAL HAZARD TERMINOLOGY …................................................... 


\section{LIST OF FIGURES}

Figure 2-1. Flood hazards assessed at US nuclear power plant (NPP) sites. .......................................2-2

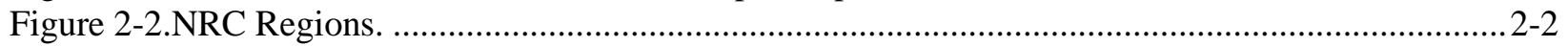

Figure 2-3. Map of flood hazards assessed at US nuclear power plant sites in Region 1......................2-3

Figure 2-4. Map of flood hazards assessed at US nuclear power plant sites in Region 2.......................2-4

Figure 2-5. Map of flood hazards assessed at US nuclear power plant sites in Region 3.......................2-4

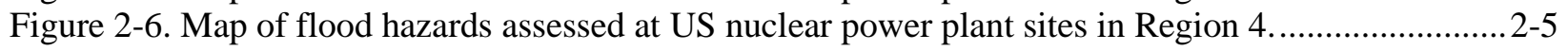

Figure 2-7. Multi-mechanism flood terminology hierarchy. ..................................................... 2-7

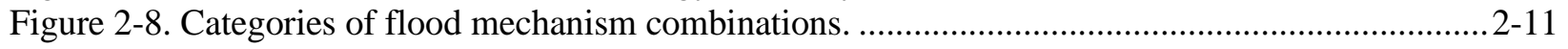

Figure 3-1. Conceptual example of hazard curves................................................................... 3-2

Figure 3-2. (left) Conceptual example of probability density function and (right) cumulative distribution function.

Figure 3-3. (left) Example of bivariate probability density function and (right) bivariate cumulative distribution function.

Figure 3-4. Example of generalized extreme value distribution with differing $\boldsymbol{k}$ values $(\boldsymbol{\alpha}=$ $\mathbf{1}, \boldsymbol{\beta}=\mathbf{1})$.

Figure 3-5. Illustration of (a) the joint Probability density function (PDF) $\boldsymbol{f} \boldsymbol{X} \boldsymbol{Y} \boldsymbol{x}, \boldsymbol{y}$ along with projections of marginal PDFs $\boldsymbol{f} \boldsymbol{X}(\boldsymbol{x})$ and $\boldsymbol{f} \boldsymbol{Y}(\boldsymbol{y})$; (b) contour plot of joint PDF $\boldsymbol{f} \boldsymbol{X} \boldsymbol{Y}(\boldsymbol{x}, \boldsymbol{y})$; and (c) joint Cumulative distribution function $\boldsymbol{F} \boldsymbol{X} \boldsymbol{Y}(\boldsymbol{x}, \boldsymbol{y})$ generated using copulas.

Figure 3-6. Simple Bayesian network.

Figure 4-1. Illustration of concurrent correlated flood mechanisms (storm surge and runoffinduced river flooding) generated by a common flood-forcing phenomena (hurricane).

Figure 5-1. (a) Graphical model representing the process considered in Archetti et al. (2011). (b) Graphical model presenting variables included in model developed in Archetti et al. (2011).

Figure 5-2. (a) Graphical model representing the process considered in Lian et al. (2012). (b) Graphical model presenting variables included in model developed in Lian et al. (2012).

Figure 5-3. (a) Graphical model representing the process considered in Bass and Bedient (2018).

(b) Graphical model presenting variables included in model developed in Bass and Bedient (2018)..

Figure B-1. (top) Example of observed water levels and predicted water levels and (bottom) example of storm surge and skew surge.

Figure B-2. Illustration of storm tide and storm surge.

\section{LIST OF TABLES}

Table 3.1. Illustrative expressions of joint distributions for several applications................................ 3-18

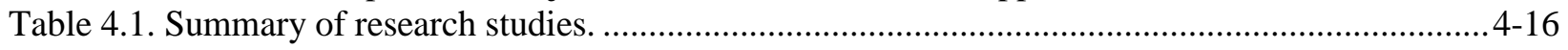

Table 5.1. Summary of copulas used in literature and basis for selection. 



\section{ABBREVIATIONS, ACRONYMS, AND INITIALISMS}

\begin{tabular}{|c|c|}
\hline ADCIRC & Advanced Circulation Model \\
\hline AEP & Annual exceedance probability \\
\hline $\mathrm{CDF}$ & Cumulative distribution function \\
\hline CFFA & Coincidental flood frequency analysis \\
\hline COFF & Copula-based flood frequency \\
\hline DEM & Digital elevation model \\
\hline DFHA & Deterministic flood hazard assessment \\
\hline EPRI & Electrical Power Research Institute \\
\hline ETC & Extratropical cyclone \\
\hline $\mathrm{EV}$ & Extreme value \\
\hline EVA & Extreme value analysis \\
\hline FEMA & Federal Emergency Management Agency \\
\hline FERC & Federal Energy Regulatory Commission \\
\hline FFIRM & Federal flood insurance rate map \\
\hline GEV & Generalized extreme value \\
\hline GOW & Global Ocean Wave \\
\hline IAEA & International Atomic Energy Agency \\
\hline JPM & Joint probability method \\
\hline LIP & Local intense precipitation \\
\hline MMF & Multi-mechanism flood \\
\hline NFRMP & National Flood Risk Management Program \\
\hline NGDC & National Geodetic Data Center \\
\hline NOAA & National Oceanic and Atmospheric Administration \\
\hline NPP & Nuclear power plant \\
\hline $\mathrm{NRC}$ & Nuclear Regulatory Commission \\
\hline PDF & Probability density function \\
\hline PFHA & Probabilistic flood hazard assessment \\
\hline PHRaM & Parametric hurricane rainfall model \\
\hline PMSS & Probable maximum storm surge \\
\hline PoT & Peak-over-threshold \\
\hline PRA & Probabilistic risk assessment \\
\hline PSA & Probabilistic safety assessment \\
\hline PWL & Peak water level \\
\hline $\mathrm{RCM}$ & Regional climate model \\
\hline RiskMAP & Risk Mapping, Assessment and Planning \\
\hline SLR & Sea level rise \\
\hline SRP & Standard Review Plan \\
\hline SWH & Significant wave height \\
\hline $\mathrm{TC}$ & Tropical cyclone \\
\hline TCR & Tropical cyclone rainfall \\
\hline USACE & US Army Corps of Engineers \\
\hline USBR & US Bureau of Reclamation \\
\hline USGS & US Geological Survey \\
\hline WAM & Wave model developed by the Wave Model Development and Implementation Group \\
\hline WETC & Wet extratropical cyclone \\
\hline WRF & Weather and Research Forecasting model \\
\hline
\end{tabular}





\section{ACKNOWLEDGMENTS}

\section{US Nuclear Regulatory Commission}

The authors would like to acknowledge and express their appreciation to the US Nuclear Regulatory Commission (NRC) for overseeing and funding this research. The following NRC staff were heavily involved in supporting this research effort:

- Meredith Carr

- Joseph Kanney

- Yuan Cheng

- Elena Yegorova

\section{Oak Ridge National Laboratory}

The following individuals from Oak Ridge National Laboratory provided technical review and support for this report and associated review:

- Kevin Stewart

- Deborah Counce

- Olivia Shafer 



\section{EXECUTIVE SUMMARY}

This report documents the initial findings from the Nuclear Regulatory commission (NRC)-sponsored research project Methods for Estimating Joint Probabilities of Coincident and Correlated Flooding Mechanisms for Nuclear Power Plant Flood Hazard Assessments. ${ }^{1}$ This research project is a part of NRC's Probabilistic Flood Hazard Assessment (PFHA) Research Program and will aid the development of guidance on the use of PFHA methods to evaluate infrastructure safety for existing and proposed US nuclear power plants (NPPs). More specifically, this project intends to provide technical background for the development of flood hazard curves for multi-mechanism floods (MMFs). MMFs are flood events caused by more than one flooding mechanism (e.g., flood events due to the simultaneous occurrence of precipitation-induced river flooding and storm surge).

Project activities include three main tasks:

- Task 1-Survey of current concepts and methods in assessing MMF hazards

- Task 2-Critical assessment of selected methods and approaches for quantifying probabilistic MMF hazard risk

- Task 3-Development of example case studies to illustrate best practices for quantifying probabilistic MMF hazard risk

The initial findings from Tasks 1 and 2 are documented in this report. Task 1 comprised a survey of approaches and methods that have been applied to understand and assess flood hazards due to MMFs. Task 2 involved a critical review of the selected approaches and methods. To that end, the scope of this report includes documentation of (1) a reconnaissance-level survey of the current state of concepts and practice for MMF hazard assessment; (2) a generalized MMF assessment framework to address the distinctions among various types of flood-forcing phenomena, flood mechanisms (grouped into three mechanism types), and flood severity metrics; (3) a wide-ranging survey of approaches and methods that have been applied to various flooding phenomena and settings; and (4) a critical assessment of MMF hazard assessment methods.

Studies were identified involving MMFs related to coastal flooding mechanisms, fluvial (rivers/streams) flooding mechanisms, and associated combinations of coastal and fluvial flooding mechanisms. Studies were also identified that address MMFs involving coastal and fluvial flooding mechanisms as well as coastal flooding mechanisms along with extreme precipitation (without specific attribution to fluvial or pluvial mechanisms). The studies identified for review in this report included assessments at varying spatial scales (from local to global) with differing geographic regions of focus using both observed and synthetic data. The majority of studies identified and reviewed were site-specific assessments focusing on relatively short return periods. Studies considered a range of flood severity metrics, made differing assumptions regarding the occurrence of extrema, and used multiple statistical techniques; the use of copulas for the development of joint distributions was a particularly popular analysis technique. The literature review highlighted the differences among existing studies relative to terminology used, means of presenting results, framework and techniques employed, and level of sophistication regarding the number and types of variables considered. Despite the significant diversity in existing studies, the review identified several promising techniques that will be considered in future work under this project, including the development of joint distributions for MMFs using copula and Bayesian-motivated approaches.

\footnotetext{
${ }^{1}$ NRC Agreement No. NRCHQ2514D0004, Task Order 31310018F0038, DOE Interagency Agreement No. 1886$761-13$
} 


\section{INTRODUCTION}

\subsection{PURPOSE AND OBJECTIVES}

The purpose of this report is to provide a summary of the current state of practice, including concepts and methods used for assessing flood hazards due to a combination of flood mechanisms. This report refers to a flood hazard due to a combination of flood mechanisms as a "multi-mechanism flood" (MMF). Based on the most recent studies and regulatory guidance, this report documents a broad range of flood-forcing phenomena, hydrologic settings (e.g., flooding in coastal, estuary, or riverine locations subject to various geographic and seasonal conditions), and available methods to estimate hazards associated with MMFs.

Furthermore, this report provides a critical review of the current state of practice for MMF hazard assessment, with particular emphasis on assessing research and applied guidance from the perspective of nuclear power plant (NPP) applicability, which includes severe events with low annual frequencies of exceedance (long return periods). This report also provides background context regarding key components of probabilistic flood hazard assessment (PFHA) and related mathematical formulations necessary to assess MMFs.

This report has been developed through a research project funded by the US Nuclear Regulatory Commission (NRC) intended to assist NRC in developing the technical basis for guidance on developing probabilistic estimates of flood hazards for combinations of flood mechanisms. This research project is a part of NRC PFHA Research Program and will support development of guidance on the use of PFHA methods in safety evaluations for existing or proposed US NPP infrastructure.

According to the NRC PFHA Research Plan (USNRC 2014),

the current limited risk-informed guidance with respect to flooding constitutes a significant gap in the NRC's risk-informed, performance-based regulatory approach to the assessment of natural hazards and potential consequences for safety of commercial nuclear facilities.

According to Safety Strategy 2 of its Strategic Plan for Fiscal Years 2018-2022 (USNRC 2018a), NRC aims to

further risk-inform the current regulatory framework in response to advances in science and technology, policy decisions, and other factors, including prioritizing efforts to focus on the most safety-significant issues.

To support this strategy, NRC (USNRC 2018a) identifies a contributing activity to

conduct research activities to confirm the safety of operations and enhance the regulatory

framework by addressing changes in technology, science, and policies.

The research effort documented in this report supports this activity.

\subsection{REPORT SCOPE}

This report summarizes the initial findings from the NRC-sponsored research project Methods for Estimating Joint Probabilities of Coincident and Correlated Flooding Mechanisms for Nuclear Power Plant Flood Hazard Assessments. This report's content will be combined with future research products to produce a synthesized NRC NUREG/CR report documenting the project's outcomes across three main research tasks. These three main project research tasks are 
- Task 1 - Survey of current concepts and methods in assessing MMF hazards

- Task 2-Critical assessment of selected methods and approaches for quantifying probabilistic MMF hazard risk

- Task 3-Development of example case studies to illustrate best practices for quantifying probabilistic MMF hazard risk

The main outcomes of Tasks 1 and 2 reported here include documentation of (1) a reconnaissance-level survey of the current state of concepts and practice for MMF hazard assessment; (2) a generalized MMF assessment framework to address the distinctions among flood-forcing phenomena, flood mechanisms (which are categorized into three types of mechanisms), and flood severity metrics; (3) a wide-ranging survey of approaches and methods that have been applied to various flooding phenomena and settings; and (4) a critical assessment of MMF hazard assessment methods. Ultimately, this report aims to document a collection of available MMF methods that are sufficiently general or flexible for application to the range of flooding phenomena expected at US NPPs.

The discussion of specific references, methods, software or tools in this report does not constitute endorsement or approval for any specific use by Oak Ridge National Laboratory, the University of Maryland, or NRC.

\subsection{REPORT STRUCTURE AND ORGANIZATION}

The report is organized into the following sections:

- Section 2 provides background and context for the report, including defining key terms and concepts that will be used throughout the report and identifying flooding hazards of relevance to US NPPs.

- Section 3 provides an overview of PFHA and summarizes the mathematical formulations necessary to assess MMFs, including an overview of random variables and distributions; approaches for developing joint distributions; and hazard curve development.

- Section 4 provides a descriptive summary of available MMF-related literature and a description of the hazards and geographic regions/scales addressed in existing literature. It also identifies the data and statistical methods applied in existing studies.

- Section 5 provides a critical review of identified resources and describes considerations in existing MMF-related studies with a focus on identifying key themes across the broad scope of studies reviewed under this project. Additionally, it identifies key gaps and challenges.

- Section 6 summarizes the report's initial findings and next steps.

This report also includes appendices that provide detailed information to supplement the main report's more generalized content. Appendices address the following topics:

- Appendix A summarizes current practice related to MMFs by providing summaries of relevant guidance used in the United States and international nuclear industries, as well as nonnuclear applications.

- Appendix B introduces key terminology related to coastal hazard assessment. 


\section{BACKGROUND AND CONTEXT}

This background section identifies flood hazards of relevance to US NPPs, presents key terminology related to MMFs, and introduces a graphical model-based framework and terminology for discussing combinations of flooding mechanisms.

\subsection{HAZARDS OF RELEVANCE TO US NUCLEAR POWER PLANTS}

US NRC guidance for evaluation of flooding addresses the following hazards (USNRC 2007a):

- Local intense precipitation (LIP)

- River/streams

- Dam failures

- Storm surge

- Seiches

- Tsunamis

- Ice effects

Figure 2-1 shows the percentage of sites for which an analysis was performed for each hazard during NRC's plant-specific Japan lessons-learned activities for flooding hazard reevaluation. ${ }^{2}$ A flooding hazard was considered to affect a US NPP if the mechanism (1) was included in the plant's design basis or (2) was found to exceed or otherwise go beyond the hazards considered in a plant's design basis based on evaluations performed as part of the post-Fukushima hazard reevaluations, as documented in NRC staffissued interim staff responses (USNRC 2018b). ${ }^{3}$ Figure 2-2 shows different NRC regions used for preparation of flood hazard maps. Figure 2-3 through Figure 2-6 show the hazards evaluated at each nuclear site, segmented by region. These maps include sites for which LIP, fluvial (rivers/streams), dam failure, storm surge, and other (i.e., seiche-, tsunami-, and ice-induced) flooding were assessed.

\footnotetext{
${ }^{2}$ Figure 2-1 and the maps that follow reflect hazards for which an analysis was performed at each site. The performance of an analysis may, in some cases, identify that the analyzed hazard did not result in at-site flood effects. In these cases, if the hazard was assessed, it is included in the maps and figures presented herein. ${ }^{3}$ As a result of the lessons learned from the March 2011 events at the Fukushima Daichi nuclear power facility in Japan, NRC undertook a series of actions. One of those actions was to request that all US NPP licensees perform flood hazard reevaluations using present-day guidance and methods (which typically employ deterministic approaches). The staff evaluated the licensees' reevaluations and issued summary information that included tables documenting the design basis flood hazard elevations (stillwater plus waves/runup) as well as the reevaluated flood hazard elevations, if those elevations exceeded the design basis elevations.
} 


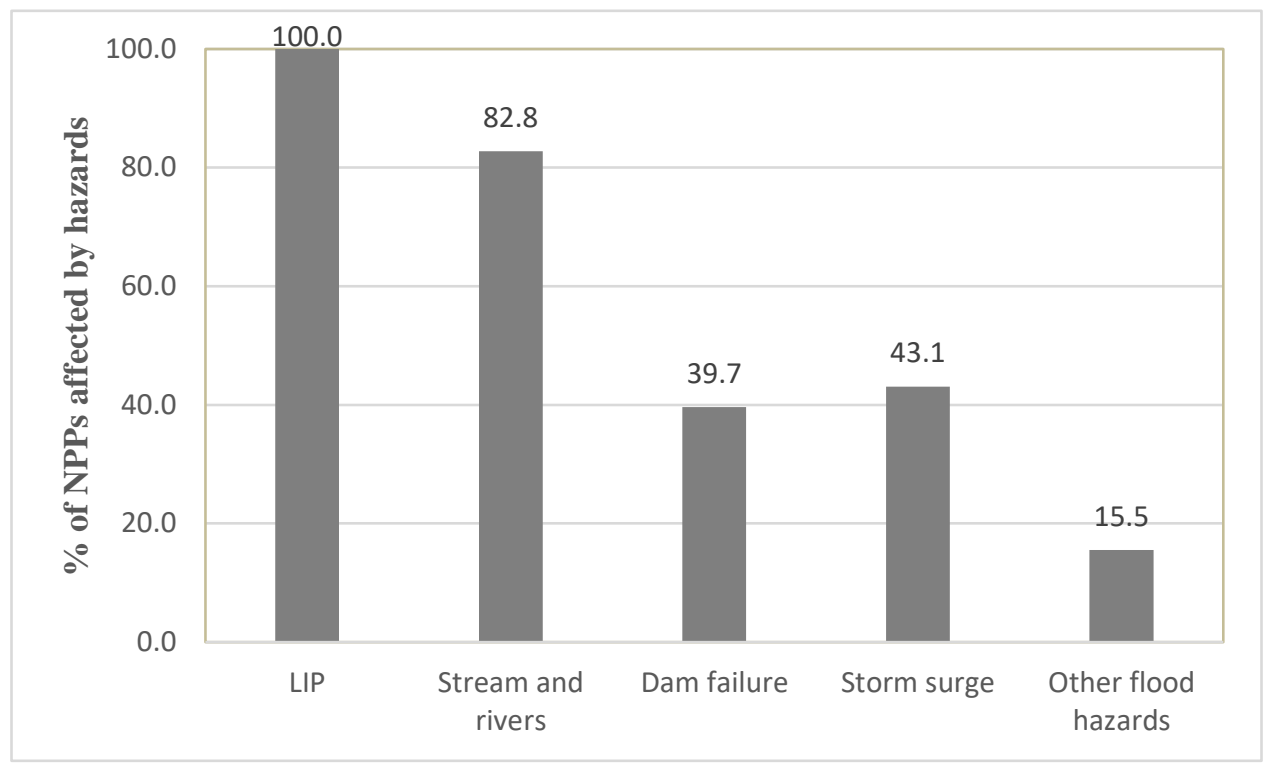

Figure 2-1. Flood hazards assessed at US nuclear power plant (NPP) sites. LIP $=$ local intense precipitation. Data from USNRC $(2018 b)^{4}$

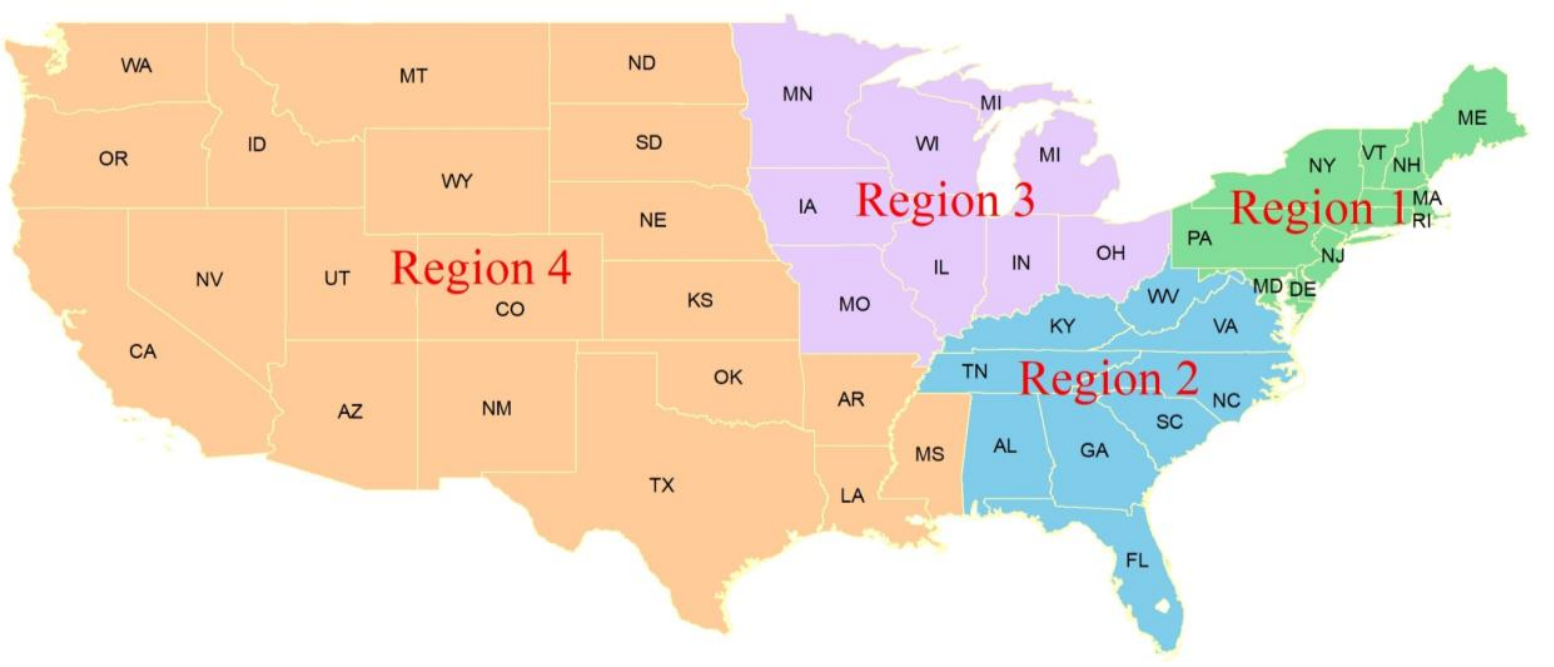

Figure 2-2.NRC Regions.

${ }^{4}$ This figure includes NPP sites operating as of August 2019. 


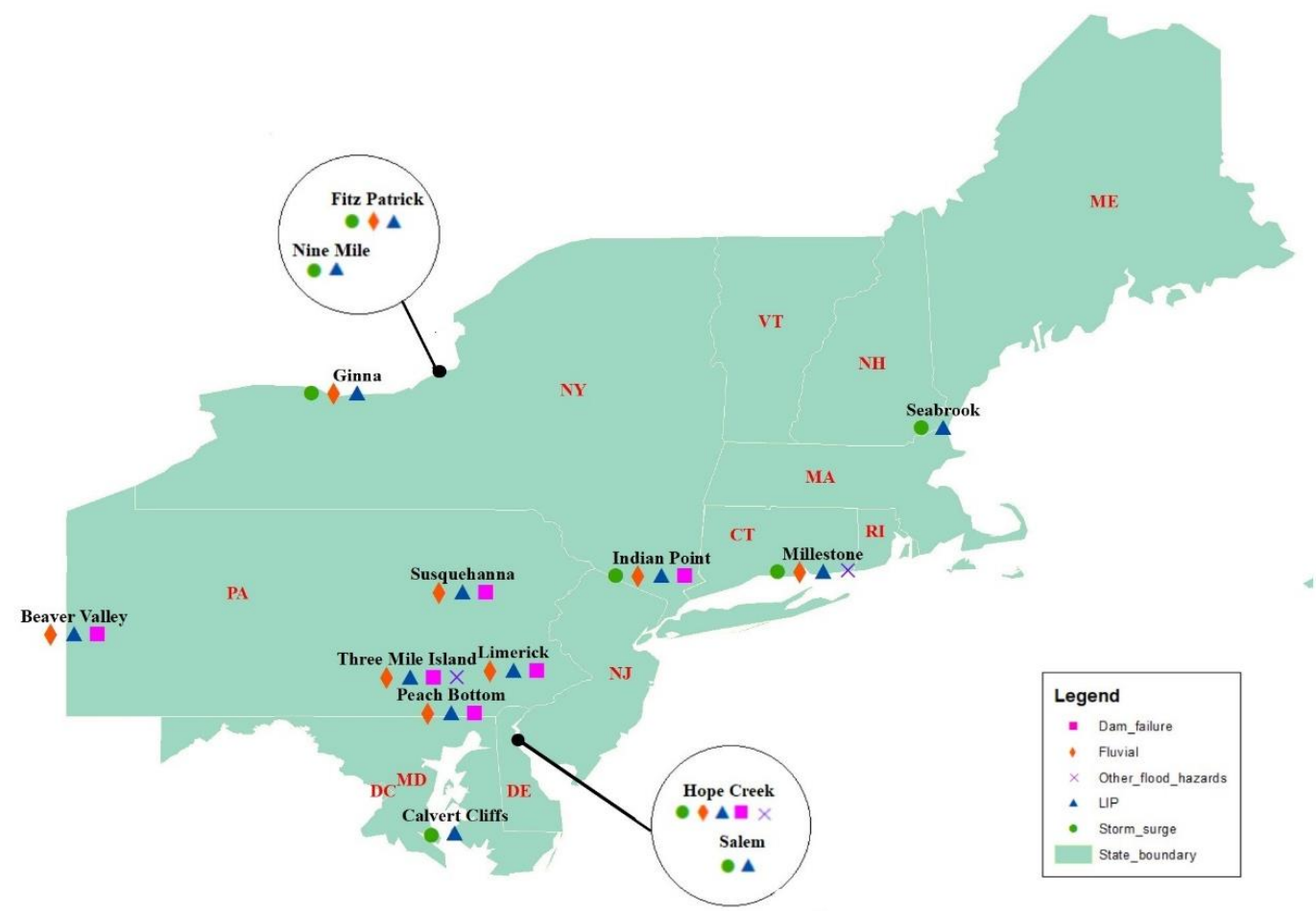

Figure 2-3. Map of flood hazards assessed at US nuclear power plant sites in Region 1. LIP $=$ local intense precipitation. Data from USNRC (2018b). ${ }^{4}$ 


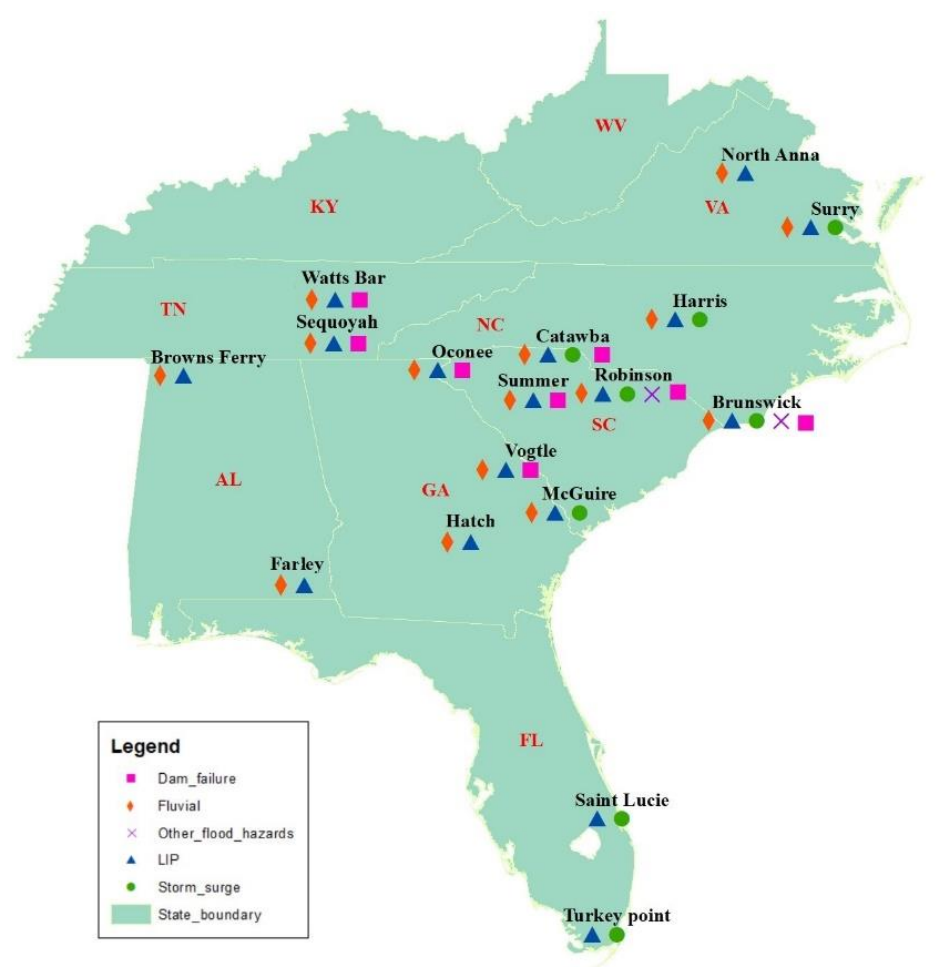

Figure 2-4. Map of flood hazards assessed at US nuclear power plant sites in Region 2. LIP $=$ local intense precipitation. Data from USNRC (2018b). ${ }^{4}$

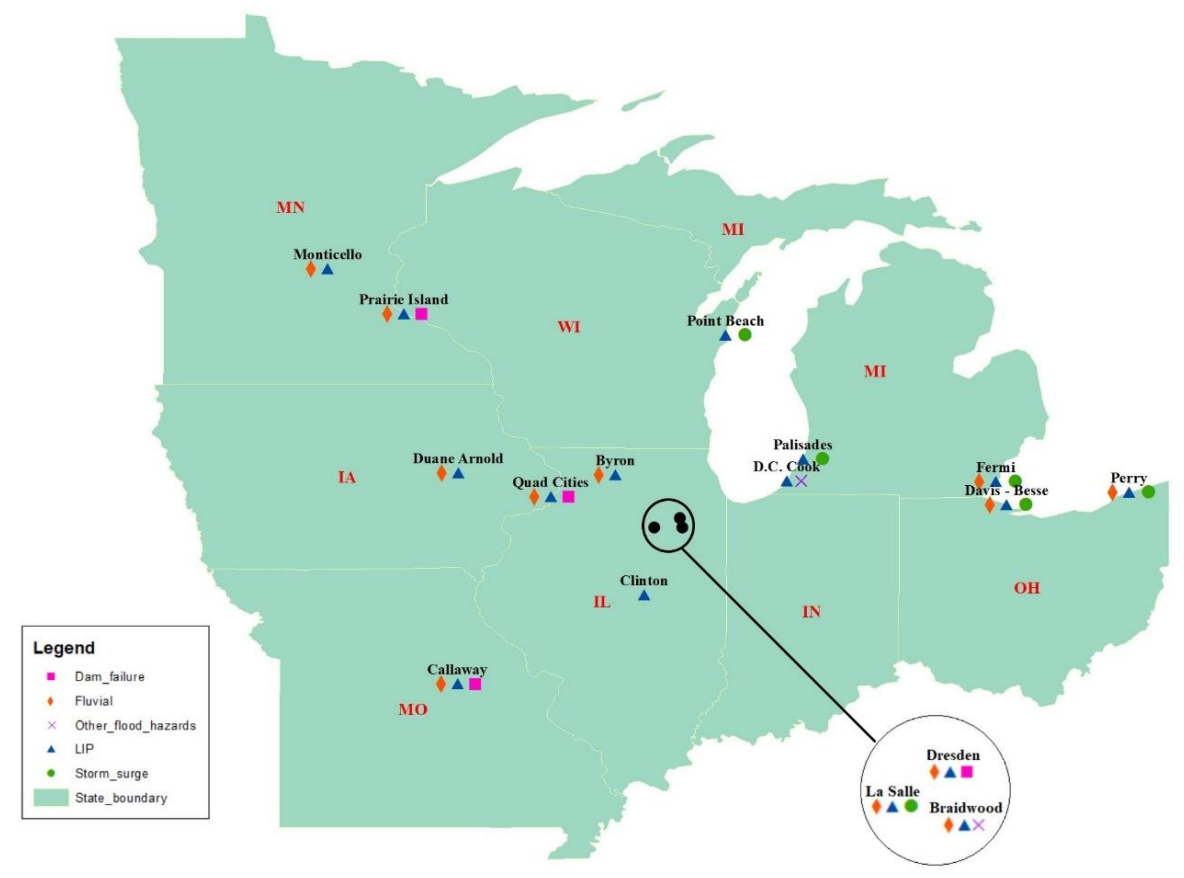

Figure 2-5. Map of flood hazards assessed at US nuclear power plant sites in Region 3. LIP $=$ local intense precipitation. Data from USNRC $(2018 b){ }^{4}$ 


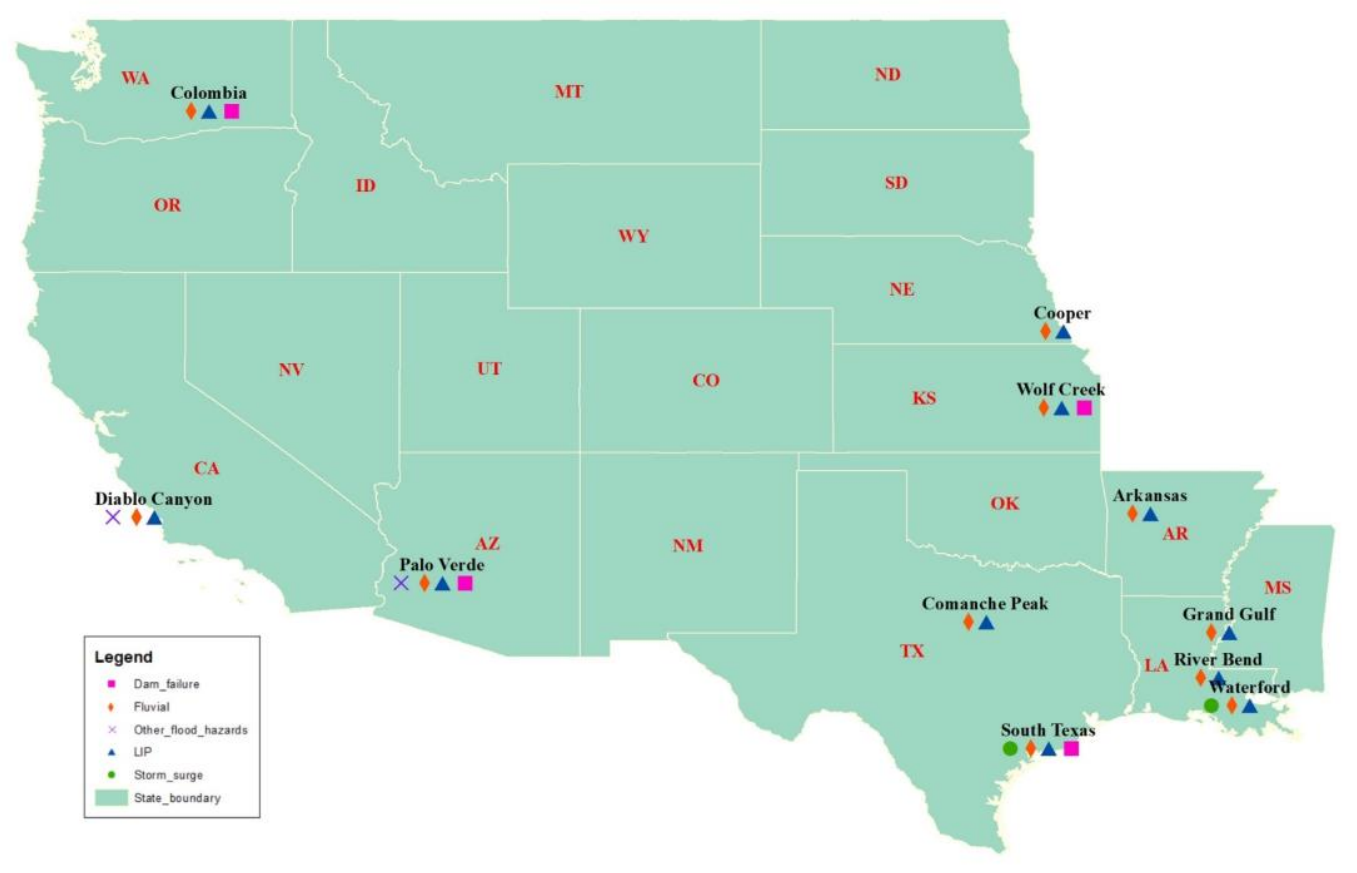

Figure 2-6. Map of flood hazards assessed at US nuclear power plant sites in Region 4. LIP $=$ local intense precipitation. Data from USNRC (2018b). ${ }^{4}$

\subsection{KEY TERMINOLOGY AND FLOOD MECHANISM TYPES}

This section introduces terminology and contextual information that serves as the basis for discussions in the remainder of this report and will be used in subsequent case studies. This section provides a hierarchical structure for discussing topics related to combinations of flood mechanisms, which is necessary because of the wide variety of terminology used across academic and scientific literature and across existing regulatory guidance and standards. For example, the literature reviewed as part of this study was found to use a range of terms to refer to combinations of flood mechanisms, including (but not limited to) coincident, combined, concurrent, compound, joint, cascading, concomitant, simultaneous, and successive. This report uses the phrase "multi-mechanism flood."

Existing NRC documents have also used various MMF-relevant terminology to describe deterministic flood hazards (e.g., "combined events" (USNRC 2007b) and "combined effects" (USNRC 2011). However, the existing terminology does not offer sufficient specificity and clarity to capture the considerations necessary for developing a mathematical framework for PFHA. For example, the terms "events" and "effects" do not provide information regarding the specific quantities being combined or the nature of the probabilistic relationship (e.g., the correlation or dependence structure). The existing terminology and hierarchy are also not fully consistent with various reviewed literature. Therefore, the terminology used in the following sections is more expansive than that used in existing NRC documentation.

Figure 2-7 presents the hierarchy of flood terminology that will be used in this report. The MMF terminology hierarchy shown in Figure 2-7 includes three "tiers" with the first tier representing the floodforcing phenomena that can ultimately lead to MMFs. "Flood-forcing phenomena" refers to natural or man-made forcings that create conditions that can ultimately lead to flooding at a site. Relevant flood- 
forcing phenomena include severe weather events (e.g., hurricanes, LIP, rapid temperature changes), land movement events (e.g., earthquakes, landslides), operational events (e.g., releases from dams, equipment aging and failure), and natural cyclic processes (e.g., tides).

Flood-forcing phenomena can lead to site flooding through a variety of different "flood mechanisms," which are physical processes by which a natural or man-made flood-forcing phenomenon can lead to overflow or accumulation of water on or near a site. These flood mechanisms represent the second tier of the flood terminology hierarchy shown in Figure 2-7 and used in this report. Overall, three primary flood mechanism types (separated in Figure 2-7 into separate dashed-outline boxes) are identified:

- "Pluvial flood mechanisms" occur when local precipitation or snowmelt directly cause flooding of a site. They are independent of the overflow of nearby major rivers or water bodies.

- "Fluvial flood mechanisms" occur when the cumulative surface runoff, snowmelt, and baseflow from upstream watersheds increase significantly and result in a river or reservoir stage exceeding nearby riverbanks, levees, or dams.

- "Coastal flood mechanisms" involve the flooding of land adjacent to a sea, ocean, lake, or other open or semi-enclosed body of water.

Further discussion of these three flood mechanism types is provided in the following subsections, which aggregate information from several references (e.g., FEMA 2014; Maddox 2014).

In linking these broad flood mechanism types and the hazards described in NRC guidance (see Section 2.1), the authors note that LIP is a flood-forcing phenomenon associated with pluvial flooding. Flooding from rivers/streams, dam failures, and ice effects is associated with fluvial flooding. Storm surges, seiches, and tsunamis are coastal flooding mechanisms. As shown in Figure 2-1, all nuclear facilities can potentially be affected by pluvial (i.e., LIP) flooding hazards, and a large fraction can potentially be affected by fluvial flooding hazards (i.e., stream and rivers, dam failures, ice effects). A smaller portion of sites can be affected by coastal flooding hazards (i.e., storm surges, seiches, tsunamis). In addition to evaluating hazards individually, existing NRC guidance specifies that licensees should also consider deterministic combinations of these mechanisms.

The third tier of the flood terminology hierarchy (Figure 2-7) captures the metrics used to measure flood severity. Flood severity is typically measured by (1) flood height (i.e., stage) or elevation, (2) flood volume, (3) peak discharge, (4) flood event duration, (5) associated effects, and (6) other study-specific metrics. 


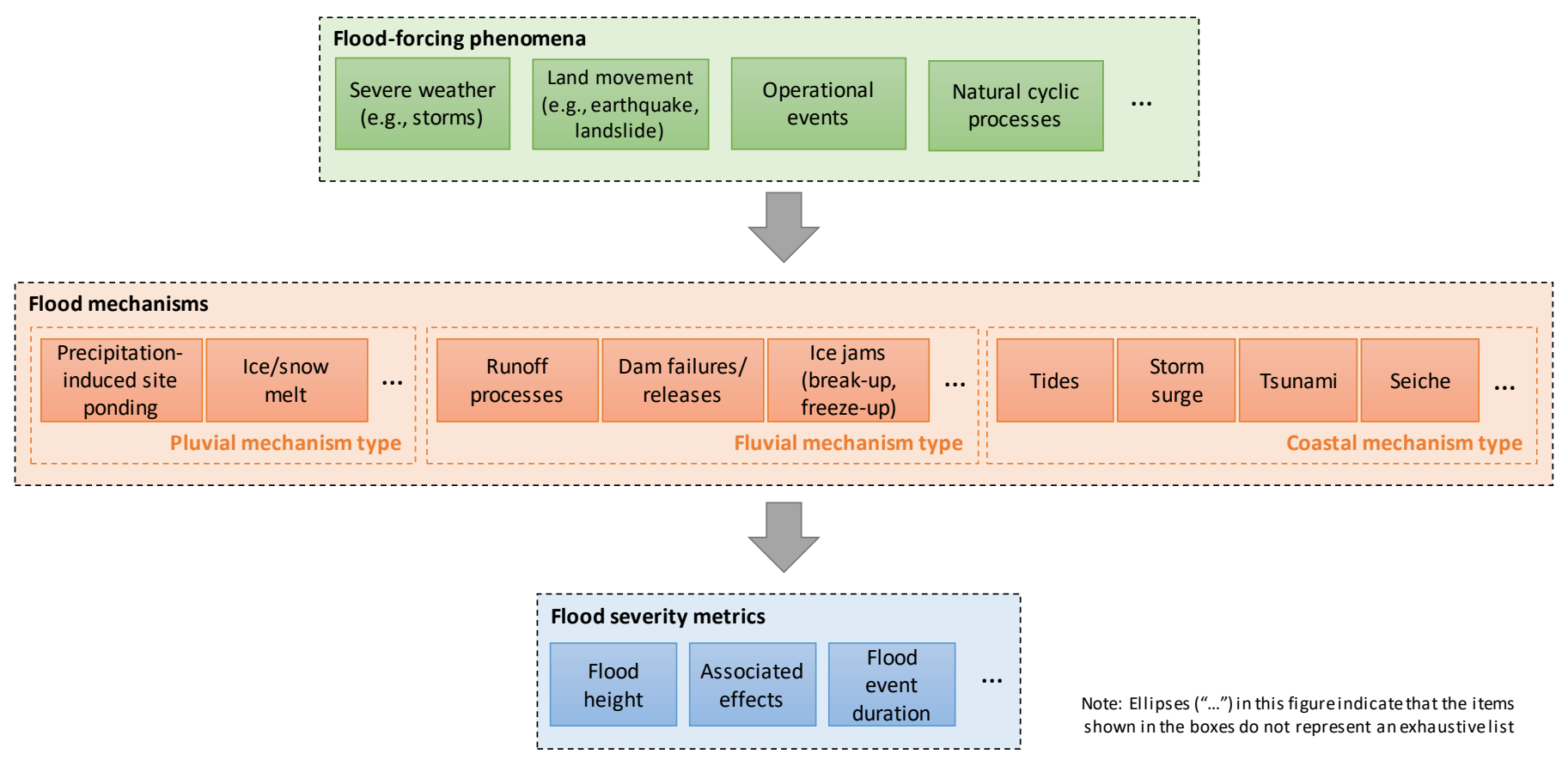

Figure 2-7. Multi-mechanism flood terminology hierarchy.

Depending on the phenomena and mechanisms under consideration, flood height or elevation may be associated with stillwater elevation alone or may be calculated to include additional wave effects (e.g. wind-induced wave and wave runup effects). Appendix B provides an overview of terminology used to differentiate between several metrics related to flood water levels used in coastal hazard assessment. Flood volume and peak discharge are commonly used to characterize fluvial flooding. Flood event duration is defined in NRC regulatory guidance as the "length of time that the flood affects the site, beginning with conditions being met for entry into a flood procedure or notification of an impending flood (e.g., a flood forecast or notification of dam failure), including preparation for the flood and the period of inundation, and ending when water has receded from the site and the plant has reached a safe and stable state that can be maintained indefinitely" (USNRC 2012). "Associated effects" is a phrase used in NRC regulatory guidance to identify factors such as wave effects (when not included in the calculation of flood elevation), velocity effects, debris quantities and characteristics, and sediment erosion/deposition.

The severity of a flood is affected by various characteristics, including the intensity and duration of the underlying flood-forcing phenomena and the number and characteristics of flood mechanisms that contribute to flooding. The combination of multiple mechanisms may increase the severity of flood height (e.g., owing to the superposition of the water level contributions from multiple flooding mechanisms), lead to more severe or a wider diversity of associated effects, and alter the length of the flood event (e.g., increase the period of inundation or lead to multiple "flood pulses").

\subsubsection{Pluvial Flooding}

Pluvial flooding occurs when precipitation or snowmelt directly causes flooding of a site independent of the overflow of a nearby major river or water body. It may also be referred to as urban flooding, surface (water) flooding, overland flow flooding, or shallow (sheet) flooding. Pluvial flooding typically occurs when the volume and rate of precipitation or snowmelt exceed the capacity of drainage or pumping systems (if available) and otherwise cannot be infiltrated into the ground. Flood-forcing phenomena that 
are typically associated with pluvial flooding include tropical and extratropical storm systems, thunderstorms, mesoscale convective complexes, and other rainfall producing phenomena (e.g., atmospheric rivers). Additionally, pluvial flooding may be caused by melting snow or ice (e.g., due to a rapid increase in temperature) as well as combinations of rainfall and snow/ice melting (e.g., "rain-onsnow" events).

This flooding type is associated with the movement of water (due to precipitation or snowmelt) via overland flow to points of relatively low elevation without reaching large natural river channels or constructed conveyance systems. However, pluvial flooding may involve movement of water via smaller conveyances (e.g., site drainage systems and ditches), as well as retention in small reservoirs and ponds. The primary flood mechanism associated with pluvial flooding is the movement of water via overland flow and the resultant local ponding that develops and persists in topographic depressions. Additionally, precipitation events can lead to the overflow of isolated retention facilities not associated with conveyance systems (e.g., cooling water ponds created by ring levees) and result in pluvial site flooding. Although pluvial and fluvial flooding are described as distinctive types of flood mechanisms herein, the distinction is not always obvious during flood events.

Pluvial flooding is primarily related to the quantity, timing, and spatial and temporal distribution of precipitation over the site, or the rate of snow and ice melt. In urban areas, inadequately sized drainage systems, development activities that overtake natural drainage patterns, and increases in impervious areas can exacerbate pluvial flooding. For nuclear facility sites, clogged drains and culverts, changes to site layouts (e.g., the addition of security barriers), and new structures can change site drainage characteristics and potentially exacerbate pluvial flooding.

In the context of US commercial nuclear power facilities, pluvial flooding is generally addressed in the evaluation of the impacts of LIP on site and roof drainage. LIP-related impacts have been evaluated for all US commercial nuclear facilities as a part of initial licensing or subsequent analyses and reviews performed as part of NRC's response to the 2011 events at the Fukushima Dai-chi nuclear power facility. More broadly, pluvial flooding is being increasingly recognized as an important type of flooding in communities throughout the United States (Galloway et al. 2018). However, federal flood insurance rate maps, which delineate flooding hazards from fluvial and coastal flooding, do not generally capture the hazards from pluvial flooding. In the United States, about $25 \%$ of all national flood insurance claims come from areas that federal flood insurance rate maps indicate have low to moderate flood risks (i.e., claims made in regions that fall outside the 100-year flood zone) (FEMA n.d.).

\subsubsection{Fluvial Flooding}

Fluvial flooding is defined as flooding that occurs adjacent to a defined channel such as a river or stream. It may also be referred to as riverine or overbank flooding. It occurs when the cumulative surface runoff, snowmelt, and flow from upstream watersheds increase significantly and results in increased river stage. Fluvial floods can happen relatively slowly (e.g., over several days to weeks) or extremely quickly (e.g., in minutes to hours). Quickly developing river flooding is often referred to as "flash flooding." Floodforcing phenomena that typically lead to fluvial flooding include large-scale extreme precipitation events (e.g., tropical and extratropical storm systems, mesoscale convective complexes, synoptic-scale storms), snowmelt events (including gradual snowmelt events and rapid melting events that lead to pulse-like increases in river discharge), and dam failures and operational releases.

This flooding type is associated with several flood mechanisms as shown in Figure 2-7. The most common type of fluvial flooding is river (overbank) flooding, which occurs when precipitation and snow/ice melt run off into a conveyance system. In that case, the severity of fluvial flooding is a function 
of the quantity, timing, and spatial and temporal distribution of precipitation over the site or the rate of snow and ice melt. It can be exacerbated by saturated soils, impervious surfaces, and steep terrain.

Fluvial flooding can also be associated with dam failures due to seismic, hydrologic, and other failure mechanisms (e.g., piping, gate failure, or random design flaws) as well as intentional, operational releases from dams (e.g., releases to conform with regulatory and water use requirements or to provide flood protection to populated areas). Fluvial flooding is also associated with ice-induced flood mechanisms. For example, ice jams in a river can lead to a rise in the water upstream of the jam. Moreover, the failure (breakup) of the jam can lead to the sudden release of water to downstream locations. Fluvial flooding can also be caused by debris blockages and breakup releases and is associated with the movement (migration) of channels due to erosion, sedimentation, mud flows, and ground failures.

In the context of nuclear facilities, fluvial flooding hazards are typically addressed as part of evaluations related to flooding on rivers and streams due to rainfall runoff, dam failure evaluations, and factors such as channel migration and ice effects. More broadly, fluvial flooding hazards are assessed for a variety of applications including dam safety analyses and the National Flood Insurance Program (FEMA 2018a).

\subsubsection{Coastal Flooding}

Coastal flooding is associated with flooding of land adjacent to a sea, ocean, lake, or other open or semienclosed body of water. Flood-forcing phenomena that typically lead to coastal flooding generally fall into two types: (1) storm-related phenomena, such as hurricanes and extratropical storms, and (2) displacement-related phenomena, such as earthquakes and subareal and submarine landslides.

Additionally, atmospheric forcing may lead to tides that can cause or exacerbate flooding resulting from other phenomena.

This flooding type is associated with a wide variety and disparate set of flood mechanisms. These mechanisms include (1) storm surge, ${ }^{5}$ which is generated when a tropical or extratropical storm event pushes water toward the shore as a result of pressure differential, winds, and related effects; (2) seiche, which occurs when oscillations in an enclosed or semi-enclosed body of water are generated as a result of pressure- or displacement-related phenomena; and (3) tsunamis, which include (typically large) waves generated by earthquakes, landslides, and volcanic eruptions. In certain regions, a tsunami-like wave that has a meteorological origin (e.g., is due to a pressure change) may be referred to as a meteo-tsunami. For storm-generated phenomena, the severity of flooding relates to the characteristics of the metrological flood-forcing conditions (e.g., pressure differentials, wind speeds). For displacement-related phenomena, the severity of flooding relates to the characteristics of the geologic event (e.g., earthquake). Additionally, the bathymetry in the region affects the flooding severity.

In the context of nuclear facilities, coastal flooding hazards are typically addressed as a part of evaluations related to storm surge, seiche, and tsunami hazard assessments. More broadly, coastal flooding hazards (particularly those associated with storm surge) are assessed by the US Army Corps of Engineers (USACE) and various state and local governments for the design of shoreline and infrastructure protection, and also by the Federal Emergency Management Agency (FEMA) to estimate risks for the National Flood Insurance Program (FEMA 2018a).

Appendix B introduces coastal hazard terminology that will be used throughout this report.

\footnotetext{
5 "Storm surge" is typically used to refer to the abnormal rise in water level generated by a meteorological event above the tide. When tides are included, the resulting flooding mechanism is typically referred to as "storm tide." However, the terms may be used interchangeably in some applications.
} 


\subsection{MULTI-MECHANISM FLOOD HAZARD FRAMEWORK}

Literature related to MMF assessment is wide-ranging in context, application, and terminology. Existing literature and other resources may address combinations at any of the tiers illustrated in Figure 2-7. Efforts may seek to characterize hazards associated with combinations of (1) multiple flood-forcing phenomena (e.g., earthquakes and hurricanes), (2) multiple flood mechanisms (e.g., tides and storm surge), or (3) multiple flood severity metrics (e.g., water levels and wave heights). Overall, most existing methods for characterizing MMFs focus on characterizing the occurrence of multiple mechanisms or multiple flood severity metrics (i.e., the second and third tiers of the hierarchy in Figure 2-7).

Although the focus of this research project is mostly on characterizing hazards associated with floods caused by combinations of multiple flood mechanisms (i.e., the second tier in Figure 2-7), the discussion of existing resources in this report extends to considering the literature addressing combinations at any of the tiers. The reason for this expansive approach is to broaden the range of techniques and tools considered for application within mathematical frameworks and to inform the subsequent case studies developed through this research project.

To provide structure and consistency in describing the available literature within this report and broader project activities, the following paragraphs introduce a graphical model-based framework and terminology for discussing combinations of flooding mechanisms. In particular, three categories of flood mechanism combinations are defined in conjunction with the conceptual diagrams in Figure 2-8. These flood mechanisms may be associated with one or more flood-forcing phenomena and flood severity metrics. Throughout this report, graphical models such as those shown in Figure 2-8 are used as a means of representing probabilistic models. In these graphical models, nodes (ovals) represent random quantities (e.g., random variables or stochastic events) and links (arrows) represent dependencies. The direction of the arrow is typically used to represent a causal relationship.

In this report, the phrase "coincident mechanisms" (see Figure 2-8a) is used to refer to two or more flood mechanisms that affect a facility at the same time but result from independent flood-forcing phenomena. An example of coincident mechanisms is a fluvial flood caused by a seismically induced dam failure that occurs while a rainfall-induced river flood is also occurring. The flood resulting from the occurrence of coincident mechanisms may be characterized by a single flood severity metric (e.g., flood elevation) or multiple flood severity metrics.

The phrase "correlated mechanisms" is used in this report to refer to combinations of flood mechanisms that are directly or indirectly driven by the same flood-forcing phenomena. This dependence takes two forms.

1. The phrase "concurrent correlated mechanisms" (see Figure 2-8b) is used to refer to flood mechanisms generated by a common flood-forcing phenomenon. For example, for sites located on estuaries or tidally influenced rivers, flooding mechanisms from both storm surge (coastal flooding) and rainfall runoff flooding (fluvial flooding) can be caused by a single hurricane event (flood-forcing phenomenon).

2. The phrase "induced correlated mechanisms" (see Figure 2-8c) is used to refer to scenarios in which the occurrence of one flood mechanism leads to (induces) another flood mechanism. For example, a rainfall-induced river flood may lead to (induce) a hydrologic dam failure-induced flood. As with coincident mechanisms, the occurrence of correlated mechanisms may be associated with floods that are characterized by either a single or multiple flood severity metrics. 


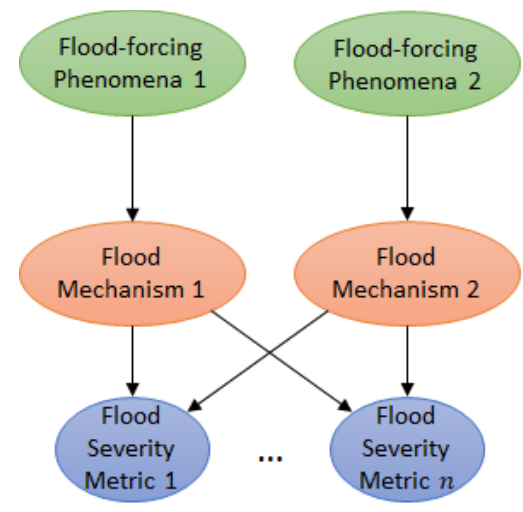

(a) Coincident Mechanisms

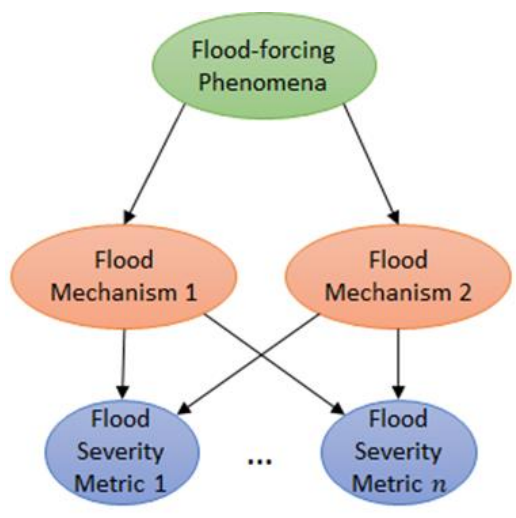

(b) Concurrent Correlated Mechanisms

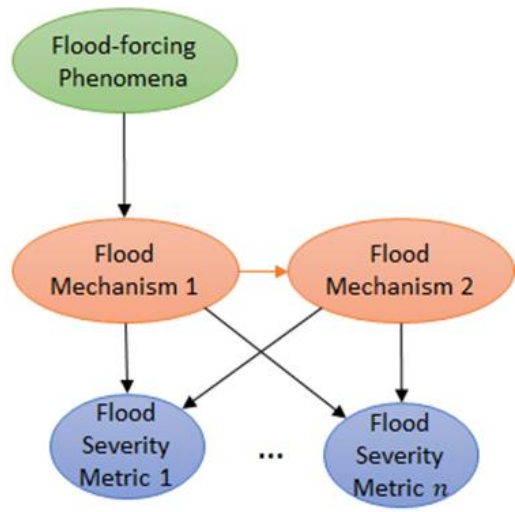

(c) Induced Correlated Mechanisms

Figure 2-8. Categories of flood mechanism combinations. 


\section{OVERVIEW OF PROBABILISTIC FLOOD HAZARD ASSESSMENT}

The following subsections provide information on deterministic flood hazard assessment (DFHA) and PFHA and summarize the mathematical formulations necessary to assess MMFs, including an overview of random variables and distributions, approaches for developing joint distributions, and hazard curve development.

\subsection{INTRODUCTION TO FLOOD HAZARD ASSESSMENT}

Two broad classes of approaches are used to assess flood hazards involving a single or multiple flood mechanisms: DFHA and PFHA.

DFHA considers a single scenario or a set of candidate scenarios intended to define a sufficiently severe flood hazard for consideration in a target application (e.g., design, analysis, or retrofit of a component or system). Following the terminology defined in Section 2, a deterministic MMF flood hazard scenario is characterized as consisting of the assumed occurrence of one or more flood-forcing phenomena leading to one or more flood mechanisms. In particular, under deterministic frameworks, MMFs are typically addressed by considering a limited number of prespecified scenarios that involve the occurrence of multiple flood mechanisms. One or more flood severity metrics are then calculated under each of the limited number of assumed scenarios using numerical, empirical, or analytical models. Current NRC flooding guidance focuses on DFHA methods, which typically use a hierarchical hazard assessment in which a step-wise approach is applied to identify the most conservative plausible assumptions, consistent with available data (USNRC 2011). Current NRC guidance related to MMFs is further described in Appendix A.

Although DFHA is the current standard approach for most US NPPs, given its deterministic nature, this approach offers limited risk information and cannot be used to support risk-informed decision-making. In contrast, PHFA enables quantitative estimation of flood risk. According to USNRC (2014),

a truly risk-informed and performance-based approach requires quantitative probabilistic models for the flooding phenomena combined with probabilistic models for the fragility of flood protection features and reliability of flood protection or mitigation procedures.

In other words, a PFHA is a systematic assessment of the likelihood that a specified flood severity metric or set of metrics will be exceeded at a site or in a region during a specified interval (typically one year). The results of such an assessment are expressed as estimated probabilities (e.g., annual exceedance probability $[\mathrm{AEP}])$ or frequencies. ${ }^{6}$

Results of a probabilistic hazard assessment are often displayed as a hazard curve or set of hazard curves that include a flood severity metric on one axis and the associated (annual) probability of exceedance (or return period) on the other axis. The disciplinary conventions for presenting hazard curves differ based on the hazard considered. Differences between conventions include the orientations of axes (e.g., in some cases, the severity parameters may be on the $\mathrm{x}$-axis and in other cases, on the y-axis), the scaling of axes

\footnotetext{
${ }^{6}$ The annual exceedance frequency represents the rate at which events of interest (e.g., floods more severe than a specified level) occur per year. It is the inverse of the return period, which represents the average time between two successive events of interest. The annual exceedance frequency differs from the annual exceedance probability, which is the annual probability that at least one event of interest will occur in a given year. In practice, for events with moderate to long return periods, the practical quantitative distinction between annual exceedance frequencies and probabilities is negligible. In this section, consistent with typical terminology used in PFHA, the phrase "annual exceedance probability" is used.
} 
(e.g., use of log or linear scales), the direction of axes, and the use of annual probability (or frequency) of exceedance versus return period. Figure 3-1 provides four examples of hazard curve presentations showing the same information with different conventions.
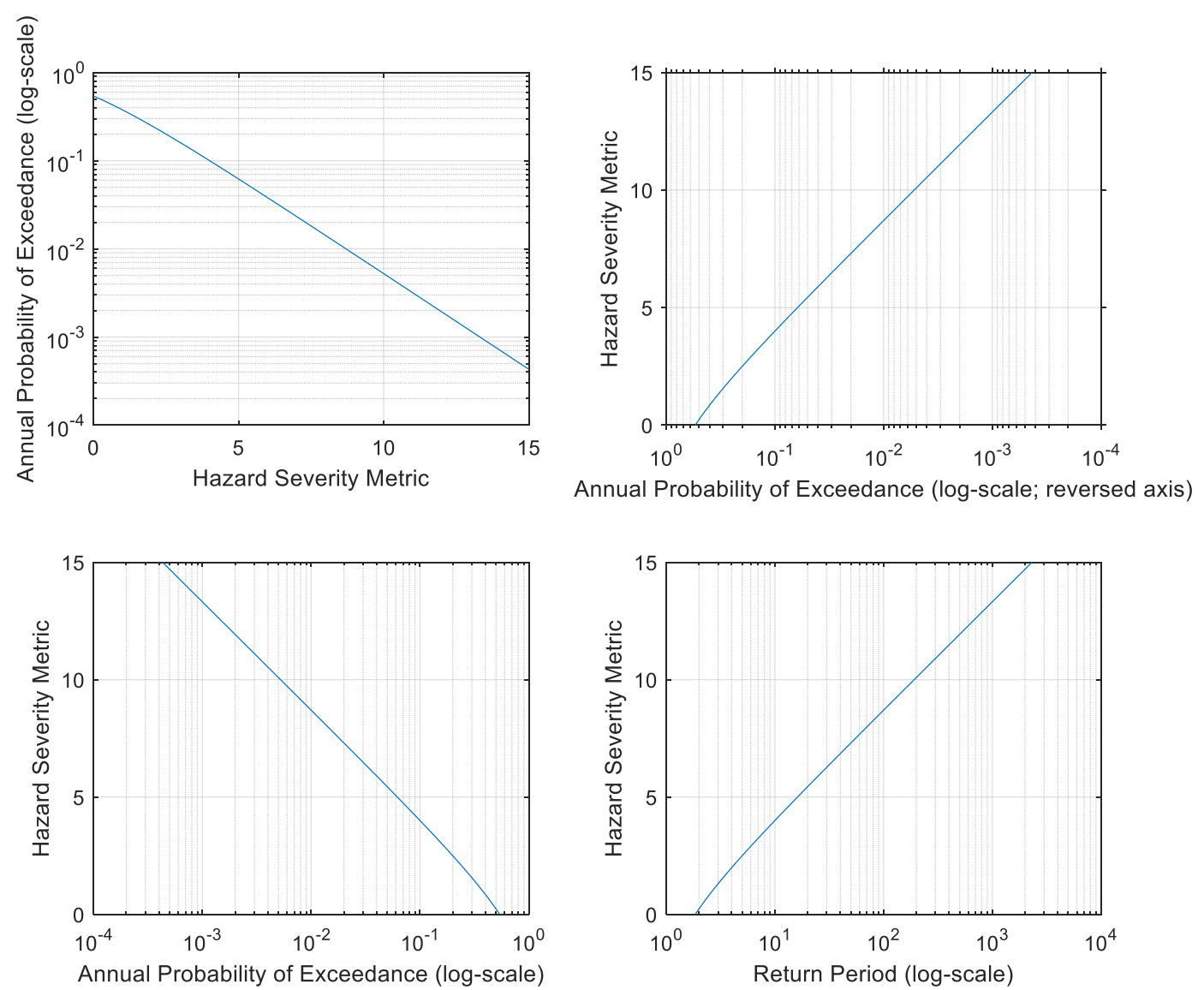

Figure 3-1. Conceptual example of hazard curves.

\subsection{INTRODUCTION TO RANDOM VARIABLES AND DISTRIBUTIONS}

This section presents an introduction to terminology and notation associated with single-variate (univariate) and multivariate distributions. Information presented in this section is adapted from Ang and Tang (2007). Consistent with the conventions of Ang and Tang (2007), throughout this document, capital letters are used to denote random variables and lowercase letters are used to represent realizations of a random variable.

\subsubsection{Univariate Distributions}

Consider a continuous random variable $X$. The univariate probability density function (PDF) is defined as

$$
f_{X}(x) d x=P(x<X \leq x+d x) \text {. }
$$

where $d x$ is an infinitely small differential element. The $\operatorname{PDF} f_{X}(x)$ is not a probability but rather a probability density. For continuous random variables, no probability is assigned to a single outcome. 
Instead, $f_{X}(x) d x$ represents the probability that the random variable $X$ will be in the interval $(x, x+d x)$. Therefore, the PDF can be viewed as providing information regarding the relative likelihood of one outcome occurring relative to other possible outcomes.

The corresponding cumulative distribution function (CDF) for $X$ can be obtained from the PDF as

$$
F_{X}(x)=P(X \leq x)=\int_{-\infty}^{x} f_{X}(a) d a .
$$

Figure 3-2 shows a conceptual example of a PDF and a CDF. If $F_{X}(x)$ has a first derivative, the PDF can expectedly be obtained from the CDF through differentiation:

$$
f_{X}(x)=\frac{d F_{X}(x)}{d x}
$$

The probability of exceedance (often referred to as the complementary CDF) is

$$
P(X>x)=1-P(X \leq x)=1-F_{X}(x) .
$$

The probability of exceedance is generally the focus of PFHA studies.
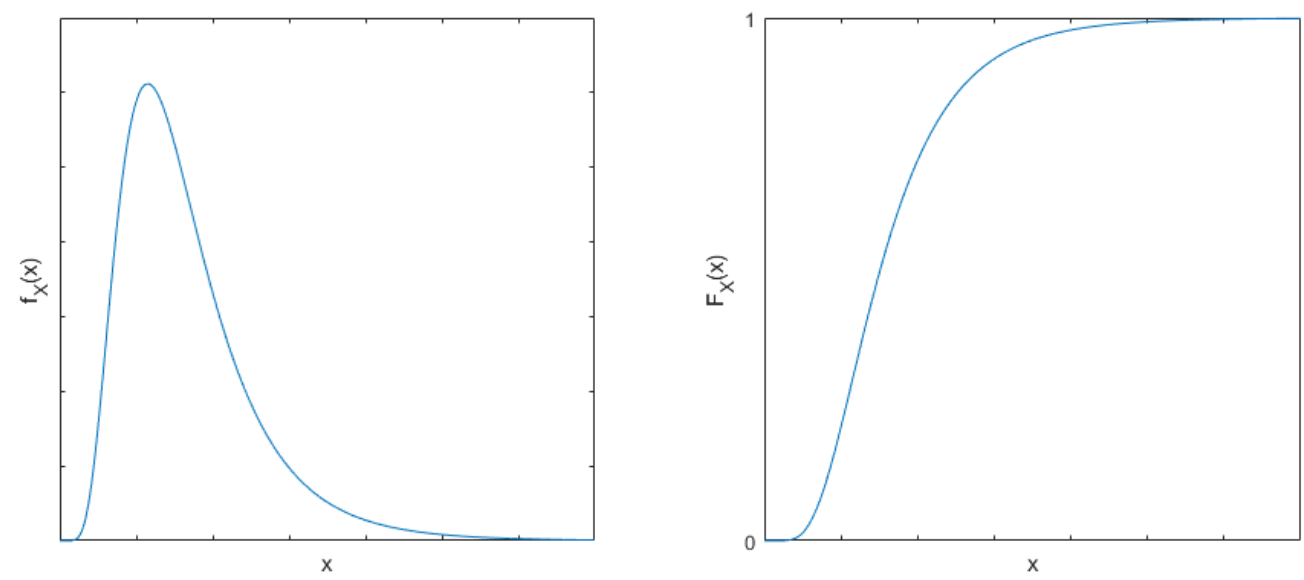

Figure 3-2. (left) Conceptual example of probability density function and (right) cumulative distribution function.

\subsubsection{Multivariate Distributions}

The univariate distributions described can be generalized to the notion of a "joint distribution," which provides information about the relative likelihood that a set of multiple random variables will take on particular values. In working with multiple random variables, the univariate expression for the distribution of a single random variable is often referred to as a "marginal distribution" because it provides the distribution of a variable irrespective of the values of other random variables. 
To expand upon the provided univariate expressions, consider a vector ${ }^{7}$ of random variables $\mathbf{X}=$ $\left[X_{1}, X_{2}, \ldots, X_{n}\right]$. The joint PDF of the random variables can be written as

$$
f_{\mathbf{X}}\left(x_{1}, x_{2}, \ldots, x_{n}\right) d x_{1} \ldots d x_{n}=P\left(x_{1}<X_{1} \leq x_{1}+d x_{1} \cap \ldots \cap x_{n}<X_{n} \leq x_{n}+d x_{n}\right),
$$

where $d x_{i}$ is an infinitely small differential element. The joint CDF can be obtained from the joint PDF as

$$
F_{\mathbf{X}}\left(x_{1}, \ldots, x_{n}\right)=P\left(X_{1} \leq x_{1} \cap \ldots \cap X_{n} \leq x_{n}\right)=\int_{-\infty}^{x_{1}} \ldots \int_{-\infty}^{x_{n}} f_{\mathbf{X}}\left(x_{1}, x_{2}, \ldots, x_{n}\right) d x_{1} \ldots d x_{n} .
$$

In Eq. 3.6, the symbol $\cap$ is the "intersection operator," which is linked to the Boolean "and" concept. For example, $A \cap B$ is used to represent an event in which both events $A$ and $B$ occur.

Similarly, the joint PDF can be naturally obtained from the joint CDF through (partial) differentiation, if the joint CDF is differentiable. The joint PDF of any subset of the random variables $\mathbf{X}^{\prime}=\left[X_{1}, \ldots, X_{k}\right]$ can be obtained from the joint PDF of $\mathbf{X}$. In other words, the joint PDF of $\mathbf{X}^{\prime}$ can be obtained as

$$
f_{\mathbf{X}}\left(x_{1}, \ldots, x_{k}\right)=\int_{x_{n}=-\infty}^{\infty} \ldots \int_{x_{k+1}=-\infty}^{\infty} f_{\mathbf{X}}\left(x_{1}, x_{2}, \ldots, x_{n}\right) d_{k+1} \ldots d x_{n}
$$

The joint CDF of the subset $X^{\prime}$ can be obtained from the joint CDF over $\mathbf{X}$ as

$$
F_{\mathbf{X}}\left(x_{1}, \ldots, x_{k}\right)=F_{X}\left(x_{1}, \ldots, x_{k}, \infty, \ldots \infty\right) .
$$

The marginal PDF of a single random variable then becomes a special case of Eqs. 3.7 and 3.8. For example the marginal PDF of $X_{1}$ can be derived as

$$
f_{X_{1}}\left(x_{1}\right)=\int_{x_{n}=-\infty}^{\infty} \ldots \int_{x_{2}=-\infty}^{\infty} f_{\mathbf{X}}\left(x_{1}, x_{2}, \ldots, x_{n}\right) d_{2} \ldots d x_{n}
$$

A "conditional distribution" provides the distribution of a random variable given (i.e., knowing or assuming) the value of another random variable or set of random variables. The conditional PDF of a subset of variables $\mathbf{X}^{\prime}=\left\{X_{1}, \ldots, X_{k}\right\}$ given the remaining variables $\mathbf{X} \backslash \mathbf{X}^{\prime}=\left\{X_{k+1}, \ldots, X_{n}\right\}$ can be obtained through a ratio of densities:

$$
f_{\mathbf{X}^{\prime} \mid \mathbf{X} \backslash \mathbf{X}}\left(x_{1}, x_{2}, \ldots, x_{k} \mid x_{k+1}, \ldots, x_{n}\right)=\frac{f_{\mathbf{X}}\left(x_{1}, x_{2}, \ldots, x_{n}\right)}{f_{\mathbf{X} \backslash \mathbf{X}^{\prime}}\left(x_{k+1}, \ldots, x_{n}\right)}
$$

\subsubsection{Special Case: Bivariate Distributions}

For the special case of two random variables, $X$ and $Y$, the joint PDF is defined as

\footnotetext{
${ }^{7}$ Bold font represents vectors of random variables.
} 


$$
f_{X Y}(x, y) d x d y=P(x<X \leq x+d x \cap y<Y \leq y+d y),
$$

where $d x$ and $d y$ are infinitely small differential elements. If $F_{X}(x)$ has a first derivative, the PDF can be obtained from the CDF through differentiation. The joint $\mathrm{CDF}_{X Y}(x, y)$ can be obtained from the joint PDF as

$$
F_{X Y}(x, y)=P(X \leq x \cap Y \leq y)=\int_{-\infty}^{x} \int_{-\infty}^{y} f_{X Y}(a, b) d a d b
$$

Figure 3-3 provides an example of a bivariate PDF and bivariate CDF.
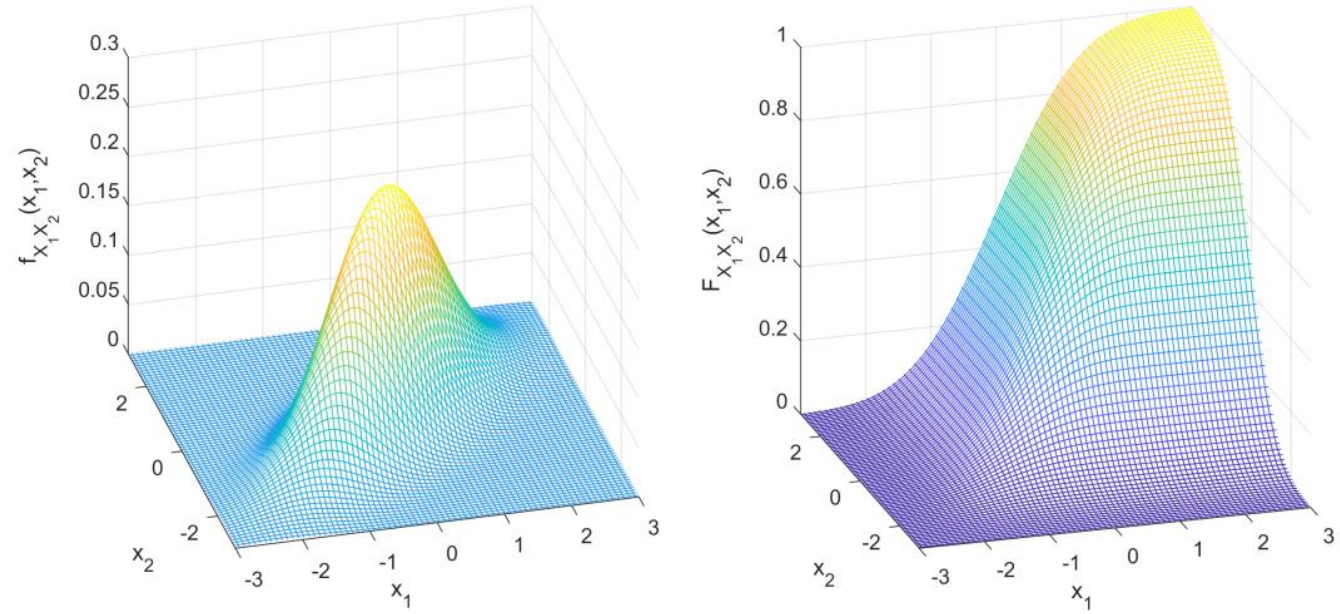

Figure 3-3. (left) Example of bivariate probability density function and (right) bivariate cumulative distribution function.

Assuming differentiability, the joint PDF can be obtained from the joint CDF as

$$
f_{X Y}(x, y)=\frac{\partial^{2} F_{X Y}(x, y)}{\partial x \partial y} .
$$

The marginal PDFs of $X$ and $Y$ can be obtained from the joint PDF as

$$
\begin{aligned}
& f_{X}(x)=\int_{-\infty}^{\infty} f_{X Y}(x, y) d y, \\
& f_{Y}(y)=\int_{-\infty}^{\infty} f_{X Y}(x, y) d x .
\end{aligned}
$$

Similarly, the marginal CDFs of $X$ and $Y$ can be obtained as 


$$
\begin{aligned}
& F_{X}(x)=\int_{-\infty}^{x} f_{X}(z) d z=F_{X Y}(x, \infty), \\
& F_{Y}(x)=\int_{-\infty}^{y} f_{Y}(z) d z=F_{X Y}(\infty, y) .
\end{aligned}
$$

The conditional PDF can be obtained from the joint and marginal distribution as

$$
f_{X \mid Y}(x \mid y)=\frac{f_{X Y}(x, y)}{f_{Y}(y)}
$$

\subsection{SUMMARY OF APPROACHES TO DEVELOP JOINT DISTRIBUTIONS}

PFHA approaches may use statistical analysis directly on data corresponding to quantities of interest (which may relate to any of the levels of the hierarchy in Figure 2-7) or may involve statistical analyses coupled with process models. Using the language of Der Kuireghian and Ditevsen (2009), "basic random variable approaches" refer to assessments that statistically analyze a data set directly corresponding to random variables that describe a quantity of interest. Under conventional univariate PFHA, these basic random variable approaches typically involve the estimation of empirical, parametric, and nonparametric (kernel density estimator) distributions using a set of observations corresponding to the quantity of interest. In considering multiple random variables related to one of the levels of the hierarchy in Figure 2-7, similar approaches can be used to directly estimate the parameters of a parametric joint distribution or to develop empirical joint distributions and other nonparametric distributions. Alternatively, the joint distribution may be "built up" using copula functions. These two strategies for implementing basic random variable approaches in the context of PFHA are described in Sections 3.3.1 and 3.3.2.

The basic random variable approaches are contrasted with the "derived random variable approaches" (Der Kiureghian and Ditlevsen 2009), which use process models to derive the random variables of interest as a function of other random variables. In this case, the other random variables correspond to input parameters representing a different (typically higher) tier of the Figure 2-7 hierarchy. Derived random variable approaches may use Bayesian-motivated approaches or stochastic simulation. In both cases, statistical analyses are used to define the distributions of input parameters, and process models are used to estimate the response (output) quantity (or quantities) as functions of input parameters. Bayesianmotivated approaches are further described in Section 3.3.3.

Stochastic simulation approaches typically sample from input parameter distributions and use process models to compute synthetic series of output quantities as functions of input parameters using numerical or other models. Typically, basic random variable statistical approaches (as described in Sections 3.3.1 and 3.3.2) are then used to analyze the resulting synthetic data series as if it were an observational record.

\subsubsection{Direct Estimation of Joint Distributions}

In the context of the methods applied for assessment of MMF, some researchers have sought to directly develop joint distributions using empirical (observational) or synthetic data sets. That process includes the estimation of empirical distributions (e.g., empirical contours based on precipitation and surge [van den Hurk et al. 2015]) as well as estimation of parametric joint distributions (e.g., development of bivariate normal distributions related to wave heights and sea level [Wadey et al. 2015]). Additional information regarding development of joint distributions is provided here. 
Joint distributions may be defined empirically using a data set consisting of two or more random variables of interest. The univariate empirical CDF is defined by estimating the fraction of observations in a sample of size $n_{s}$ that are less than or equal to a particular outcome $x$. The empirical CDF is expressed as

$$
F_{X}^{[e]}(x)=\frac{\sum_{i=1}^{n_{s}} \mathbb{I}\left[x_{i} \leq x\right]}{n_{s}} .
$$

In Eq. 3.17, $\mathbb{I}[a]$ is an indicator function that equals one when the expression $a$ is "true," and otherwise, zero. The $k$-dimensional, multivariate extension can be expressed as

$$
F_{\mathbf{X}}^{[e]}\left(x_{1}, \ldots, x_{k}\right)=\frac{\sum_{i=1}^{n_{s}} \mathbb{I}\left[x_{i, 1} \leq x_{1} \cap \ldots \cap x_{i, k} \leq x_{k}\right]}{n_{s}} .
$$

Nonparametric distributions do not have a defined parametric functional form for which parameters may be estimated using parameter estimation techniques. Nonparametric estimation may involve kernel density estimation techniques, which are not described in detail in this report. Conversely, parametric distributions provide a defined functional form for the PDF and CDF. A large number of defined parametric functional forms exists for univariate distributions, many of which are identified by name (e.g., normal or Gaussian, exponential, Weibull, and lognormal distributions). A subset of univariate distributions is associated with multivariate generalized forms, the most well-known and widely applied of which is the multivariate normal distribution.

For multivariate distributions such as the multivariate normal distribution, parameter estimation techniques can be used to directly estimate the parameters of the assumed joint distribution using a data set containing observations related to each random quantity of interest. Estimation of the parameters of a parametric probability distribution typically begins with selecting one or more candidate distributions based on considerations such as compatibility between physical processes and theoretical distribution characteristics (e.g., limiting conditions). Then, using an available data set, parameters of the distribution are estimated using one or more parameter estimation techniques (e.g., method of moments, maximum likelihood estimation, L-moments, or Bayesian parameters estimation). Then, the goodness-of-fit between the data and the fitted distribution may be assessed using graphical assessments, formal hypothesis tests, information criteria, or other measures. However, measures of fit are generally of limited value in considering values in the tails of the distribution, which is the region of interest in most hazard assessments.

Although conceptually straightforward to implement (though potentially nontrivial from a computational perspective), these multivariate techniques require an assumed functional form for the joint distribution, which is then associated with derived marginal distribution forms. For example, if two or more random variables are distributed according to the multivariate normal distribution (parameterized by a mean vector and covariance matrix), their marginal distributions are likewise necessarily normal. Similar considerations apply to other parametric multivariate distributions. For instance, in the multivariate normal distribution case, a bivariate exponential distribution requires that both variables be marginally exponentially distributed.

Although certain problem structures may be supported by such restrictive distribution assumptions, these assumptions may not be appropriate in all cases (e.g., if an analysis focuses on estimation of the joint distribution of random quantities associated with significantly different marginal distribution forms). Of particular interest to PFHA are a special class of parameter distributions called "extreme value distributions," an overview of which is provided in Section 3.3.1.1 for the univariate case. 


\subsubsection{Extreme Value Distribution}

Extreme value analysis (EVA) focuses on the estimation and application of probability distributions when the random variable range of interest deviates substantially from a central measure of the distribution. EVA is particularly important when there is limited empirical information to help define the distribution in these tail regions. There are two approaches that are broadly used in EVA: peak over threshold (PoT) approaches and block extrema approaches. The PoT approach is also referred to as a "partial duration series approach." In PFHA, the block extrema approach most often corresponds to an annual maxima series approach in which the block is taken to be one year.

The PoT approach involves a (typically Poisson) point process of values exceeding a threshold, as well as the magnitude of the exceedance. Therefore, it focuses on estimating two components: (1) the probability distribution of a random variable that exceeds some threshold of interest and (2) the probability (or rate) at which events occur that meet the threshold criteria (Coles 2001; Madsen et al. 1997). Typically, PoT focuses on estimating (and then using) a distribution fitted to a data series containing all observations of a flood severity metric that exceed a specified threshold, as well as estimating the rate at which those exceedance events occur. That is, let $X$ be a random variable representing a flood severity metric with CDF $F_{X}(x)$, and let $u$ be the selected threshold. ${ }^{8}$ The conditional CDF for the amount of the threshold exceedance $(Y=X-u)$ given that an exceedance has occurred may be expressed as

$$
F_{Y \mid X>u}(y \mid X>u)=P(Y \leq y \mid X>u)=P(X-u \leq y \mid X>u)=\frac{F_{X}(y+u)-F_{X}(u)}{1-F_{X}(u)} .
$$

Thus, if the distribution of $X$ is known, and the distribution of the threshold exceedances will likewise be known. In general, this distribution of $X$ is not known. However, the extreme value theory provides that for a sufficiently large threshold $u$ and under certain assumptions (e.g., independence of exceedance events), this conditional distribution approaches the generalized Pareto distribution with shape parameter $\zeta$ and scale parameter $\alpha$. The conditional CDF in Eq. 3.19 approaches the following functional form (Bommier, 2014):

$$
F_{Y \mid X>u}(y \mid X>u)=\left\{\begin{array}{c}
1-\left(1+\frac{\zeta y}{\alpha}\right)^{-\frac{1}{\zeta}}, y \in(0, \infty), \zeta>0 \\
1-\exp \left(-\frac{y}{\alpha}\right), y \in(0, \infty), \zeta=0 \\
1-\left(1+\frac{\zeta y}{\alpha}\right)^{-\frac{1}{\zeta}}, y \in\left(0,-\frac{\alpha}{\zeta}\right), \zeta<0
\end{array} .\right.
$$

The special case in which $\zeta=0$ gives the exponential distribution.

The probability of a flood with a severity metric $X$ greater than $x$ for a threshold exceedance event (i.e., the probability of a flood with severity greater than both $x$ and $u$ ) may be expressed as

$$
P(X>x \cap X>u)=\left(1-F_{Y \mid X>u}(x-u \mid X>u)\right) * P(X>u) .
$$

\footnotetext{
${ }^{8}$ Selection of the threshold is a nontrivial task requiring that the threshold be set at a sufficiently high level such that EVA assumptions are not violated and that observations can be considered independent. However, it must not be so high that the number of observations included in the dataset becomes small (leading to large variance). Various rules of thumb and other quantitatively motivated heuristics are available to support threshold selection (Coles 2001).
} 
In Eq. 3.21, $F_{Y \mid X>u}(x-u \mid X>u)$ may be defined by fitting a generalized Pareto distribution (e.g., using a statistical inference method such as maximum likelihood estimation) to an empirical data set containing all observations that exceed the selected threshold. The quantity $P(X>u)$ may be defined by first estimating the rate at which exceedance events occur (i.e., the number of exceedance observations divided by the length of the period of record) and then converting the rate to a probability.

Alternatively, block extrema EVA refers to a class of analyses that is focused on the estimation of probability distributions associated with block extrema (i.e., estimation of the distribution of the minima or maxima of a set of random variables [Ang and Tang 2007]). In the context of flood hazards, the univariate EVA is generally focused on estimation of the distribution of the annual maxima $\left(Y_{\max }\right)$ of a series of random variables $\left(X_{1}, \ldots, X_{n}\right)$ :

$$
Y_{\max }=\max \left(X_{1}, \ldots, X_{n}\right) .
$$

Under the assumption that the $X_{i}$ variables in Eq. 3.22 are statistically independent and identically distributed, the exact form of the distribution for $Y_{\max }$ can be derived if the underlying distribution of $X_{i}$ is known. The CDF for $Y_{\max }$ is given by

$$
F_{Y_{\max }}\left(y_{\max }\right)=P\left(Y_{\max } \leq y_{\max }\right)=\left[F_{X}\left(y_{\max }\right)\right]^{n} \text {. }
$$

However, the underlying distribution for $X_{i}$ may not be known or even if it is known, the resulting exact form of the distribution for $Y_{\max }$ may be mathematically complex. Instead, EVA typically makes use of asymptotic distributions. These asymptotic distributions are applicable as $n$ becomes large $(n \rightarrow \infty)$ and require only an understanding of the behavior of the tail(s) of the underlying distribution for $X_{i}$ in the direction of the extreme. They do not require knowledge of the exact form of the underlying distribution for $X_{i}$ (Ang and Tang 2007).

There are three broad types of asymptotic distributions. ${ }^{9}$ The generalized extreme value (GEV) distribution provides a generalized functional form that captures all three types of these distributions in a single distribution function. The PDF of the GEV distribution is given by:

$$
f_{X}(x)=\left\{\begin{array}{l}
\frac{1}{\alpha} \exp \left(-(1+k y)^{-\frac{1}{k}}\right)(1+k y)^{-1-\frac{1}{k}}, k \neq 0 \\
\frac{1}{\alpha} \exp (-y-\exp (-y)), k=0
\end{array}, y=\frac{x-\beta}{\alpha}, \alpha>0\right.
$$

In above equation $k, \alpha$, and $\beta$ are shape parameter, scale parameter, and location parameter respectively. Setting the shape parameter $k$ equal to zero corresponds to a Type I extreme value distribution, $k$ greater than zero yields a Type II extreme value distribution, and $k$ less than zero provides a Type III distribution. Type I extreme value distributions are applicable when the tail of the distribution for $X_{i}$ is unbounded and decays exponentially in the direction of the extreme. Type II extreme value distributions are applicable when the tail of the distribution for $X_{i}$ is unbounded and exhibits polynomial decay in the direction of the extreme. Type III distributions are applicable when the tail of the distribution for $X_{i}$ is bounded. These distributions may be known by various formal names (e.g., Gumbell, Frechet, and Weibull) depending on the distribution type, the direction of extreme, and conventions of the field of study (Ang and Tang 1984). Figure 3-4 shows examples of the GEV distribution with differing values of $k$ (but the same $\alpha$ and $\beta$ parameter values). The Type I distribution tail decays faster than the tail of the Type II extreme value distribution; the Type III extreme value distribution has a strict upper bound. The behavior of the tail (rate

\footnotetext{
${ }^{9}$ These are not the only asymptotic extreme value distributions; however, these forms are most applicable in
} engineering practice (Ang and Tang 1984). 
of convergence) can significantly affect the estimated frequencies of exceedance for a given flood severity metric.

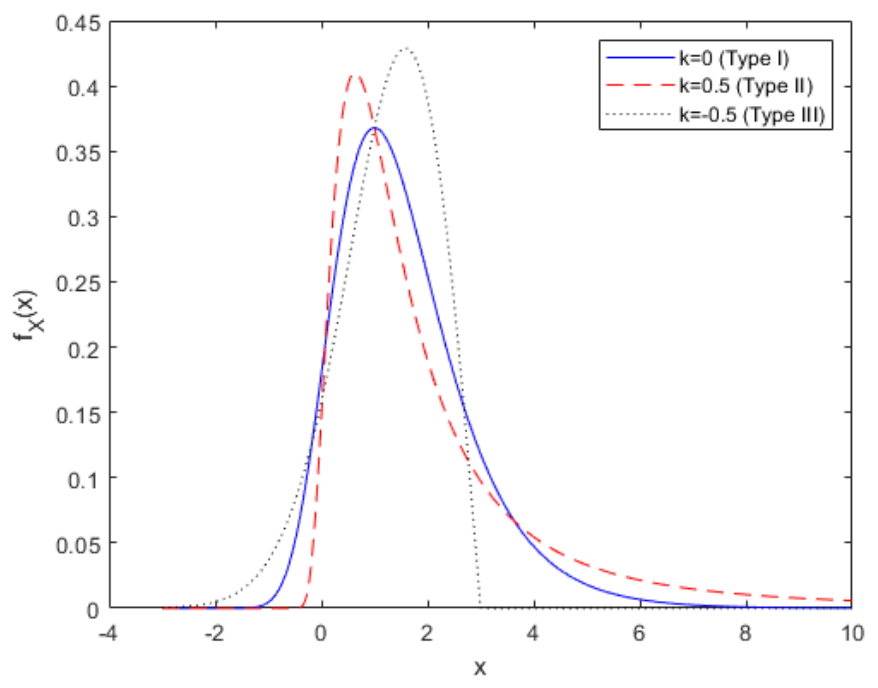

Figure 3-4. Example of generalized extreme value distribution with differing $k$ values $(\alpha=1, \beta=1)$.

The extreme value theory leading to the aforementioned asymptotic distributions assumes that the $X_{i}$ values are statistically independent and identically distributed, which is not a general characteristic of flood discharge time series. For example, in one of the foundational texts for EVA, Gumbel (1958) notes that the application of the theory to the analysis of daily flood discharges is potentially problematic because of the requirement that the underlying daily observations be independent (which is unlikely to be true) and because the number of observations (approximately 365) may not be sufficiently large (Gumbel 1958). Subsequent mathematical justification has been developed to support relaxation of the assumption of statistical independence and has shown that limiting (asymptotic) distributions under classical EVA remain applicable under conditions in which the underlying process exhibits a weak dependence structure but remains stationary (Leadbetter 1983). Therefore, the general consensus (based on both mathematical considerations and heuristics) is that the use of block maxima approaches remains appropriate in applications such as flood frequency analysis under stationary conditions because even when observations are not independent, the annual maxima are still approximately GEV-distributed and exhibit a low serial correlation (Bücher and Zhou 2018). In other words, the dependence in the underlying $X_{i}$ values can be ignored from the perspective of modeling the distribution of block extrema in stationary processes (Coles 2001). Temporal non-stationarity can be addressed within the context of EVA by expressing one or more parameters of the underlying asymptotic distribution as a function of time (Coles 2001).

Thus, the asymptotic distributions derived from extreme value theory provide parameterized functional forms for $Y_{\max }$ that facilitate estimation of the parameters of the distributions via statistical analysis of a data set containing block extrema observations. Conventional PFHA for riverine applications, often referred to as "flood (flow) frequency analysis," is an example of such an assessment approach. Under these assessments, the random variable $X$ typically corresponds to river discharge and the estimated probability distribution(s) are typically defined to correspond to an assumed asymptotic form or to an alternate formulation. ${ }^{10}$ In such assessments, data series consisting of the annual maximum river discharge

\footnotetext{
${ }^{10}$ Extreme value distributions are used for flood (flow) frequency analysis in numerous countries internationally (Castellarin et al. 2012). In the United States, federal guidance prescribes use of the Log-Pearson Type III distribution (a generalization of the gamma distribution [Griffis and Stedinger 2007]) for flood (flow) frequency analysis (England et al. 2018).
} 
values are used to estimate the parameters of the assumed distribution using maximum likelihood estimation, the method of (central or L-) moments, or other algorithms. Flood (peak flow) frequency analyses may include additional adjustments for outliers, historical information, and other considerations. EVA approaches are also used to estimate hazards associated with surge from extratropical events (USACE 2015) and precipitation (NOAA 2006).

PoT annual maxima series approaches have their own strengths and limitations. The main challenge of PoT is the selection of an appropriate threshold that can satisfy the EVA assumption that all samples can be considered independent while resulting in a sufficiently large number of samples to support the statistical analysis (Coles 2001). On the other hand, the annual maxima series approach considers only the maximum value in a given year, and all other data are discarded. If multiple "large events" occur in a given year, only the maximum event for that year will be considered in the assessment. Conversely, the annual maxima approach will include a maximum value from a "dry year" even if no floods of significance have occurred. Therefore, the use of annual maxima series approaches can lead to lower estimates of the frequency of exceedance associated with a particular severity metric compared with assessments using partial duration series, which consider all (independent) events in a record that exceeds a particular threshold. However, for estimating hazards associated with returns periods of longer than about 10 to 20 years, the difference between results obtained using the two approaches is negligible (Ball et al. 2019; NOAA 2006).

\subsubsection{Copula-Based Approaches}

One challenge associated with direct parametric joint distribution fitting is that most of the formulated parametric multivariate distributions yield certain marginal distributions. The restriction that all random variables be distributed according to the same marginal functional form is generally limiting. In reality, each individual variable can have quite different distributions (e.g., one random variable may be marginally log-normally distributed and the other may be distributed accordingly to an extreme value distribution). This reality motivates the use of copulas for a more generalized approach in constructing multivariate distributions.

A copula function provides a mathematical expression for the joint CDF of random variables. Using a copula, the joint CDF can be estimated by first assuming functional forms for the copula and the marginal distributions and then using a set observations to separately estimate (1) the parameters of the marginal distributions and (2) the parameters of the copulas, which are typically related to the correlation between the quantities, as estimated from data. For any set of marginal CDFs and an assumed copula function, a valid joint $\mathrm{CDF}$ can be constructed. Therefore, copulas offer significantly flexibility in developing joint distributions. Additional mathematical information regarding copulas is provided in the following equations. The information that follows is an amalgamation and simplification of information contained in more comprehensive introductions to copulas (Balakrishnan and Lai 2009; Genest and Favre 2007; Haugh 2016; Nelsen 2002).

Let $\mathbf{X}=\left\{X_{1}, X_{2}, \ldots, X_{n}\right\}$ be a vector of random variables with marginal (univariate) CDFs: $F_{1}\left(x_{1}\right), F_{2}\left(x_{2}\right), \ldots, F_{n}\left(x_{n}\right)$. A copula, $C(\cdot)$, provides a mathematical expression for this joint CDF. In particular, the copula expresses the joint CDF as a function of the marginal CDFs and parameter(s) $(\theta)$ that provides a measure of association between the marginal CDFs. Following Sklar's Theorem (Nelsen $1999)$, for an $n$-dimensional joint $\operatorname{CDF} F_{\mathbf{X}}(\mathbf{x})$ with marginal $\operatorname{CDFs} F_{1}\left(x_{1}\right), F_{2}\left(x_{2}\right), \ldots, F_{n}\left(x_{n}\right)$, a copula exists such that

$$
F_{\mathbf{X}}(\mathbf{x})=P\left(X_{1} \leq x_{1}, \ldots, X_{n} \leq x_{n}\right)=C\left(F_{1}\left(x_{1}\right), \ldots, F_{n}\left(x_{n}\right), \theta\right) .
$$

The PDF can then be expressed as 


$$
f_{\mathbf{X}}(\mathbf{x})=\frac{\partial^{n} F_{\mathbf{X}}(\mathbf{x})}{\partial x_{1} \partial x_{2} \ldots \partial x_{n}}=\frac{\partial^{n} C\left(F_{1}\left(x_{1}\right), \ldots, F_{n}\left(x_{n}\right), \theta\right)}{\partial F_{1} \partial F_{2} \ldots \partial F_{n}} * f_{1}\left(x_{1}\right) f_{2}\left(x_{2}\right) \ldots f_{n}\left(x_{n}\right),
$$

where $f_{i}\left(x_{i}\right)$ represents the marginal PDF of $X_{i}$.

As an example, the bivariate Farlie-Gumbel-Morgenstern family of copulas expresses the joint CDF as a function of the marginal distributions $F_{1}\left(x_{1}\right)$ and $F_{2}\left(x_{2}\right)$ and the parameter $\theta(-1 \leq \theta \leq 1)$ using the following functional form:

$$
C\left(F_{1}\left(x_{1}\right), F_{2}\left(x_{2}\right), \theta\right)=F_{1}\left(x_{1}\right) F_{2}\left(x_{2}\right)+\theta F_{1}\left(x_{1}\right) F_{2}\left(x_{2}\right)\left(1-F_{1}\left(x_{1}\right)\right)\left(1-F_{2}\left(x_{2}\right)\right) .
$$

In Eq. 3.27, the parameter $\theta$ provides information regarding the association between $X_{1}$ and $X_{2}$. The quantity can be related to Spearman's $\rho$ (i.e., $\rho=\frac{\theta}{3}$ ) and to Kendall's $\tau$ (i.e., $\tau=\frac{2 \theta}{9}$ ) (Nelsen 1994), which are measures of association (correlation) between two quantities. When $X_{1}$ and $X_{2}$ are independent, $\theta$ is equal to zero and the joint CDF is equal to the product of the marginal CDFs.

Noting that the marginal CDF of $X_{1}$ can be obtained as $F_{1}\left(x_{1}\right)=F_{X_{1} X_{2}}\left(x_{1}, \infty\right)$ (and similarly for $X_{2}$ as $F_{2}\left(x_{2}\right)=F_{X_{1} X_{2}}\left(\infty, x_{2}\right)$ ), this copula (joint CDF) will return $F_{1}\left(x_{1}\right)$ and $F_{2}\left(x_{2}\right)$ for the marginal distributions of $X_{1}$ and $X_{2}$, respectively.

A large number of copula functions have been developed with various functional forms (e.g., Gaussian copulas, Archimedean copulas), each of which induces a different dependency structure. However, since they are all representations of the joint CDF of a vector of random variables, these copulas all must abide by the properties of a CDF. In particular, in the notation of copulas, $C(\cdot)$ must be a nondecreasing, monotonic function and $C\left(1, \ldots F_{i}\left(x_{i}\right) \ldots, 1, \theta\right)=F_{i}\left(x_{i}\right){ }^{11}$

For any set of marginal CDFs and an assumed copula function, a valid joint CDF can be constructed. Thus, the joint CDF can be estimated by first assuming functional forms for the copula and the marginal distributions and then using an $n$-dimensional set observations to separately estimate the (1) parameters of the $n$ marginal distributions, and (2) parameter $\theta$ of the copula.

The copula function for the joint CDF simply couples together information about the marginal distributions and association between the marginal distributions but allows each of the components to be investigated via separate statistical analyses. The marginal distributions (for assumed probability distribution functional forms such as an extreme value distribution) may be estimated using a variety of statistical techniques, including the method of moments, method of L-moments, and maximum likelihood estimation. Conceptually similar techniques can be applied for estimation of the parameter $\theta$ of the copula. For example, in a technique conceptually analogous to the "moment matching" used in the method of moments, ${ }^{12}$ "association measure matching" can be used to estimate the parameter of the copula. That is, a population measure of association (e.g., Kendall's $\tau$, Spearman's $\rho$ ) is calculated for the assumed copula function and set equal to the corresponding measure of association estimated from a sample data set. The parameter $\theta$ is then estimated via algebraic operations. The copula parameter can also be estimated using maximum likelihood estimation techniques.

\footnotetext{
11 This last property follows from the general consistency rule for multi-variate probability distributions, meaning $F_{X}\left(\infty, \ldots x_{i}, \ldots \infty\right)=P\left(X_{1} \leq \infty, \ldots, X_{i} \leq x_{i}, \ldots, X_{n} \leq \infty\right)=P\left(X_{i} \leq x_{i}\right)=F_{i}\left(x_{i}\right)$

${ }^{12}$ When using the method of moments, the moments (expected values) of the assumed (population) distribution are calculated and expressed as a function of the distribution parameters. These distribution moments are then set equal to the corresponding moments from a sample data set and the parameters are estimated via algebraic operations.
} 
Figure 3-5a presents an example of a joint PDF constructed using a Gaussian copula (with parameter $\rho=$ 0.5 ) and with marginal PDFs defined by the standard normal PDF (i.e., normal distribution with zero mean and unit standard deviation). In Figure 3-5a, the marginal PDFs are projected onto the sides of the figure as shown by the dotted lines. Figure 3-5b presents the contour view of the resulting joint PDF. Figure 3-5c shows the bivariate CDF (copula).

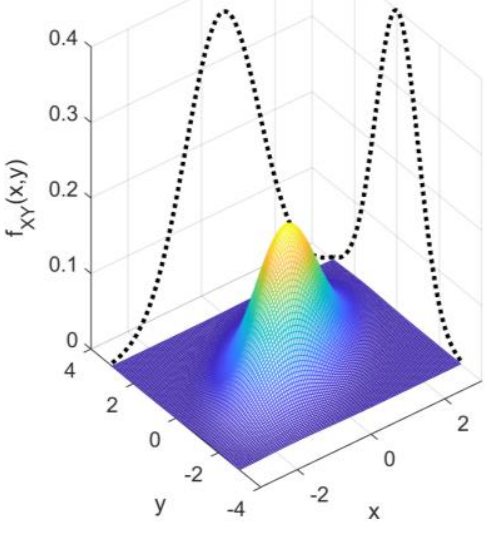

(a)

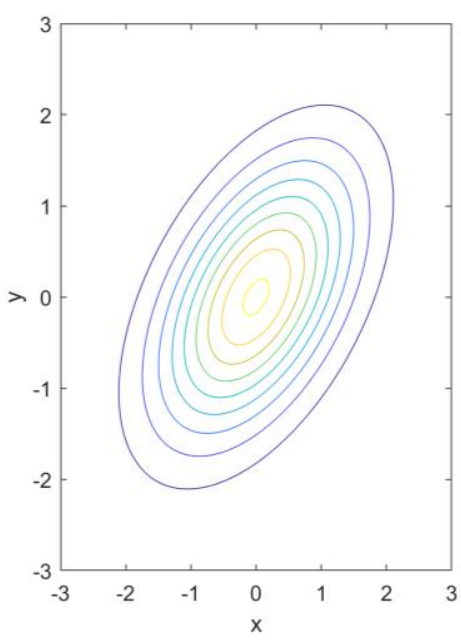

(b)

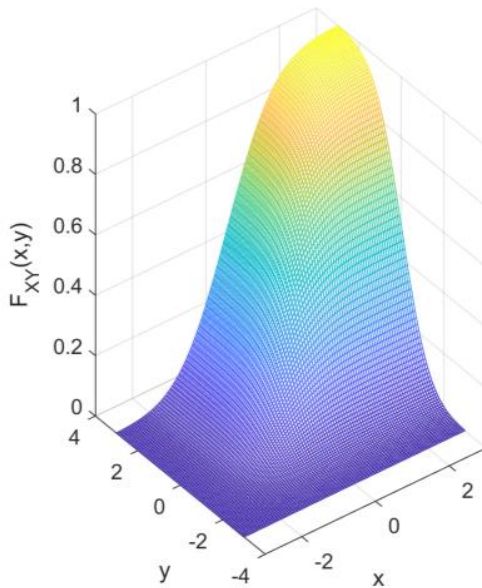

(c)

Figure 3-5. Illustration of (a) the joint Probability density function (PDF) $f_{X Y}(x, y)$ along with projections of marginal PDFs $f_{X}(x)$ and $f_{Y}(y)$; (b) contour plot of joint PDF $f_{X Y}(x, y)$; and (c) joint Cumulative distribution function $F_{X Y}(x, y)$ generated using copulas.

Given the flexibility offered by copulas, the copula method is a very popular strategy for characterizing the joint distribution of variables associated with MMF in the literature review for this study (Bender et al. 2016; De Michele et al. 2007; Gilja et al. 2018; Kao and Chang 2012; Lian et al. 2012; Masina et al. 2015; Moftakhari et al. 2017; Wahl et al. 2015; Zhong et al. 2013). Studies using copulas have been performed throughout the world, including in Italy (Bevacqua et al. 2017; Masina et al. 2015), the Netherlands (Zhong et al. 2013), China (Lian et al. 2012), and the United States (Moftakhari et al. 2017). However, this method does not appear to be popular in studies conducted in the United Kingdom (Hawkes et al. 2002; Hawkes 2008; Wadey et al. 2015), which typically use methods that directly estimate the parameters of bivariate distributions.

\subsubsection{Bayesian-Motivated Approaches}

The goal of the previous two approaches is to estimate the complete joint distribution using data sets directly related to the random variables of interest (i.e., basic random variable approaches, in the language of Der Kuireghian and Ditlevson 2009). The joint distribution is then used to estimate the marginal distribution of a flood severity metric or further estimate other statistical measures, such as quantiles, mean, and other moments. Instead of constructing the joint distribution directly from a data set related to basic random variables, the Bayesian-motivated approach provides a convenient alternative to estimate the joint distribution and derive marginal distributions from the conditional distributions. In particular, the chain (successive product) rule of probability allows any joint distribution to be expressed as the product of conditional probabilities. Although such approaches are popular in estimating seismic hazards (Baker 2008), the review of literature did not identify the Bayesian-motivated approach as a common approach among studies that addressed estimation of flooding hazards from MMF. However, such an approach is 
commonly applied to the estimation of hazards from storm surge using the joint probability method (JPM), which uses the approach to develop the joint distribution of hurricane parameters (Toro 2008). This joint distribution is defined over parameters associated with the flood-forcing phenomena of a hurricane rather than parameters associated with flood mechanisms.

Instead of directly constructing the joint distribution by assuming a defined function form or "building up" the joint distribution via copulas, the Bayesian-motivated approach provides a convenient alternative to construct the joint distribution from conditional distributions. In particular, the chain rule (successive product rule) of probability allows any joint distribution to be expressed as the product of conditional probabilities. That is, the joint distribution of a set of random variables $\mathbf{X}=\left\{X_{1}, \ldots, X_{n}\right\}$ can be expressed as the product of conditional relationships:

$$
\begin{aligned}
& f_{\mathbf{X}}\left(x_{1}, \ldots, x_{n}\right) \\
& =f_{X_{n} \mid X_{1}, . . X_{n-1}}\left(x_{n} \mid x_{1}, \ldots x_{n-1}\right) f_{X_{n-1} \mid X_{1}, \ldots X_{n-2}}\left(x_{n-1} \mid x_{1}, \ldots x_{n-2}\right) \ldots f_{X_{2} \mid X_{1}}\left(x_{2} \mid x_{1}\right) f_{X_{1}}\left(x_{1}\right) .
\end{aligned}
$$

In the general expression in Eq. 3.28, the random variables have no predefined order. However, by using knowledge of the underlying physical processes, the known (or assumed) conditional independence among variables can be used to order and simplify Eq. 3.28. Two random variables $X$ and $Y$ are said to be conditionally independent given another random variable $Z$ if $f_{X Y}(x, y \mid z)=f_{X \mid Z}(x \mid z) * f_{Y \mid Z}(y \mid z)$. Given the knowledge of conditional independence among random variables, the joint distribution may be factored into the product of local, conditional distributions. To illustrate and leverage this conceptual approach here and throughout this report, Bayesian networks were used as a modeling structure.

A Bayesian network is a graphical representation of a probabilistic model in which nodes (circles/ovals) represent random variables and directed links (arrows) represent probabilistic dependencies. Often, the direction of an arrow represents a causal relationship, although this causal relationship is not a requirement. Bayesian networks provide a graphical representation of probabilistic relationships and thus serve as a useful communication mechanism for discussing the Bayesian-motivated approach to probabilistic modeling.

For example, consider a set of five random variables $\mathbf{X}=\left\{X_{1}, X_{2}, X_{3}, X_{4}, X_{5}\right\}$. There are many ways to express the joint distribution among these random variables using the chain rule. Specifically, there are 120 permutations of order in which the variables can appear using the expression in Eq. 3.28. However, if the relationship among variables is understood, this expression can be simplified. Suppose the quantities are related as shown in the Bayesian network in Figure 3-6. In this figure, the random variable $X_{3}$ is probabilistically dependent on $X_{1}$ and $X_{2}$ (in the Bayesian network terminology, $X_{3}$ is called a "child" of $X_{1}$ and $X_{2}$; in turn $X_{1}$ and $X_{2}$ are "parents" of $X_{3}$ ). Moreover, in this expression, $X_{3}$ and $X_{4}$ share a common parent, which is $X_{1} . X_{3}$ and $X_{4}$ are said to be conditionally independent given $X_{1}$ (i.e., knowing or assuming the occurrence of $X_{1}$ renders $X_{3}$ and $X_{4}$ independent). Using a causal interpretation, observing the cause $X_{1}$ will block any dependence between the effects $X_{3}$ and $X_{4}$. Using the relationships expressed in this Bayesian network, the joint distribution can be expressed as

$$
f_{\mathbf{X}}\left(x_{1}, \ldots, x_{5}\right)=f_{X_{5} \mid X_{4}}\left(x_{5} \mid x_{4}\right) f_{X_{4} \mid X_{1}}\left(x_{4} \mid x_{1}\right) f_{X_{3} \mid X_{2}, X_{1}}\left(x_{3} \mid x_{2}, x_{1}\right) f_{X_{1}}\left(x_{1}\right) f_{X_{2}}\left(x_{2}\right) .
$$




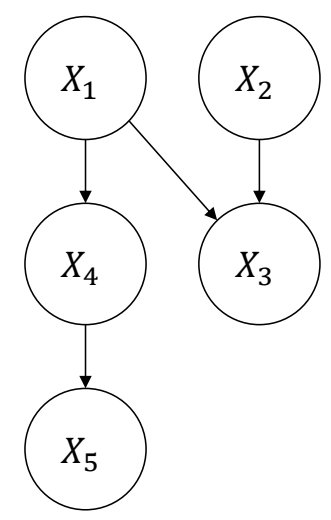

Figure 3-6. Simple Bayesian network. (Bensi et al. 2011)

Applying this concept to PFHA for MMFs, the random variables may represent parameters associated with any of the levels of the hierarchy shown in Figure 2-7 (e.g., random variables corresponding to the characteristics of flood-forcing phenomena, flood mechanisms, or flood severity). Then, using knowledge of the relationship among quantities (e.g., based on physical reasoning or empirical models), a joint distribution can be constructed by applying the chain rule of probability and knowledge of conditional relationships and independence of quantities. For example, taking Figure 2-8b and letting $X_{1}$ represent a random variable describing the flood-forcing phenomena, $Y_{1}$ and $Y_{2}$ represent random variables describing the two flood mechanisms, and $Z_{1}$ represents the targeted flood severity metric, the joint distribution over all random variables $\left(\Omega=\left\{\mathrm{X}_{1}, Y_{1}, Y_{2}, Z_{1}\right\}\right)$ may be defined using the conditional relationships shown in the graphical model as

$$
f_{\Omega}\left(x_{1}, y_{1}, y_{2}, z_{1}\right)=f_{Z_{1} \mid Y_{1}, Y_{2}}\left(z_{1} \mid y_{1}, y_{2}\right) f_{Y_{2} \mid X_{1}}\left(y_{2} \mid x_{1}\right) f_{Y_{1} \mid X_{1}}\left(y_{1} \mid x_{1}\right) f_{X_{1}}\left(x_{1}\right)
$$

Although such distributions can be developed directly without the use of Bayesian networks, the use of such a graphical tool provides transparency regarding assumed relationships.

Using the joint PDF expression in Eq. 3.30, the exceedance probability for the severity metric $Z_{1}$ may be defined as

$$
\begin{aligned}
P\left(Z_{1}>z_{1}\right) & =\int_{-\infty}^{\infty} P\left(Z_{1}>z_{1} \mid x, y\right) f_{Y_{2} \mid X_{1}}\left(y_{2} \mid x_{1}\right) f_{Y_{1} \mid X_{1}}\left(y_{1} \mid x_{1}\right) f_{X_{1}}\left(x_{1}\right) d y_{2} d y_{1} d x_{1} \\
& =\int_{z=z_{1}}^{\infty} \int_{-\infty}^{\infty} f_{Z \mid Y X}(z \mid x, y) f_{Y_{2} \mid X_{1}}\left(y_{2} \mid x_{1}\right) f_{Y_{1} \mid X_{1}}\left(y_{1} \mid x_{1}\right) f_{X_{1}}\left(x_{1}\right) d y_{2} d y_{1} d x_{1} d z
\end{aligned}
$$

In Eq. 3.31, the conditional probability $P\left(Z_{1}>z_{1} \mid X, Y\right)$ may be implemented as an indicator function when a deterministic process model is used to map between the input parameters $Y_{1}, Y_{2}$, and $X_{1}$, and the response (output) parameter $Z_{1}$ (or as a probability if numerical model errors are considered).

\subsubsection{Data Needs}

The development of marginal and joint distributions requires data to support the selection of distribution functional forms and estimation of associated parameters. Data used for such statistical assessments may come directly from observational records or may be generated synthetically. Observational data may provide information directly on the flood severity metric(s) of interest to the study (e.g., water levels or 
volumes). Univariate analyses supporting PFHA typically use EVAs, whereas multivariate extensions may be used to directly estimate the parameters of joint distributions or may use copula-based approaches. Observational data may also be used to develop probabilistic distributions assigned to random variables representing parameters or other quantities relevant to modeling flood-forcing phenomena (e.g., hurricane or meteorological event characteristics). Such distributions can then be used to support stochastic simulations or Bayesian probabilistic approaches. Observational data may also be available from paleo-flood studies or historical information, although such information is usually included in statistical analyses as censored observations (e.g., England et al. 2018).

In some cases, observational records are insufficient (e.g., the temporal length of a record is too short) to support probabilistic analysis, particularly in performing assessments focused on hazards with longer return periods. In these situations, researchers have employed strategies to generate results that are more robust in data-sparse locations, including synthetic data generation. Different techniques are available for synthetic data generation, including using Monte Carlo methods as well as leveraging output from numerical models. Synthetic data generated using simulations (e.g., based on statistical models and/or analytical or numerical models) can be used in conjunction with standard statistical techniques (e.g., techniques that are used for analysis of observational data) to generate hazard estimates. Model simulations can also be useful in using Bayesian-motivated approaches by facilitating the generation of conditional distributions.

Simulation techniques identified in the literature include analytical models, numerical models, and surrogate modeling methods. Physics-based models attempt to capture the physical behavior of a system or process (consistent with physical laws) using analytical/mathematical expressions, typically represented by a series of differential equations. Often, these physical models are applicable to simplified or idealized conditions. The use of physics-based models requires knowledge of the physical processes and interactions. Moreover, they may also require numerical solutions to extensive systems of equations that are mathematically complex and may become infeasible for complex domains, boundary conditions, and initial conditions.

Numerical models seek to provide accurate approximations of such physical models, typically by discretizing the spatial domain and incrementally solving the problem at discrete spatial locations. Typically, solution algorithms use a time-stepping approach whereby the system is incrementally solved at discrete points in time. Numerical models can be computationally demanding and expensive to run. In response, surrogate modeling techniques have become increasingly popular. These modeling methods attempt to emulate (mimic) a complex numerical model by developing a response structure that maps a vector of input parameters to a single or a vector of output parameters. These model emulators are generally data driven and typically use a limited number of synthetic or historical observations (inputoutput pairs) from a numerical model to fit or train a surrogate model. In addition to seeking to emulate numerical process models, parametric and nonparametric models can be built to reflect physical processes using other data sources. For example, surrogate modeling tools have been developed using observational data as well as reanalysis or interpolated (gridded) data, and combinations of data types. Nonparametric models often rely on machine learning-derived modeling approaches. Alternatively, conventional statistical modeling techniques (e.g., regression) may be used to build a parametric model for output parameters as a function of input parameters. Increasingly, machine learning methods are being used to create this mapping between input and output parameters.

\subsection{DEVELOPMENT OF HAZARD CURVES AND SURFACES}

Most work related to PFHA focuses on estimating the annual probability of exceedance associated with a single measure of flood severity. Such studies take interest in the annual probability that a random variable $Z$ representing flood severity (e.g. peak flow) will be exceeded: 


$$
P(Z>z)=1-P(Z \leq z)=1-F_{Z}(z)
$$

where $F_{Z}(z)$ is the CDF of $Z$. Such studies may or may not make distinctions regarding the flood-forcing phenomena and flood mechanisms that may lead to the exceedance of flood severity metrics considered in the assessment.

Once the joint distribution over all random variables of interest is defined, the joint, marginal, and conditional distributions of any subset of the random variables can be obtained through a series of calculus and algebraic operations. In particular, the joint distribution of flood severity metrics can be obtained, which supports the development of hazard curves.

Table 3.1 shows the development of the joint distribution using a Bayesian modeling formulation for numerous generalized combinations involving one or more flood-forcing phenomena, flood mechanisms, and flood severity metrics that might be of interest in probabilistic flood hazard studies. 
Table 3.1. Illustrative expressions of joint distributions for several applications.

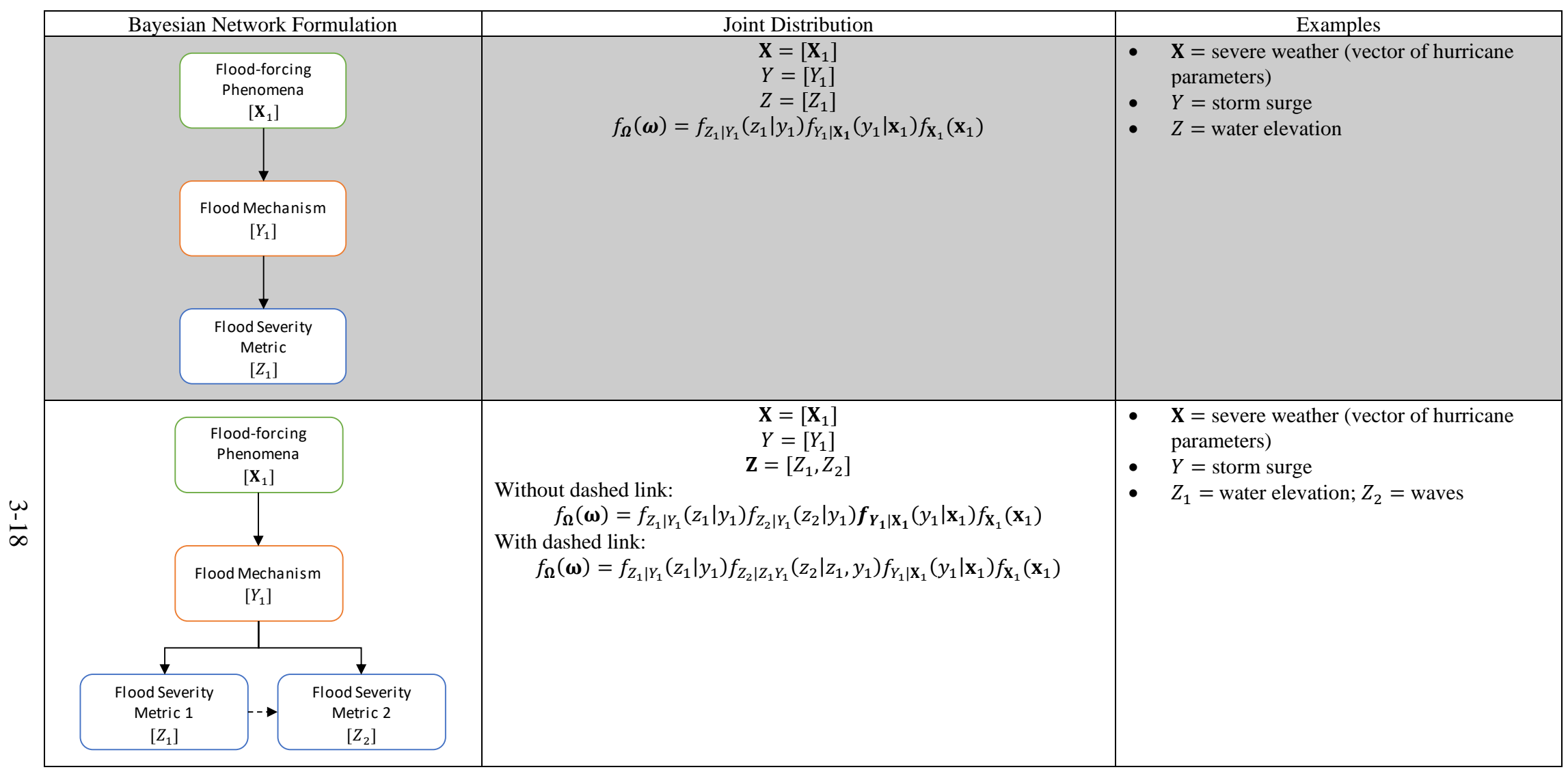




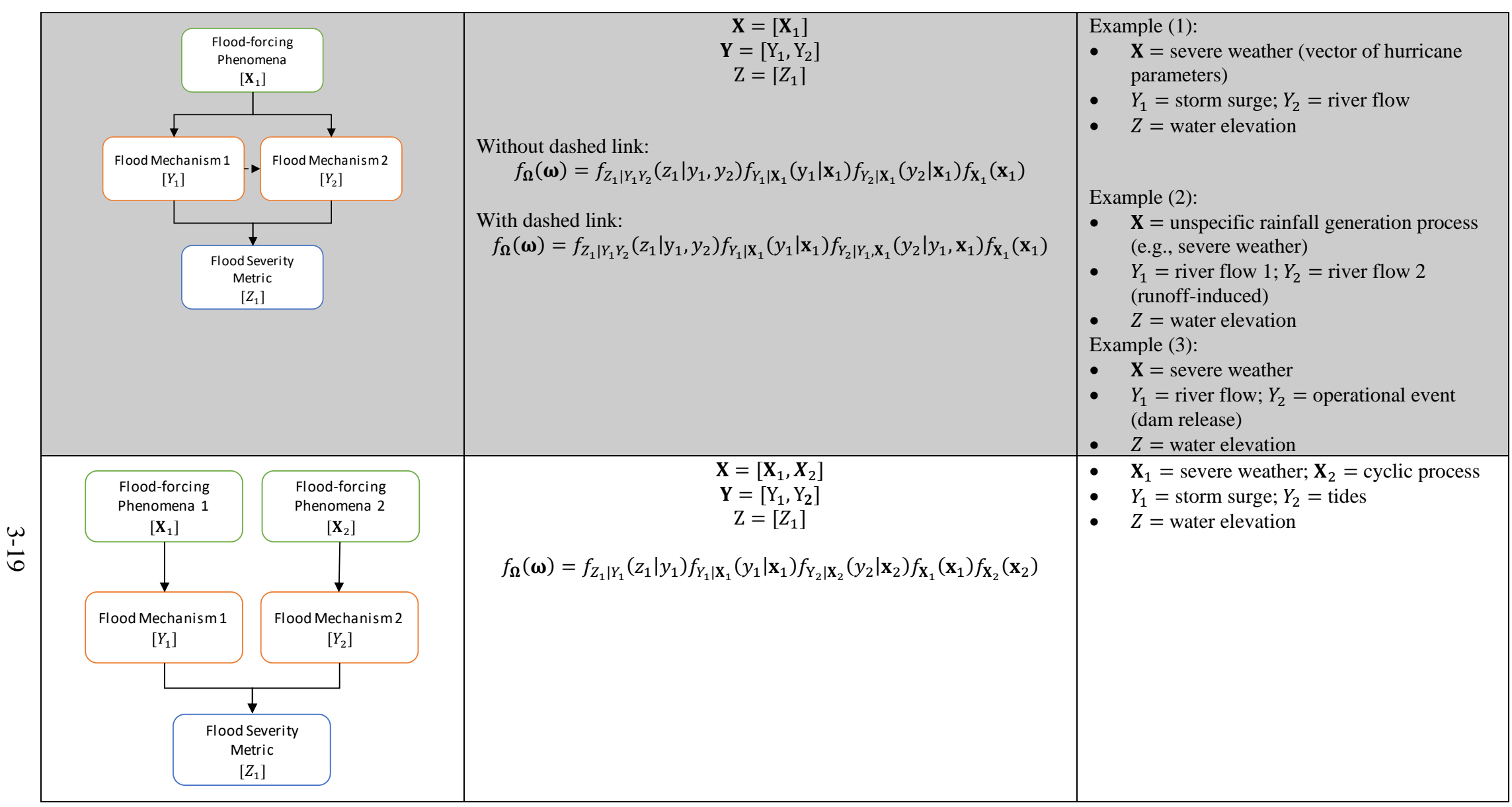

Notes: In this table, bold font represents vectors of random variables. 
In Table 3.1, the set of random variables contained in the model is denoted:

$$
\mathbf{\Omega}=[\mathbf{X}, \mathbf{Y}, \mathbf{Z}],
$$

where

- $\mathbf{X}=\left[\mathbf{X}_{1}, \ldots, \mathbf{X}_{n_{x}}\right]$ with $\mathbf{X}_{i}=\left[X_{i, 1}, X_{i, 2}, \ldots, X_{i, n_{i}}\right], i=1, \ldots, n_{x}$ is a vector of random variables characterizing flood-forcing phenomena $i$.

- $\quad \mathbf{Y}=\left[\mathbf{Y}_{1}, \ldots, \mathbf{Y}_{n_{y}}\right]$ with $\mathbf{Y}_{j}=\left[Y_{j, 1}, Y_{j, 2}, \ldots, Y_{j, n_{j}}\right], j=1, \ldots, n_{y}$ is a vector of random variables characterizing flood mechanism $j$.

- $\mathbf{Z}=\left[Z_{1}, Z_{2}, \ldots, Z_{n_{z}}\right]$ is a vector of random variables representing flood severity metrics.

The joint PDF of flood severity metrics can then be obtained as

$$
f_{\mathbf{Z}}(\mathbf{z})=\int_{\mathbf{\Omega}^{\prime}} f_{\boldsymbol{\Omega}}(\boldsymbol{\omega}) d \mathbf{\Omega}^{\prime},
$$

where $\boldsymbol{\Omega}^{\prime}=\boldsymbol{\Omega} \backslash \mathbf{Z}$ is the set of all random variables exclusive of the vector of random variables, $\mathbf{Z}$, representing flood severity.

The probabilistic models may be developed using explicit probabilistic modeling of the conditional relationships associated with all relevant stochastic quantities. However, in many cases, only a subset of variables will be explicitly considered in an assessment. For example, a study may focus on developing the joint distribution of river discharge in two rivers (rainfall runoff flood mechanism) for the purpose of modeling the combined effect on flood elevation at the river confluence as the flood severity metric. In such cases, there may be no explicit consideration of the flood-forcing phenomena; instead the study will focus on the development of the joint distribution of river discharge (e.g., via development of a joint distribution using copulas) and the conditional distribution of river elevation.

The availability of the joint, marginal, and conditional distributions over the random variables selected to represent flood-forcing phenomena, flood mechanisms, and/or flood severity metrics facilitates development of a joint distribution for the subset of random variables representing flood severity (i.e., using the described mathematical operations). In turn, this process supports the development of hazard curves or, more generally, hazard surfaces.

In a conventional hazard curve (Figure 3-1), one axis represents a measure of flood severity (e.g., flood height) and the other axis represents the annual probability (or frequency) of exceeding the measure of severity; in other words, $P(Z>x)$. In extending this concept to multiple measures of flood severity (and thus development of hazard surfaces), it is first necessary to identify what constitutes a hazard from the perspective of the exceedance events of interest. For example, some assessments focus on estimation of the "joint exceedance probability" (i.e., probability that multiple exceedance events will occur). In the case of two random variables representing flood severity metrics $\left(Z_{1}\right.$ and $\left.Z_{2}\right)$, this quantity may be written as 


$$
\begin{aligned}
P\left(Z_{1}>z_{1} \cap Z_{2}>z_{2}\right)= & 1-P\left(\overline{Z_{1}>z_{1} \cap Z_{2}>z_{2}}\right) \\
= & 1-P\left(Z_{1} \leq z_{1} \cup Z_{2} \leq z_{2}\right) \\
= & 1-\left[P\left(Z_{1} \leq z_{1}\right)+P\left(Z_{2} \leq z_{2}\right)-P\left(Z_{1} \leq z_{1} \cap Z_{2} \leq z_{2}\right)\right] \\
= & 1-\left[F_{Z_{1}}\left(z_{1}\right)+F_{Z_{2}}\left(z_{2}\right)-F_{Z_{1} Z_{2}}\left(z_{1}, z_{2}\right)\right]
\end{aligned}
$$

where $F_{Z_{1}}\left(z_{1}\right)$ and $F_{Z_{2}}\left(z_{2}\right)$ represent the marginal CDFs of $Z_{1}$ and $Z_{2}$, and $F_{Z_{1} Z_{2}}\left(z_{1}, z_{2}\right)$ represents their joint CDF. As noted previously, these quantities can be readily obtained through integration over the joint distribution of all variables included in the model. Equation 3.35 can be extended to more than two random variables through application of an "inclusion/exclusion" formula for operations involving unions of events. For example, in the case of three random variables, Eq. 3.35 may be written as

$$
\begin{aligned}
P\left(Z_{1}>z_{1} \cap Z_{2}\right. & \left.>z_{2} \cap Z_{3}>z_{3}\right)=1-P\left(Z_{1} \leq z_{1} \cup Z_{2} \leq z_{2} \cup Z_{3} \leq z_{3}\right) \\
= & =1 \\
& -\left[F_{Z_{1}}\left(z_{1}\right)+F_{Z_{2}}\left(z_{2}\right)+F_{Z_{3}}\left(z_{3}\right)-F_{Z_{1} Z_{2}}\left(z_{1}, z_{2}\right)-F_{Z_{1} Z_{3}}\left(z_{1}, z_{3}\right)\right. \\
& \left.-F_{Z_{2} Z_{3}}\left(z_{2}, z_{3}\right)+F_{Z_{1} Z_{2} Z_{3}}\left(z_{1}, z_{2}, z_{3}\right)\right] .
\end{aligned}
$$

Conversely, the hazard may be defined so that the quantity of interest is the probability that at least one exceedance event occurs. In the case of two flood severity metrics, this can be written as the union of exceedance events:

$$
\begin{aligned}
P\left(Z_{1}>z_{1} \cup Z_{2}>z_{2}\right) & =1-P\left(\overline{Z_{1}>z_{1} \cup Z_{2}>z_{2}}\right) \\
& =1-P\left(Z_{1} \leq z_{1} \cap Z_{2} \leq z_{2}\right) \\
& =1-F_{Z_{1} z_{2}}\left(z_{1}, z_{2}\right) .
\end{aligned}
$$

More generally, this can be expressed as

$$
P\left(\bigcup_{i=1}^{n} Z_{i}>z_{i}\right)=1-F_{\mathbf{Z}}\left(z_{1}, \ldots, Z_{n}\right) .
$$

The hazard of interest may also be the probability of exceedance of one flood severity metric conditioned on either (1) the value of another variable or (2) the exceedance of another variable. In the first case, the conditional exceedance event can be written as

$$
\begin{aligned}
P\left(Z_{1}>z_{1} \mid Z_{2}=z_{2}\right) & =1-P\left(Z_{1} \leq z_{1} \mid Z_{2}=z_{2}\right)=1-F_{Z_{1} \mid Z_{2}}\left(z_{1} \mid z_{2}\right) \\
& =1-\int_{-\infty}^{z_{1}} f_{Z_{1} \mid Z_{2}}\left(a \mid z_{2}\right) d a=1-\int_{-\infty}^{z_{1}} \frac{f_{Z_{1} Z_{2}}\left(a, z_{2}\right)}{f_{Z_{2}}\left(z_{2}\right)} d a .
\end{aligned}
$$

In the second case, the conditional exceedance event can be written as a conditional expression involving both random variables exceeding specified values:

$$
\begin{aligned}
P\left(Z_{1}>z_{1} \mid Z_{2}>z_{2}\right) & =\frac{P\left(Z_{1}>z_{1} \cap Z_{2}>z_{2}\right)}{P\left(Z_{2}>z_{2}\right)} \\
& =\frac{1-\left[F_{Z_{1}}\left(z_{1}\right)+F_{Z_{2}}\left(z_{2}\right)-F_{Z_{1} Z_{2}}\left(z_{1}, z_{2}\right)\right]}{1-F_{Z_{2}}\left(z_{2}\right)}
\end{aligned}
$$




\section{SUMMARY OF AVAILABLE LITERATURE}

This section provides a summary of available literature related to MMFs. The section begins with a descriptive summary of existing studies and then continues with an integrative summary that focuses on the hazards and geographic regions considered in existing studies, as well as data and statistical methods used. Additionally, Table 4.1 provides summary-level information related to studies reviewed under this project. The table seeks to provide quick-reference information about the following (as applicable):

- Flood-forcing phenomena, flood mechanisms (and the associated pluvial, fluvial, and coastal types), and flood severity metrics considered in each study

- Case studies or geographic regions addressed by each study

- Joint probability analysis approach used (when applicable), data sources, and numerical models/software used in each study

Distilling divergent research studies into a tabular summary format is challenging, so it is emphasized that Table 4.1 does not capture details and nuances associated with individual studies.

This literature summary provides information about studies specifically focused on joint probability approaches. Studies not directly related to joint probability assessment are also included if they are judged to provide information/insights, computational "building blocks," or mathematical formulations that may potentially be relevant to addressing MMFs.

The subsections summarize the research literature rather than focusing on more applied guidance. Although MMFs have been the focus of research studies, limited guidance and experience exists regarding the application of MMF modeling frameworks, particularly for US applications (both nuclear and nonnuclear). Probabilistic frameworks used outside of nuclear applications generally focus on singlemechanism flood hazard assessments; however, some documentation does acknowledge the potential impacts of MMF hazards. Additional discussion of existing guidance used in the nuclear industry and more broadly is provided in APPENDIX A.

\subsection{OVERVIEW OF AVAILABLE LITERATURE}

The text that follows provides a summary description of existing research reviewed in this study. Research summaries are organized by hazard focus; in other words, studies are grouped based on the hazard mechanism type(s) that they address. First, studies that address multiple mechanisms in the coastal mechanism type are addressed, followed by studies focusing on multiple mechanisms in the fluvial mechanism type. Then, studies addressing multiple flood mechanisms in multiple types are addressed (i.e. coastal and fluvial, coastal and pluvial).

Although the following discussions focus specifically on flooding events, interest in compound events ${ }^{13}$ more broadly is growing in the academic and other research communities in the United States and internationally. This growing interest includes a focus on events (or series of events) that include hazards from multiple hazard groups such as earthquakes, wildfires, and floods, as well as consideration of the impacts of such factors on droughts (e.g., water availability, temperature, and soil moisture).

Additionally, although the summaries focus on literature that addresses combinations of flood mechanisms and closely related topics, more general literature also addresses topics such as compound

\footnotetext{
${ }^{13}$ For example, see "Compound Events," http://compoundevents.org/ (accessed February 2019)
} 
event frameworks (Leonard et al. 2014), best practices for estimation of extremes involving multiple characteristics of flood-forcing processes or flood severity measures (Hawkes et al. 2008), and general discussion of correlation models in flood risk applications (Diermanse and Geerse 2012) and joint probability analyses (Hawkes 2008).

The studies summarized use disparate terminology to describe flood mechanisms and severity metrics, which is particularly noticeable in the context of coastal flooding hazards. The terminology used in the summaries aligns with the terminology used in the original references. Appendix B introduces key coastal hazard terminology and information regarding the relationship between terms, and it identifies some key synonyms.

\subsubsection{Coastal Flooding}

This section describes current research literature related to flood hazards involving multiple coastal flood mechanisms (e.g., tsunami and tidal processes). This section also includes a summary of selected literature related to multiple aspects of a coastal flood event that may be best characterized as involving several flood severity metrics (e.g., stillwater and wave characteristics). Coastal flooding from weatherinduced phenomena (e.g., hurricane-induced storm surge) and land movement (e.g., earthquake-induced tsunami) are distinctive processes, and the induced waves are governed by fundamentally different physical phenomena. Therefore, they are discussed separately in the summaries that follow.

Several studies have explored the interactions between tides and tsunamis in computing water levels. Those studies focused on modeling of processes and interactions and did not address probabilistic characterization or dependence structures. Kowalik and Proshutinsky (2010) investigated the interaction between tides and tsunamis using numerical experiments with an idealized 1D model and a 2D highresolution regional model. The idealized model was developed by using 1D shallow water equations applied to a 1D idealized channel with a gradually decreasing depth from 1,000 $\mathrm{m}$ to $20 \mathrm{~m}$. Based on the results of the idealized model experiments, the authors noted that simulated elevations, considering both tsunami and tides at the same time, were different from simulated elevations using linear superposition of tides and a tsunami in isolation. This finding emphasized the importance of considering the interaction between tides and tsunamis. The investigation using the high-resolution regional model involved a 2D numerical model for two sites along Cook Inlet in Alaska. Finally, based on the results of both models, it was concluded that interaction between tides and tsunamis varies depending on basin bathymetry, configuration of coastal line, and characteristics of tsunami and tidal forces. Tsunami-tide interactions can lead to both amplification and damping of impacts. Kowalik and Proshutinsky (2010) also recommended that simultaneous simulation of a tsunami and tides be conducted in cases with strong tides that have comparable magnitudes to water depths.

Additionally, Zhang et al. (2011) investigated the interaction between a dynamic tide (i.e., a tide following the dynamic theory of tides as opposed to the static theory of tides) and a tsunami. The 3D finite element model SELFEE was used. Simulations were conducted for two scenarios. One scenario considered a tsunami with the presence of tides, and the other scenario considered a tsunami with the absence of dynamic tides. For model verification, observed National Geodetic Data Center ${ }^{14}$ (NGDC) data were used. Based on the results of the study, the interaction between tsunami and tide significantly affected wave runup and inundation extent. In particular, the authors noted that the tide-tsunami interaction was responsible for around $50 \%$ of the wave runup and up to $100 \%$ of the inundation area in estuary and river environments. This interaction was negligible in open coast areas. The study also emphasized the importance of using a high-resolution digital elevation model (DEM) in simulations for

\footnotetext{
${ }^{14}$ Now part of the National Center for Environmental Information.
} 
key areas under study. A high-resolution DEM was created by using NGDC's mosaic tsunami DEM ${ }^{15}$ and $0.3 \mathrm{~m}$ topographic Lidar ${ }^{16}$ derived data for Coos Bay, Oregon.

Several coastal studies have explored the interaction of stillwater levels and wave effects or other wave characteristics during storm events (e.g., wave period). For example, Hawkes et al. (2002) explored the dependence between high stillwater levels and large waves, as well as wave height and period. In particular, the study developed a joint density function for water level, wave height, and wave period. The study focused on return periods of up to 200 years and on locations around England and Wales. Empirical records were compiled for each variable of interest: 10 years of available empirical water level data from measurements of stillwater level at high water, and estimated wave height and mean wave periods derived from hindcasts. The authors then fitted statistical distributions to each empirical data series, developed statistical models for the dependence between the variables of interest using one or more bivariate normal distribution, used Monte Carlo simulation to generate simulated data from the models, performed joint extremal analysis on the simulated data, and computed overtopping rates for idealized slopes and walls.

De Michele et al. (2007) proposed a copula-based statistical model for multidimensional frequency analysis of several variables related to sea storms (e.g., hurricane, typhoon, or any storm that can occur on the sea), including significant wave height ( $\mathrm{SWH})$, storm duration, storm direction, and storm interarrival time (i.e., the time interval between the occurrence of two storms). For multivariate analysis of variables, the study used a copula method that considered a mixture of conditional distributions on several distinct sets of the aforementioned variables. The objective was to compute the return periods associated with multivariate events and sea storm magnitude, which was defined by the authors as a function of SWH and duration. Events of interest had return periods of less than approximately 100 years. For model validation, the study used 12 years of data from the Alghero wave buoy in Sardinia, Italy. Observed parameters included the SWH, peak period, wave direction, and water temperature. Conclusions about model validity were based on an observed good fit between case study data and model results.

Masina et al. (2015) investigated the joint occurrence of water levels and waves. The study used a simplified case study of a coastal zone of the Ravenna coast in Italy using 6 years of data related to sea level (i.e., peak water level [PWL]) and waves (i.e., SWH) in the area, and it estimated the number of events that exceeded a specified water level threshold within a 100 year time period. In the study, coastal flooding was considered to be a function of water level, SWH, peak wave height, direction of wave propagation, and variations due to different seasons. The study investigated the dependence between PWL and SWH using Kendall's rank correlation coefficient, Spearman's correlation coefficient, and Pearson's correlation coefficient. The dependence structure was characterized using a copula-based approach. Based on statistical analysis of data, a one-parameter extreme value copula was selected for defining the dependence between the extreme values of PWL and SWH.

Corbella and Stretch (2013) used Archimedean copulas to explore dependencies between storm parameters. Wadey et al. (2015) assessed sea levels and waves that occurred in the 2013/2014 storm seasons in two coastal areas in the United Kingdom. The study investigated the joint probability of sea levels and waves for these case studies. The data sources used included tide gauge records and wave buoy data. In the study, generalized Pareto distributions were fitted as marginal distributions to high water level and SWH. To capture the dependence structure between variables and then generate a large number of pairs related to wave height and sea level, a single bivariate normal distribution and a mixture of two bivariate normal distributions were used.

\footnotetext{
15 http://www.ngdc.noaa.gov/mgg/inundation/ (accessed February 2019)
}

16 https://www.oregongeology.org/lidar/ (accessed February 2019) 
Orton et al. (2016) introduced an approach for flood hazard assessment that focused on predicting the risk of flooding at New York Harbor. The goal of the study was accurate prediction of storm tides for return periods from 5 to 10,000 years. This work separately analyzed the flood risk due to tropical cyclones (TCs) and extratropical cyclones (ETCs). A statistical-stochastic model for North Atlantic TCs (19502013) was used for generation of synthetic storm events. In the case of ETCs, flood hazard assessment was conducted based on simulation of historical events (1950-2009). The results were presented as hazard curves for TCs and ETCs. These curves were consistent with curves created form historical data. By combining ETC and TC results, the 100-year flood level was calculated. Based on the results of the study, Hurricane Sandy's storm tide, which hit the area in 2012, was found to be a 260-year flood level.

Research has also explored the effects of sea level rise (SLR) on estimated coastal hazards. Tebaldi et al. (2012) used an extreme value theory framework to investigate the effects of SLR on storm surge-induced water levels and on the occurrence frequency of extreme water levels along the US coasts (where extreme was associated with a $1 \%$ chance of occurrence). Hourly and monthly data related to 55 tidal gauges located along the contiguous United States were used. The study demonstrated that even in the areas with slow SLR, a substantial increase in the frequency of extreme waters could occur. The study highlighted the importance of considering the joint effects of SLR with other flooding mechanisms. Vitousek et al. (2017) conducted a study at the global scale to analyze the effects of SLR in combination with other flooding mechanisms (i.e., tides, waves, and storm surges), focusing on the change in frequency of events currently estimated to have a return period of 50 years. That study investigated the combination of SLR with waves, surges, and tides by using extreme value theory, and it considered linear interactions among tides, surges, and waves. In the study, 21 years of coincident data related to tides, surges, and waves were used for 1993 to 2013. The data for deep-water wave height and wave period were obtained by Global Ocean Wave (GOW) reanalysis (Reguero et al. 2012). Storm surge and tidal water level data were obtained from the Mog2D barotropic model and TPXO tidal inversion model, respectively. The method used in the study ignored anomalies in sea level caused by seasonal differences and climate cycles such as El Nino. The authors concluded that the increase in flooding risk is particularly discernable in tropical areas.

Probabilistic storm surge studies often refer to applications involving JPM. For example, Toro et al. (2010) assessed the accuracy of two JPMs for frequency analysis of hurricane surge, focusing on surge severities associated with approximately 100-500-year return periods. These two methods, based on optimal sampling of parameter values, are called "JPM-optimal sampling-response surface" and "JPMoptimal sampling-quadrature". This subset of literature is not discussed in detail in this report because of its focus on the joint probability of flood-forcing phenomena (e.g., hurricane characteristics) rather than on characterization of hazards from multiple flood mechanisms.

\subsubsection{Fluvial Flooding}

This section describes current research literature related to flood hazards involving multiple fluvial flood mechanisms (e.g., combined runoff from basin-wide precipitation and snowmelt), as well as assessment of fluvial hazards at river confluences.

Sui and Koehler (2001) investigated the joint occurrence of precipitation on snow and snow melt. The study involved the investigation of the spatiotemporal variability of precipitation and snow, as well as dependences between related quantities. Study activities included the EVA of several series of annual precipitation and snow (i.e., snow depth and snow water equivalent), as well as discharge data, exploration of the simultaneous occurrence of snow melt and rain-on-snow events, and investigation of the characteristics of discharges from combined runoff. A forest region in southern Germany was selected as a case study. The study used long-term data series for average monthly and annual precipitation data, as well as snow depth and snow water equivalent data observed at meteorological stations and discharge 
observed at hydrologic gauge stations. Comparisons were made with other regions in Germany. The authors concluded that for areas with elevations higher than $400 \mathrm{~m}$ from sea level, rainfall on snow was a more important significant contributor to the runoff-generating process than pure rainfall events. In a study not directly related to MMFs, Ozga-Zielinski et al. (2016) explored snowmelt-induced floods by developing a joint distribution between peak discharge and flood volume using a copula analysis and through development of a bivariate normal distribution. The analysis was performed specifically for parameters extracted for snowmelt flood events in northeastern Poland.

Several authors have addressed flooding at the confluence of two rivers. For example, Wang et al. (2009) developed a copula-based flood frequency (COFF) method that was employed for river confluences by using Archimedean copulas. The Des Moines River in Iowa was selected as a case study for the purposes of testing the proposed method against the National Flood Frequency Program model. Annual peak flow data from three US Geological Survey (USGS) gauge stations (two of the stations upstream of the confluence and the third one nearby) for 38 years (1968-2005) were used. The COFF approach used in the study included (1) fitting a probability distribution to tributary stream flow data, (2) identifying a joint probability distribution by using a copula method, (3) identifying stream flow at the river confluences (synthetically and by using Monte Carlo simulation), and (4) identifying flood frequency at river confluences by applying univariate flood frequency analysis. The study considered return periods up to 200 years. A companion paper applied a joint probability approach to looking at ungauged confluences (Wang 2016).

Kao and Chang (2012) extended the use of the coincidental flood frequency analysis (CFFA) method to analyze coincident floods due to several tributary streams in ungauged basins. A step-by-step CFFA was conducted at ungauged basin confluences by using copulas. The method can be considered as an alternative to the National Flood Frequency Program model and the National Streamflow Statistics Program model, which have been developed for applications involving ungauged basins. The approach used in the study included four primary steps: (1) data collection and data quality control, (2) fitting of a marginal distribution to the peak flows of the tributaries, (3) using Gaussian copulas to construct dependence structure, and (4) estimating flood frequency at the river confluence. The study considered return periods of up to 200 years. To evaluate the performance of the proposed approach, standard goodness-of-fit tests (Kolmogorov-Smirnov and Cramer-von Mises) were used, along with four numeric criteria (Nash-Sutcliffe efficiency coefficient, root-mean-square error, coefficient of determination, and mean of percent error). The proposed approach was applied to an event in the case study region in Nashville, Tennessee.

Bender et al. (2016) introduced a methodology for bivariate analysis by using multivariate copulas that allowed for differing assumptions: (1) considering that the annual maxima on both rivers occurs concurrently and (2) assuming that only a single river is in the maxima state at a point in time (with the other river not necessarily at its annual maxima). The second case is considered more realistic than the first. Thus, the authors focused on estimation of AEP (with a focus on an AEP of 0.01) for applications in which the annual maxima of river discharge on two rivers does not occur at the same time. As a case study, the proposed method was applied for a flood hazard assessment related to the confluence of the Rhine and Sieg Rivers in Germany. The study leveraged daily (or more frequent) mean discharge time series for both rivers recorded at gauges upstream of the confluence. The proposed method was based on bivariate statistical analysis (using copulas) of annual (block) maxima of discharge on one river, and the concurrent river discharge on the other river. For transforming discharge values into water levels (required for the design of flood protection facilities), the 2D hydrodynamic model Hydro_AS-2D, which uses the finite volume method for solving shallow water equations, was used. The results of the proposed method were different from the more conservative method in which the annual maxima values for both variables (river discharges) were assumed to occur simultaneously. The authors concluded that the 
proposed approach could be applied to any data in which extreme values related to variables do not necessarily occur at the same time.

Gilja et al. (2018) conducted a joint probability analysis related to flood hazards at river confluences. This work used bivariate Gumbel-Hougaard copulas to calculate the joint probability of peak flood discharge exceedance at two river confluences. The study considered return periods of up to 1,000 years. The Sava River (a tributary of the Danube River) in Europe was selected as the case study region. River discharge data were obtained from gauging station records near Kupa River and Una River confluences. Based on the results of the study, the use of traditional univariate flood frequency analysis was found to underestimate flood hazard. Flood hazard estimates using the multivariate copula method were significantly higher than the estimated values obtained by using the univariate method. Furthermore, based on the data observed, the authors concluded that the copula approach proposed in the study estimated flood events with higher accuracy. Gilja et al. (2018) also recommended the copula-based approach for areas with a change in flow regime or multiple variables that govern flood intensity.

Research has also been performed by examining several flood severity metrics associated with a single fluvial mechanism to, for example, address flood peaks and volumes; volumes and durations (e.g., Bastian et al. 2010; Papaioannou et al. 2016; Yue et al. 1999; Zhang and Singh 2006); or magnitudes and dates of occurrence(e.g., Lu et al. 2012).

\subsubsection{Coastal and Fluvial Joint Flooding}

This section describes current research literature related to flood hazards involving joint coastal and fluvial flooding mechanisms (typically hurricane-induced storm surge with concurrent river flooding caused by hurricane-induced precipitation). This section begins with descriptions of literature addressing coastal and fluvial flooding hazards that focus on investigating the degree of dependence or dependence structure between coastal and fluvial flooding mechanisms. This group of literature focuses on characterization of this dependence structure but does not typically include estimation of probabilistic hazard measures (e.g., probabilities or frequencies of exceedance).

Svensson and Jones (2002) conducted a research study in eastern Britain to investigate the dependence among high sea surge, river flow, and precipitation. An extremal dependence measure $(\chi)$ was used that estimated the probability of one variable's being "extreme" conditioned on the other variable's being extreme, in which the definition of "extreme" is based on a threshold that yields about 2.3 events per year. Sea surge and total sea level data were obtained from observations at eight stations located on the east coast of Britain for 1965 to 1997. The differences between total sea level and predicted astronomical tide were considered as surge residuals. For river data, daily mean river flows from 40 stations in watersheds draining to the North Sea for 1965 to 1997 were used. Precipitation data were obtained from daily precipitation observations at 20 stations in eastern Britain for 1965 to 1997. Based on the statistical analysis of sea surge, river flow, and precipitation data, the strongest inter-station dependence measure (over longer distances) was observed for maximum values of daily sea surge. Maximum cross-variable dependence existed between river flow data related to the north shore of the Firth of Forth and sea surge in Scotland (at Aberdeen, Wick, and Lerwick). Seasonal analysis showed a stronger dependence between surge and flow during the winter, which emphasized the need to consider the effect of seasonality for dependence estimation and its temporal variations. Finally, a lag analysis was performed, which indicated that the strongest dependence between precipitation and sea surge existed if precipitation preceded the surge by one day. The same impact of lag was found for dependence between precipitation and river flow. The dependence between surge and flow was strongest when they occurred on the same day, with a strong dependence also found with lags on plus or minus one day. 
Subsequently, Svensson and Jones (2004) investigated the dependence among sea surge, river flow, and precipitation in coastal areas in south and west Britain. A dependence measure was used for estimating the probability of one variable's being extreme conditioned on the other variable's being extreme (as used in Svensson and Jones 2002). Sea surge data were collected from hourly sea surge and total sea level data related to 19 stations in the southern and western coasts of Britain for 1963 to 2001. River flow data related to 72 stations in watersheds draining to the south and west coasts of Britain were extracted for 1963 to 2001. Precipitation data were obtained from the UK Met office for 27 stations in watersheds draining to the south and west coasts of Britain for 1963 to 2001. Based on the results of the study, dependence between flow and surge was found to be strong in three regions of the study area, including the western part of the English south coast, southern Wales, and around the Solway Firth. The strongest dependence between river flow and precipitation was observed for cases in which both surge and river flow occurred at the same day. Based on seasonal analysis, in summer, a slightly stronger dependence between flow and surge was observed for the west coast from Wales and northward. However, for the southern part of the area under study, a stronger dependence was found in the winter.

Building upon the aforementioned studies, Hawkes (2006) provides a "best practices" guide for the application of joint probability analysis. The guidance covers several combinations of mechanisms or combinations of flood severity metrics, including (1) wave height and surge (sea level); (2) river flow and surge; (3) precipitation and surge; and (4) wind and swell. It includes guidance on data preparation, parameter estimation, applications, treatment of climate change, and interpretation of results. It also provides several case studies. Two associated technical reports provide further supporting information. Hawkes and Svensson (2006) present the results of research related to the dependence between key pairs of variables related to waves, surge, tide, river flow, rainfall, swell, and wind around England, Wales, and Scotland. Svensson and Jones (2006) describe the dependence among extreme sea surge, river flow, and precipitation in south and west Britain.

Kew et al. (2013) explored the simultaneous occurrence of storm surge and river discharge under current and future climate scenarios. The study focused on the Rhine Delta in the Netherlands. In particular, the study explored the simultaneous occurrence of extreme winds and extreme $n$-day precipitation as proxies for storm surge and river discharge (where "extreme" is defined as events that exceed the 99\% quantile). They explored the degree to which storm and precipitation are dependent by comparing the conditional probability of observing various wind events (conditioned on precipitation) with the marginal probability of those wind events. Klerk et al. (2015) also examined the occurrence of storm surge and extreme (i.e., up to return periods of 100 years) discharges within the Rhine-Meuse Delta using a cascade of models.

Lian et al. (2012) investigated the joint effects of rainfall and tidal level in an urban area in China using precipitation and tidal data for a single hydrologic station. The optimal copula was used for joint exceedance probability estimation (i.e., to compute the probability of both rainfall and tidal level exceeding specified thresholds). To estimate flood severity (i.e., ratio of the flooded length of the rivers to the total length of the rivers) for combinations of rainfall intensities and tidal levels associated with return periods of 5 to 100 years, the hydrodynamic model HEC-RAS was used for a river network in the case study region. For verification of this model, observed data related to Typhoon Longman (2005) were used. Based on the results of the study, the authors concluded that the joint probability of both precipitation and tidal level exceeding a specified consequential threshold level was estimated to be low. However, the authors noted "some positive dependence" between rainfall and tidal levels. An extension of the study was published in Xu et al. (2014).

Petroliagkis (2018) performed a statistical analysis of 32 rivers along European coasts to investigate the dependence between surge and wave height at river end points. The results of the study for 35 years of data obtained by hindcasting were presented in the form of correlation and statistical dependence $(\chi$ value) between variables. This work also defined the top 80 compound events for every river at their end 
points using a PoT approach yielding 2.3 events per year. For surge hindcasts, the hydrodynamic model Delf3D-FLOW was used. This was done by introducing 6-hourly wind and pressure fields obtained from the ECMWF ERA-Interim ${ }^{17}$ reanalysis data set to the Deflt3D-FLOW model. For wave hindcasts, the latest stand-alone version of the ECWAM wave model was used to produce hourly wave data. Based on the results of the study, the frequency of occurrence for the top 80 compound events was higher during cold months. The work found significant dependence and noticeable values for positive correlation in some areas, whereas other areas were associated with moderate values of dependence and correlation near zero. Associated with this paper, Petroliagkis et al. (2016) is a comprehensive technical report published by the European Commission Joint Research Centre.

Although global studies may have limited applicability to the site-specific evaluations performed for nuclear facilities, Ward et al. (2018) performed a global exploration of the dependence between coastal and river flooding on a global scale. The authors describe an initial assessment of the dependence between observations of high sea levels (from the GESLA-2 data set) and high river discharge (from the Global Runoff Data Centre) in 187 deltas and estuaries around the world. Dependence was assessed using Kendall's rank correlation coefficient and copula models.

Going beyond the studies that investigate the dependence or dependence structure for coastal and fluvial mechanisms, several references seek to estimate the frequency of exceedance of water levels or inundation probabilities when considering combinations of flooding mechanisms.

Zhong et al. (2013) performed a joint probability analysis in the Lower Rhine Delta. The goal of the study was to estimate the frequency of high water levels and to quantify the exceedance probability of the current design water level, which is the level used for the design of flood protection features such as levees. The selected threshold for peak surge is a surge residual of $1 \mathrm{~m}$ and peak flow of $6,000 \mathrm{~m}^{3} / \mathrm{s}$. Flooding mechanisms discussed in the study were astronomical tide, wind-induced storm surge, and fluvial flow on the Rhine and Meuse rivers. Three combinations of variables were defined for the development of joint probability distributions: (1) surge tide and normal upstream flow; (2) tide and high upstream flow; and (3) surge tide and high upstream flow. Joint probability distributions for each pair of variables were developed through statistical analysis of observed data using a copula-based approach for the first two combinations and a simple method (rather than copula) for the third combination. Sources of data used include observed sea level (1939-2009 in Hook of Holland station), predicted astronomic tidal level (1939-2009 in Hook of Holland station), and observed discharges for the Rhine and Meuse Rivers at the Lobith (1901-2009) and Borgharen stations (1911-2009), respectively. Monte Carlo simulation was used to generate a large number of scenarios for data from the estimated joint probability distributions. To estimate high water levels, a simple, deterministic, 1D hydrodynamic model with a large grid size of $20 \mathrm{~km}$ was used. Simulated scenarios were introduced as inputs to the $1 \mathrm{D}$ hydraulic model to predict PWL. Finally, predicted PWLs and the associated probability or occurrence were used for generating PWL frequency curves. To consider the effects of climate changes, mean SLR and peak Rhine discharge estimates for 2050 were considered.

Zheng et al. (2014) compared three bivariate statistical extreme value methods in terms of their ability to estimate the exceedance probability (focusing on return periods of up to 100 years) for given flood levels at a given location considering storm surge and rainfall. The three methods considered were (1) thresholdexcess method, (2) point process method, and (3) conditional method. These methods were used for modeling dependence between extreme rainfall and storm surge, and the study assessed the ability of the models to accurately and efficiently simulate the dependence structure that is commonly observed in data related to storm surge and rainfall. Among the three methods, the threshold-excess method provided unbiased results; however, the authors noted it could not model scenarios in which just one of the

\footnotetext{
${ }^{17}$ ERA-Interim is a global atmospheric reanalysis product for 1979 to the present.
} 
variables was extreme. In this regard, the advantage of the point process and conditional methods could be their ability to cover the whole distributions of extremes. Based on study results, the disadvantages of point process and conditional methods are, respectively, overestimating and underestimating the dependence levels between variables. The authors concluded that the point process method was most suitable when dependence was relatively strong, but they noted that none of the methods produced satisfactory results for extremes with weak dependence. Additionally, the authors used a case study in Sydney, Australia to illustrate the three methods and to demonstrate the implications of various strengths of dependence on estimated flood hazards. Case study results showed that estimated hazard levels (i.e., flood levels for given average recurrence intervals) based on extrapolation results were sensitive to the strength of dependence.

A PFHA study (Orton et al. 2018) investigated the joint combination of storm tides and riverine flow for the Hudson River. Flood-forcing phenomena in the study included TCs, ETCs, and wet extratropical cyclones (WETCs). The Stevens ECOM 3D hydrodynamic model was used to combine stream flow and storm tide and predict the response variable (water level). Sources of data included the HURDAT2 for TCs, and USGS gauge data series for flow rate. Probabilistic analysis in the study covered long return periods of up to 1,000 years. For statistical analysis, a Bayesian simultaneous quantile regression approach was used to translate TC characteristics into river flow. The GEV distribution was used for fitting a distribution to the WETCs rate distributions, and empirical distribution were used for ETCs. Based on the results of the study, in the upper tidal part of the river, WETCs were important in terms of flood risk, and ETCs were important for flood risk in the estuary and lower tidal part of the river. TCs, however, were considered as an important factor causing flood risk at all locations because they can cause both surge and extreme precipitation.

Moftakhari et al. (2017) investigated the combined effects of fluvial flow and SLR on computed "failure probabilities" (i.e., coastal inundation probabilities) using data for several estuaries in the United States, focusing on hazards associated with return periods of 5 to 50 years. The authors proposed a bivariate flood hazard assessment approach for assessing the compound effects of flooding induced by river flow and coastal water levels. To assess the extent to which compound effects of multiple flooding mechanisms could affect the failure probabilities, the study compared the results of multivariate and univariate flooding analyses. When applying the univariate model, one flooding mechanism (fluvial flow or coastal water level) was used to assess flooding hazards using GEV. In the case of the multivariate model, a copulas method was used for bivariate analysis. The authors also assessed failure probabilities under multiple future SLR scenarios. Based on the models considered in the study, the authors concluded that considering the compound effects of fluvial flow and coastal water level will increase failure probabilities. Moreover, the authors concluded that future SLR will exacerbate compounding effects.

Bevacqua et al. (2017) developed a conceptual model for multivariate analysis of storm surge and river flow. Pair-copula constructions were used for multivariate dependency modeling. The conceptual conditional model used in the study included several components: (1) an impact function for quantifying water levels on the case study river due to the joint occurrence of surges and river flow; (2) predictors $(X)$ for contributing variables $(Y)$; and (3) a conditional joint PDF of $Y$ given $X$. The predictors $(X)$ represented variables that provide insight into physical processes (e.g., meteorological variables), and the contributing variables $(Y)$ represented sea and river levels. To apply the method developed in the paper, the Ravenna coast in Italy was considered as a case study. The data used in the study were in the form of daily winter water levels for 2009 to 2015 . Meteorological predictors were extracted from the ECMWF ERA-Interim reanalysis data set ${ }^{18}$ for 1979 to 2015 and resolution of $0.75 \times 0.75^{\circ}$. Based on the results of the study, the authors concluded that ignoring the dependence between sea levels and river flow will lead to underestimation of flood risk (considering return periods of up to 100 years). In particular, the authors

${ }^{18}$ Available via http://apps.ecmwf.int/datasets/data/interim-full-daily/levtype=sfc/ 
observed that ignoring the dependence between river flow and storm surge resulted in an increase in the estimated return period for the highest flood level (due to a combination of fluvial flow and storm surge) from 20 years when considering dependence to 32 years when ignoring dependence. The authors cautioned that uncertainties associated with risk analysis were large as a result of the short period of data available.

Serafin et al. (2019) investigated the compound effects of stillwater level and river flow on extreme water levels along the Quillayute River in Washington along the western coast of the United States. The data sources included tide gauge data and river gauge data (measuring river flow and stage). The study used a hybrid statistical-physical approach for predicting the response variable (water surface elevation). This hybrid model included a hydraulic model (HEC-RAS) for predicting water surface elevation and a probabilistic model (SR14, developed by Serafin and Ruggiero 2014) for simulation of joint boundary conditions due to stillwater level and river flow. Surrogate models were used to generate along-river water levels for different combinations of sea water level and river flow. To train the surrogate models, outputs from the HEC-RAS model for different combinations related to the joint occurrence of sea level and river discharge were used.

Although not focusing specifically on probabilistic characterization, several studies address the modeling of events involving the joint occurrence of coastal and fluvial flooding mechanisms. These studies do not seek to characterize the dependence structure or compute probabilities; rather, they focus on numerical modeling tools. For example, Bunya et al. (2010) developed a coupled model for simulating river flow, tide, wind, waves, and storm surge. Chen and Liu (2014) propose an integrated modeling system for simulation of storm surge and river discharge in a coastal area of Taiwan; they considered three scenarios. The first two scenarios focused on investigating the effects of surge and river flow in isolation. The third scenario investigated the joint effects of surge and river flow. The method used involved the use and modification of a numerical 3D model called SELFE, a finite element model that uses a semi-implicit Eulerian-Lagrangian method for solving shallow water equations. For model validation, the study used three sets of observed data related to Typhoon Krosa (2007), Typhoon Kalmagei (2008), and Typhoon Morakot (2009). After model validation, the model was used for the investigation of surge and riverine flow in the Tsengwen River basin and neighboring coastal area in southern Taiwan. To investigate storm surge effects concurrent with a 200-year river flow, the super Typhoon Haiyan (2013) was synthetically shifted to hit the study region. Based on comparison of the models related to the aforementioned scenarios, the study concluded that considering the combined effects of surges and fluvial flow increased inundation areas.

Bass and Bedient (2018) investigated the joint effects of hurricane-induced surge and precipitationinduced runoff in a coastal area in southeast Houston, Texas. In particular, the study analyzed rainfall runoff, storm surge, and the interaction between them for estimation of flood peaks (inundation level) in riverine flood plains in the case study region. The goal of the study was to develop a method for efficient and rapid flood estimation through the use of surrogate models that relate hurricane characteristics (e.g., minimum central pressure, radius to maximum winds, forward speed, angle of approach, and landfall location) to peak flood levels. The method was intended to facilitate efficient estimation of flood risk due to surge and precipitation caused by a hurricane using JPM with the fundamental integral calculated using Monte Carlo simulation. The surrogate model was built using aggregated results from a series of models, including the modified Smith rainfall model, HEC-HMS hydrologic model, ADCIRC and SWAN surge model, and HEC-RAS hydraulic model. Although the study did not focus specifically on probabilistic hazard assessment, comparisons were made for events associated with 10, 50, 100, and500 year return periods. These comparisons were achieved by performing Monte Carlo simulations in which storm parameters were sampled from the probability distributions employed in an existing study. A total of 100,000 synthetic storms (i.e., storm parameter combinations) were drawn from the assumed 
distributions, and the resulting surge was computed using a trained surrogate model. Then, hazard levels were computed by applying an empirical, rate-adjusted Weibull plotting position formula.

\subsubsection{Coastal and Pluvial Joint Flooding}

Archetti et al. (2011) performed a study aimed at quantifying the flooding threshold condition for a storm sewer network of a coastal town. The study included a probabilistic investigation of the simultaneous occurrence of two flooding mechanisms: precipitation (rainfall) and sea level conditions (storm surge, waves, and tides). The study considered rainfall and sea level with return periods of up to 100 years. It focused on a case study drainage system along the Adriatic coast in Italy. To estimate the correlation between rainfall and sea level, a copula method was applied by using water level data derived from measurements at a regional tide gauge, and rainfall intensity data derived from annual maxima rainfall data series. The numerical modeling code, InfoWorks CS, was used to estimate the number of flooded nodes in the sewer network as a function of rainfall and sea level. Modeling results were verified by comparing the simulated results with results for one year of observed data for rainfall and sea level. The sources of data were a local utility database providing information on basement flooding, backwater effects, and sewer system malfunctions and a fire department emergency calls database.

\subsubsection{Coastal and Precipitation (Pluvial or Fluvial)}

This section describes current research literature related to flooding hazards involving joint coastal and pluvial flooding mechanisms. It also addresses literature related to coastal flooding mechanisms and precipitation in general (e.g., precipitation quantity, intensity) even when an explicit link is not made to subsequent pluvial or fluvial flooding.

This section begins with descriptions of literature addressing coastal and pluvial flooding hazards (or coastal hazards in conjunction with precipitation events) that focus on investigating the degree of dependence or dependence structure between these mechanisms. For example, Zheng et al. (2013) explored the dependence between large rainfall and storm surge to assess flood risk in coastal zones of Australia. The study used processed tide level data (with tide effects removed) from 49 tide gauges along the Australian coast and daily precipitation data from 4,890 precipitation stations across the Australian continent. The study employed a bivariate logistic threshold-excess model to study the dependence between the two quantities. The study identified individual extreme rainfall and surge events (where "extreme" was based on a precipitation threshold of $40 \mathrm{~mm}$ and surge threshold of $0.3 \mathrm{~m}$ ), with a subset involving both rainfall and surge co-occurrence. The study found significant dependence between extreme storm surge and rainfall for the majority of regions studied, although it noted spatial and seasonal differences in the dependence level. In particular, the study observed that — by considering the dependence between storm surge and precipitation - an increase of up to 35 times was observed in the probability of extreme storm surge occurring when an extreme rainfall event is occurring compared with the assumption of independence. The study also explored related factors such as the relationship between the strength of dependence and temporal factors (e.g., the length of the storm burst and the time lag between the occurrences of extremes). The study provided insights regarding the causal mechanism of the dependence structure (e.g., synoptic-scale meteorological forcing). The paper was associated with a broader project associated with the Australian Rainfall and Runoff model referred to as Project 18, "Interaction of Coastal Processes and Severe Weather Events." Project reports related to Project 18 are available on the project website (Engineers Australia 2015).

Wahl et al. (2015) addressed the likelihood of the joint occurrence of storm surge and precipitation for the contiguous United States. In particular, the study investigated the dependence between storm surge and precipitation and explored how it has changed over time. The study used hourly storm surge data (with astronomical tide and mean sea level effects removed) for 30 tide gauges and mean daily precipitation 
data derived from stations within 25 miles of the tidal gauges. For measuring the dependence between precipitation and surge, Kendall's rank correlation coefficient $(\tau)$ was used. To find the structure of the dependence between these two variables, a copula-based method was used in which three extreme value copulas were considered. The study found that the "risk of compound flooding is higher for the Atlantic/Gulf coast relative to the Pacific coast" and "the number of compound events has increased significantly over the past century" for major cities along the coast of the contiguous United States.

Van den Hurk et al. (2015) investigated the physical relationship between, and the joint probability distribution of, storm surge (which prevents discharge of water to the open sea) and precipitation (which generates inland water levels) using 800 years of simulated data related to current climate conditions. To generate these data, for 1950 to 2000, each member of the global climate model EC-Earth was downscaled and 800 years of simulated data were generated. The study focused on precipitation and surge in the Netherlands. The study analyzed compound events involving storm surge and precipitation using a regional climate model (RCM) called RACMO2. RACMO2 was used to generate synthetic weather and precipitation data. Bias in precipitation driven from the RACMO2 model were corrected based on observations from in situ stations and rainfall radar data. Then, an empirical relationship was used to estimate storm surge as a function of the synthetic wind speed and direction. To calibrate the empirical relationship used for deriving surge, simulated wind data from RACMO2 and local surge data at Lauwersoog station were used. To estimate extreme water levels due to precipitation and surge, an inland water model (RTC-Tools) was used. The study compared the joint distribution of surge and precipitation with a randomized set of simulations. Based on the results of the study, the authors observed that for inland water levels, correlation between precipitation and surge was noticeable up to a specified inland water level. However, this correlation decreased for higher water levels in which tides were dominant and important.

Although not focusing specifically on probabilistic characterization or dependence structures, several studies address the modeling of events involving the joint occurrence of coastal and precipitation events. These studies focus on numerical modeling tools and approaches.

Lin et al. (2010) investigated storm surge, wind, and precipitation from TCs. In particular, the study explored current modeling capabilities for simulation and forecasting of multiple hazards from TCs. The study focused on case study analyses of Hurricane Isabel (2003) and the urbanized coastal area in the Chesapeake Bay watershed in the United States. The Weather Research and Forecasting (WRF) model was used to simulate storm evolution following landfall. The WRF simulations were coupled with the 2D Advanced Circulation Model (ADCIRC). A wide range of observation data were used to evaluate model performance. For evaluating the performance of the WRF-ADCIRC model in surge prediction, observed data at US National Oceanic and Atmospheric Administration gauge stations were used. To assess simulated rainfall data, radar rainfall fields from Hydro-NEXRAD ${ }^{19}$ were used. Simulated wind fields were evaluated using time series related to local wind from stations located at the coastal area. The authors concluded that numerous factors leading to damage during the case study event were not captured in the models used, particularly those associated with outer rain bands, which produced wind damage and urban flash flooding.

Lu et al. (2018) evaluated the ability of the physics-based tropical cyclone rainfall (TCR) model to accurately reflect the magnitude and spatial distribution of such rainfall. In the study, simulation results from the WRF model for two case studies involving Hurricanes Isabel (2003) and Irene (2011) were used to assess the TCR model. Based on the results, rainfall fields resulting from TCR for both case studies matched the results of the WRF model. After coupling the simulated rainfall from TCR with the hydrologic model CUENCAS (a distributed, hillslope-based model discussed by Cunha [2012] and

${ }^{19}$ Hydro- Next-Generation Doppler Radar (Hydro-NEXRAD) system 
Mantilla and Gupta [2005]), the study found the estimated peak flood results from TCR were at the same level of accuracy as WRF. The authors concluded that spatiotemporal changes in tropical cycloneinduced winds greatly affected simulated rainfall distributions. Finally, the authors noted that if the TCR model could be coupled with some analytical models for wind, climatology, and hydrology, it could produce synthetic events for risk analysis related to flooding from tropical cyclone-induced rainfall. Additional focused case study applications have also been published (e.g., Martyr et al. 2013; Torres et al. 2015; Tyler et al. 2011).

In addition to literature that focuses directly on coastal hazards and pluvial hazards (or precipitation), additional studies are available that provide building blocks for further evaluation involving multiple mechanisms. These studies focus on improving the capabilities for modeling tropical cyclone-induced precipitation. For example, Lonfat et al. (2007) developed a parametric hurricane rainfall model (PHRaM) that considers the effects of topography and shear and can model an asymmetric hurricane rainfall field. In that work, the effects of shear and stress were modeled parametrically and were combined with the RCLIPER model to form PHRaM. For considering the effects of shear and topography, two models were developed: one incorporated only shear effects and the other considered the effects of both vertical shear and topography. In the work, all storms that made landfall along US coasts in 2004 were simulated by the two proposed models and the R-CLIPER model. The resolution considered for all of the models was $10 \mathrm{~km}$. Fifteen-minute rainfalls were estimated for each grid cell in the models. To evaluate the performance of the two proposed models and the R-CLIPER model, a comparison was made between radar observations and the results of the three models. The comparison demonstrated that including shear in the model improved the simulated results (in terms of special distribution and amplitude of rainfall) to some extent relative to the R-CLIPER results; however, considering both topography and shear led to a higher level of accuracy in results. As another example, Langousis and Veneziano (2009) developed a combined physical-statistical model to estimate the frequency of extreme precipitation intensity induced by TCs, considering return periods of 100 years or more. Since the method presented in the study ignored landfall effects, it is more suitable for coastal areas that are flat. A mean rainfall field was calculated using a physics-based model. Variations in rainfall were calculated statistically. The method quantified the distribution of the intensity of maximum rainfall in a given location and for an averaging duration. The data used in the study included precipitation radar data from the Tropical Rainfall Measuring Mission. To demonstrate application of the model for long-term rainfall risk assessment, the model was used to assess rainfall risk in New Orleans. Based on the results of the study, the authors concluded that TCs are the dominant type of rainfall for return periods of 100 years or more and long averaging duration of 12 to 24 hours. The inverse is true for shorter return periods (i.e., TCs are not responsible for dominant rainfall related to short return periods).

\subsection{SCOPE OF HAZARDS ADDRESSED}

The technical literature related to the probabilistic assessment of MMFs is wide-ranging in application and scope (e.g., hazards considered, geographic regions of focus, study objectives). Despite this diversity in application and scope, recent literature (which is the focus of this report) primarily addresses concurrent flood mechanisms, and concurrent correlated mechanisms (Figure 2-8b) are addressed more frequently than induced correlated mechanisms (Figure 2-8c). Figure 4-1 provides an example of how this existing literature maps into the framework proposed in Section 2.3. Coincident mechanisms (Figure 2-8a) are rarely addressed in the literature because their independence makes probabilistic assessment relatively trivial. Table 4.1 includes columns that identify, for each study reviewed, the flood-forcing phenomena, flood mechanisms, and flood severity metrics considered.

As shown in Table 4.1, in the context of MMFs, several combinations of flood hazard mechanisms have been considered in existing literature, and combinations involving at least one coastal hazard mechanism are a common research focus. A significant portion of existing literature focuses on analysis of the joint 
probability of storm surge in conjunction with precipitation and/or river flow, (Archetti et al. 2011; Bevacqua et al. 2017; Chen and Liu 2014; van den Hurk et al. 2015; Kew et al. 2013; Moftakhari et al. 2017; Orton et al. 2016; 2018; Serafin et al. 2019; Svensson and Jones 2002; Svensson and Jones 2004; Wahl et al. 2015; Zheng et al. 2013, 2014; Zhong et al. 2013; Bass and Bedient 2018). In fact, combinations involving surge hazards in conjunction with another flood mechanism have been analyzed in existing literature more frequently than other pairs of mechanisms. Typically, these studies can be categorized as addressing concurrent correlated mechanisms associated with hurricanes or ETC events as the common flood-forcing phenomena.

In addition to literature directly related to MMFs, further studies have focused on rainfall hazards due to hurricanes (TCs), with particular emphasis on predicting hurricane-induced precipitation (Langousis and Veneziano 2009; Lin et al. 2010; Lonfat et al. 2007). Although not specifically involving MMFs, such studies provide a building block for work focused on combinations of mechanisms generated by hurricanes as the flood-forcing phenomena. A smaller portion of literature related to coastal hazards has investigated the joint probability of multiple flood severity metrics associated with surge events, typically waves and water levels (Hawkes et al. 2002; Masina et al. 2015; Wadey et al. 2015). A few researchers have also analyzed a more comprehensive combination of flood mechanisms from the perspective of process modeling (but without addressing considerations associated with probability of occurrence). For example, Bunya et al. (2010) developed a coupled model of river flows, tide, wind, wind wave, and storm surge for southern Louisiana and Mississippi. Work has also addressed combinations of mechanisms involving tsunami hazards (Kowalik and Proshutinsky 2010; Zhang et al. 2011); however, as shown in Figure 4-1, tsunami hazards are not a dominant hazard for the majority of US NPPs; thus, those studies are not a focus of this report.

MMFs not associated with a coastal hazard have received less attention in the literature. Several researchers have performed joint probability analyses of combined discharges at river confluences. Bender et al. (2016), Gilja et al. (2018), and others have performed COFF analyses for river confluences (Kao and Chang 2012; Wang et al. 2009). Additionally, several researchers have explored dependences between multiple flood severity metrics associated with fluvial hazards (Yue 2001; Yue et al. 1999; Zhang and Singh 2006). Overall, gaps exist in addressing several fluvial flood mechanisms of interest. One of these gaps is rain on snow (i.e., liquid precipitation that falls on an existing snow pack). Sui and Koehler (2001) identified that rain on snow can generate more runoff than a pure rainfall event. In addition to rain on snow, the literature review found few studies that involve probabilistic assessment of event combinations involving dam failures and ice effects, both of which involve fluvial flood mechanisms and may occur in combination with antecedent or concurrent large discharges. 


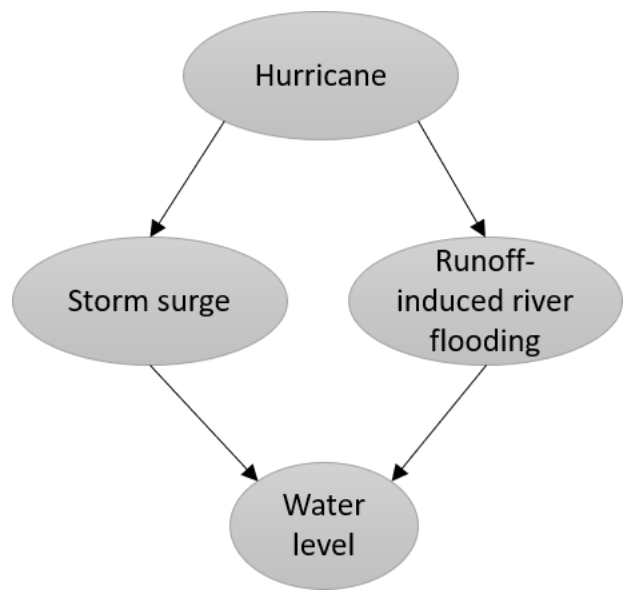

Figure 4-1. Illustration of concurrent correlated flood mechanisms (storm surge and runoff-induced river flooding) generated by a common flood-forcing phenomena (hurricane).

\subsubsection{Study Regions and Scales Covered}

Literature reviewed includes MMF case studies for a range of locations across multiple scales. For example, Hawkes et al. (2002), Lian et al. (2012), Masina et al. (2015), Moftakhari et al. (2017), Svensson and Jones (2002), Wadey et al. (2015), and Zheng et al. (2014) performed local-scale studies. At the national scale, Wahl et al. (2015) performed a study for the contiguous United States, and van den Hurk et al. (2015) analyzed events involving surge and precipitation in the Netherlands. Vitousek et al. (2017) performed work related to combinations involving global scale SLR (i.e., tides, waves, and storm surge). Generally, a plurality of studies reviewed focused on UK or US applications.

\subsubsection{Data Used}

Data source information is included in the Data Sources column of Table 4.1. Reviewed studies have used empirical data related to numerous flood-relevant variables from a variety of sources. Some studies have generated or used synthetic data to support assessment.

A substantial portion of the studies reviewed in this report use observational data from tide, rainfall, or streamflow gauges, with the frequency of observations differing among studies. Daily data are most common, but a limited number of studies consider hourly data. Data series record length varies from 10 years or less (e.g., Masina et al. 2015, Hawkes et al. 2002) to over 30 years (e.g., Wahl et al. 2015). Synthetic data generation techniques have also been employed in existing literature to supplement observational data. For example, Monte Carlo methods have been used to develop synthetic sequences of data observations (Hawkes et al. 2002; Wang 2016; Zhong et al. 2013). Studies have also leveraged output from numerical models (e.g., the WRF model, Lu et al. 2012).

A subset of existing literature focuses specifically on process-based methods and models. These studies focus on understanding the physical interactions between flood mechanisms, as well as the modeling of multiple flood mechanisms using coupled or integrated modeling tools. However, these modeling-focused studies do not typically address estimation of probabilities and risks (e.g., Chen and Liu [2014] addressed storm surge and river flow deterministically). Nonetheless, they are included in Table 4.1 because they provide a set of tools that can be used in conjunction with stochastic simulations or Bayesian-motivated approaches to support probabilistic hazard assessments. 
Table 4.1. Summary of research studies.

\begin{tabular}{|c|c|c|c|c|c|c|c|c|}
\hline Reference & $\begin{array}{l}\text { Flood } \\
\text { type }\end{array}$ & $\begin{array}{l}\text { Flood-forcing } \\
\text { phenomena }^{a}\end{array}$ & $\begin{array}{l}\text { Flood } \\
\text { mechanism }\end{array}$ & $\begin{array}{l}\text { Flood severity } \\
\text { metric }\end{array}$ & $\begin{array}{l}\text { MMF flood } \\
\text { mechanism }^{b}\end{array}$ & $\begin{array}{l}\text { Joint probability } \\
\text { approach }^{c}\end{array}$ & $\begin{array}{l}\text { Data sources and models/software used } \\
\text { (if applicable) }\end{array}$ & $\begin{array}{l}\text { Case study/ } \\
\text { focus area }\end{array}$ \\
\hline $\begin{array}{l}\text { Archetti } \\
\text { et al. } 2011\end{array}$ & $\begin{array}{l}\text { Coastal, } \\
\text { pluvial }\end{array}$ & $\begin{array}{l}\text { Storms, } \\
\text { astronomical } \\
\text { forces }\end{array}$ & $\begin{array}{l}\text { Sea level } \\
\text { (storm surge, } \\
\text { tide, waves), } \\
\text { precipitation }\end{array}$ & $\begin{array}{l}\text { Number of } \\
\text { flooded nodes }\end{array}$ & $\begin{array}{l}\text { Precipitation, storm } \\
\text { surge, wave, tide }\end{array}$ & $\begin{array}{l}\text { Copula-based } \\
\text { approach }\end{array}$ & $\begin{array}{l}\text { Regional tide gauge, observed data for } \\
\text { rainfall and sea level }\end{array}$ & $\begin{array}{l}\text { Drainage system } \\
\text { along the } \\
\text { Adriatic coast, } \\
\text { Italy }\end{array}$ \\
\hline $\begin{array}{l}\text { Bass and } \\
\text { Bedient } 2018\end{array}$ & $\begin{array}{l}\text { Coastal, } \\
\text { fluvial }\end{array}$ & TCs & $\begin{array}{l}\text { Sea level } \\
\text { (surge, tide), } \\
\text { precipitation- } \\
\text { induced } \\
\text { runoff }\end{array}$ & $\begin{array}{l}\text { Peak inundation } \\
\text { levels }\end{array}$ & $\begin{array}{l}\text { Rainfall runoff } \\
\text { processes—river, } \\
\text { storm surge, wind }\end{array}$ & $\begin{array}{l}\text { Bayesian-motivated } \\
\text { approach (surrogate } \\
\text { modeling focus) }\end{array}$ & $\begin{array}{l}\text { Gridded hourly observed rainfall; } \\
\text { observed river streamflow and stage (for } \\
\text { validation); HURDAT TC parameters; } \\
\text { synthetic storms and flood peaks } \\
\text { Models/software: HEC-HMS, Advanced } \\
\text { Circulation (ADCIRC) model, SWAN, } \\
\text { HEC-RAS }\end{array}$ & $\begin{array}{l}\text { Southeast } \\
\text { Houston, Texas }\end{array}$ \\
\hline $\begin{array}{l}\text { Bender et al. } \\
2016\end{array}$ & Fluvial & $\begin{array}{l}\text { Winter storm, } \\
\text { snowmelt }\end{array}$ & $\begin{array}{l}\text { Runoff- } \\
\text { induced } \\
\text { flooding }\end{array}$ & $\begin{array}{l}\text { Flood level, } \\
\text { discharge }\end{array}$ & $\begin{array}{l}\text { Rainfall runoff } \\
\text { processes-river }\end{array}$ & $\begin{array}{l}\text { Copula-based } \\
\text { approach }\end{array}$ & Daily mean discharge time series & $\begin{array}{l}\text { Rhine and Sieg } \\
\text { Rivers, Germany }\end{array}$ \\
\hline $\begin{array}{l}\text { Bevacqua } \\
\text { et al. } 2017\end{array}$ & $\begin{array}{l}\text { Coastal, } \\
\text { fluvial }\end{array}$ & $\begin{array}{l}\text { Low-pressure } \\
\text { system, winds }\end{array}$ & $\begin{array}{l}\text { Sea level } \\
\text { (surge, tide), } \\
\text { precipitation- } \\
\text { induced } \\
\text { runoff } \\
\end{array}$ & Flood level & $\begin{array}{l}\text { Rainfall runoff } \\
\text { processes—river, } \\
\text { storm surge }\end{array}$ & $\begin{array}{l}\text { Copula-based } \\
\text { approach (pair-copula } \\
\text { construction) }\end{array}$ & Daily winter water, reanalysis dataset & Ravenna, Italy \\
\hline $\begin{array}{l}\text { Bunya et al. } \\
2010\end{array}$ & $\begin{array}{l}\text { Coastal, } \\
\text { fluvial }\end{array}$ & $\begin{array}{l}\text { Hurricane, } \\
\text { astronomical } \\
\text { forcing }\end{array}$ & $\begin{array}{l}\text { Flow, tide, } \\
\text { wind, wave, } \\
\text { storm surge }\end{array}$ & Water level & $\begin{array}{l}\text { Rainfall runoff } \\
\text { processes - river, } \\
\text { storm surge, wave, } \\
\text { tide }\end{array}$ & $\begin{array}{l}\text { N/A } \\
\text { (process-based, } \\
\text { numerical method; } \\
\text { coupled model for } \\
\text { simulation of river } \\
\text { flow, tide, wind waves, } \\
\text { and storm surge) }\end{array}$ & $\begin{array}{l}\text { Anemometers, airborne and land-based } \\
\text { Doppler radar, airborne stepped-frequency } \\
\text { microwave radiometer, buoys, ships, } \\
\text { aircraft, coastal stations, satellite } \\
\text { measurements, and observed water marks } \\
\text { Models/software: Wave Model (WAM) } \\
\text { offshore and Steady-State Irregular Wave } \\
\text { (STWAVE), ADCIRC model }\end{array}$ & $\begin{array}{l}\text { Southern } \\
\text { Mississippi and } \\
\text { Louisiana }\end{array}$ \\
\hline $\begin{array}{l}\text { Chen and } \\
\text { Liu } 2014\end{array}$ & $\begin{array}{l}\text { Coastal, } \\
\text { fluvial }\end{array}$ & $\begin{array}{l}\text { Typhoons, } \\
\text { monsoon (or } \\
\text { other rain } \\
\text { inducing } \\
\text { storms) }\end{array}$ & $\begin{array}{l}\text { River flow } \\
\text { (runoff- } \\
\text { induced } \\
\text { flooding), } \\
\text { tides and } \\
\text { storm surge }\end{array}$ & $\begin{array}{l}\text { Flood depth, } \\
\text { inundation area }\end{array}$ & $\begin{array}{l}\text { Rainfall runoff } \\
\text { processes-river, } \\
\text { storm surge, tides }\end{array}$ & $\begin{array}{l}\text { N/A } \\
\text { (process-based } \\
\text { methods, numerical } \\
\text { model; considered } \\
\text { scenarios involving an } \\
\text { historical typhoon and } \\
\text { concurrent river floods } \\
\text { with specified return } \\
\text { periods) }\end{array}$ & $\begin{array}{l}\text { Observed data related to Typhoon Krosa } \\
\text { (2007), Typhoon Kalmagei (2008), and } \\
\text { Typhoon Morakot (2009) } \\
\text { Models/software: SELFE }\end{array}$ & $\begin{array}{l}\text { Tsengwen River } \\
\text { basin and } \\
\text { neighboring } \\
\text { coastal area, } \\
\text { southern Taiwan }\end{array}$ \\
\hline $\begin{array}{l}\text { De Michele } \\
\text { et al. } 2007\end{array}$ & Coastal & Sea storm & Surge, waves & $\begin{array}{l}\text { Sea storm } \\
\text { magnitude } \\
\text { (function of } \\
\text { significant } \\
\text { wave height } \\
\text { and storm } \\
\text { duration) } \\
\end{array}$ & Storm surge, waves & $\begin{array}{l}\text { Copula-based } \\
\text { approach }\end{array}$ & Wave buoy data & $\begin{array}{l}\text { Wave buoy in } \\
\text { Sardinia, Italy } \\
\text { (model } \\
\text { validation) }\end{array}$ \\
\hline
\end{tabular}




\begin{tabular}{|c|c|c|c|c|c|c|c|c|}
\hline Reference & $\begin{array}{l}\text { Flood } \\
\text { type }\end{array}$ & $\begin{array}{l}\text { Flood-forcing } \\
\text { phenomena }^{a}\end{array}$ & $\begin{array}{l}\text { Flood } \\
\text { mechanism }\end{array}$ & $\begin{array}{l}\text { Flood } \\
\text { severity } \\
\text { metric } \\
\end{array}$ & $\begin{array}{l}\text { MMF flood } \\
\text { mechanism }^{b}\end{array}$ & $\begin{array}{l}\text { Joint probability } \\
\text { approach }^{c}\end{array}$ & $\begin{array}{l}\text { Data sources and models/software } \\
\text { used (if applicable) }\end{array}$ & $\begin{array}{l}\text { Case study/ } \\
\text { focus area }\end{array}$ \\
\hline $\begin{array}{l}\text { Gilja et al. } \\
2018\end{array}$ & Fluvial & $\begin{array}{l}\text { Hydrologic event } \\
\text { (rain, snowmelt) }\end{array}$ & $\begin{array}{l}\text { Runoff- } \\
\text { induced } \\
\text { flooding }\end{array}$ & $\begin{array}{l}\text { Flood } \\
\text { discharge }\end{array}$ & $\begin{array}{l}\text { Rainfall runoff } \\
\text { processes_-river }\end{array}$ & $\begin{array}{l}\text { Copula-based } \\
\text { approach }\end{array}$ & Measured river discharge data & $\begin{array}{l}\text { Sava River (a } \\
\text { tributary of Danube } \\
\text { River), Europe }\end{array}$ \\
\hline $\begin{array}{l}\text { Hawkes et } \\
\text { al. } 2002\end{array}$ & Coastal & $\begin{array}{l}\text { Meteorological } \\
\text { conditions (wind), } \\
\text { astronomic forces }\end{array}$ & $\begin{array}{l}\text { Sea water } \\
\text { level (storm } \\
\text { surge, waves, } \\
\text { tides) }\end{array}$ & $\begin{array}{l}\text { Water level, } \\
\text { wave height, } \\
\text { wave period, } \\
\text { overtopping } \\
\text { rate }\end{array}$ & $\begin{array}{l}\text { Storm surge, } \\
\text { waves, tides, }\end{array}$ & $\begin{array}{l}\text { Fitting of parametric } \\
\text { joint distributions, } \\
\text { stochastic simulation, } \\
\text { Monte Carlo }\end{array}$ & $\begin{array}{l}\text { Observed data, hindcasting, synthetic } \\
\text { data }\end{array}$ & $\begin{array}{l}\text { Locations around } \\
\text { England and Wales }\end{array}$ \\
\hline $\begin{array}{l}\text { Kao and } \\
\text { Chang } 2012\end{array}$ & Fluvial & N/A & $\begin{array}{l}\text { Runoff- } \\
\text { induced } \\
\text { flooding }\end{array}$ & $\begin{array}{l}\text { Peak } \\
\text { streamflow } \\
\text { discharge, }\end{array}$ & $\begin{array}{l}\text { Rainfall runoff } \\
\text { processes - river }\end{array}$ & $\begin{array}{l}\text { Copula-based } \\
\text { approach (Gaussian } \\
\text { copulas) }\end{array}$ & Peak annual and daily discharge data & $\begin{array}{l}\text { Nashville, } \\
\text { Tennessee }\end{array}$ \\
\hline $\begin{array}{l}\text { Kew et al. } \\
2013\end{array}$ & $\begin{array}{l}\text { Coastal, } \\
\text { fluvial }\end{array}$ & $\begin{array}{l}\text { Meteorological } \\
\text { "joint events" }\end{array}$ & $\begin{array}{l}\text { Surge, } \\
\text { precipitation- } \\
\text { induced runoff }\end{array}$ & $\begin{array}{l}\text { Winds, } n \text {-day } \\
\text { precipitation } \\
\text { (proxies for } \\
\text { storm surge } \\
\text { and river } \\
\text { discharge) }\end{array}$ & $\begin{array}{l}\text { Rainfall runoff } \\
\text { processes - river, } \\
\text { storm surge, tides }\end{array}$ & $\begin{array}{l}\text { N/A } \\
\text { (statistical analysis } \\
\text { addressing conditional } \\
\text { probability of winds } \\
\text { and surge given } \\
\text { occurrence of extreme } \\
\text { precipitation) }\end{array}$ & $\begin{array}{l}\text { ESSENCE synthetic data set } \\
\text { Models/software: ECHAM5/MPI-OM } \\
\text { coupled global climate model }\end{array}$ & $\begin{array}{l}\text { Rhine delta, the } \\
\text { Netherlands }\end{array}$ \\
\hline $\begin{array}{l}\text { Kowalik and } \\
\text { Proshutinsky } \\
2010\end{array}$ & Coastal & $\begin{array}{l}\text { Earthquake in } \\
\text { water bodies, } \\
\text { astronomic forces }\end{array}$ & Tsunami, tide & Sea level & Tsunami, tide & $\begin{array}{l}\text { N/A } \\
\text { (process-based, } \\
\text { numerical model } \\
\text { addressing interactions } \\
\text { of tide and tsunami) } \\
\end{array}$ & Empirical/simulated data & Cook Inlet, Alaska \\
\hline $\begin{array}{l}\text { Langousis } \\
\text { and } \\
\text { Veneziano } \\
2009\end{array}$ & $\begin{array}{l}\text { Coastal, } \\
\text { pluvial }\end{array}$ & Hurricane & $\begin{array}{l}\text { Hurricane- } \\
\text { induced } \\
\text { precipitation }\end{array}$ & N/A & $\begin{array}{l}\text { Precipitation- } \\
\text { site or rainfall } \\
\text { runoff } \\
\text { processes-river }\end{array}$ & $\begin{array}{l}\text { N/A } \\
\text { (combined process- } \\
\text { based [physics-based] } \\
\text { and statistical model of } \\
\text { hurricane precipitation } \\
\text { as a function of } \\
\text { multiple hurricane } \\
\text { parameters) }\end{array}$ & Precipitation radar data & $\begin{array}{l}\text { New Orleans, } \\
\text { Louisiana }\end{array}$ \\
\hline $\begin{array}{l}\text { Lian et al. } \\
2012\end{array}$ & $\begin{array}{l}\text { Coastal, } \\
\text { fluvial }\end{array}$ & $\begin{array}{l}\text { Typhoon, } \\
\text { astronomical } \\
\text { forcing }\end{array}$ & $\begin{array}{l}\text { Typhoon- } \\
\text { induced } \\
\text { precipitation, } \\
\text { tide level } \\
\text { (storm tide) }\end{array}$ & $\begin{array}{l}\text { Ratio of the } \\
\text { flooded } \\
\text { length of the } \\
\text { rivers to the } \\
\text { total length } \\
\text { of the rivers }\end{array}$ & $\begin{array}{l}\text { Rainfall runoff } \\
\text { processes-river, } \\
\text { storm surge, tide }\end{array}$ & $\begin{array}{l}\text { Copula-based } \\
\text { approach (optimal } \\
\text { copula) }\end{array}$ & $\begin{array}{l}\text { Precipitation and tidal level records } \\
\text { Models/software: HEC-RAS }\end{array}$ & $\begin{array}{l}\text { City on southeast } \\
\text { coast of China }\end{array}$ \\
\hline $\begin{array}{l}\text { Lin et al. } \\
2010\end{array}$ & $\begin{array}{l}\text { Coastal, } \\
\text { pluvial }\end{array}$ & $\mathrm{TC}$ & $\begin{array}{l}\text { Rainfall, } \\
\text { surge, storm } \\
\text { tide }\end{array}$ & N/A & $\begin{array}{l}\text { Storm surge, } \\
\text { tide, } \\
\text { precipitation- } \\
\text { site or rainfall } \\
\text { runoff } \\
\text { processes - river }\end{array}$ & $\begin{array}{l}\text { N/A } \\
\text { (process-based, } \\
\text { numerical model } \\
\text { addressing hurricane } \\
\text { rainfall, winds, and } \\
\text { surge) }\end{array}$ & $\begin{array}{l}\text { Surge gauge data, radar rainfall fields, } \\
\text { time series related to local wind from } \\
\text { stations located at the coastal area } \\
\text { Models/software: } 2 \text { D ADCIRC }\end{array}$ & $\begin{array}{l}\text { Hurricane Isabel } \\
(2003) \text { and the } \\
\text { urbanized coastal } \\
\text { area in the } \\
\text { Chesapeake Bay } \\
\text { watershed, United } \\
\text { States }\end{array}$ \\
\hline
\end{tabular}




\begin{tabular}{|c|c|c|c|c|c|c|c|c|}
\hline Reference & $\begin{array}{l}\text { Flood } \\
\text { type }\end{array}$ & $\begin{array}{l}\text { Flood-forcing } \\
\text { phenomena }^{a}\end{array}$ & $\begin{array}{l}\text { Flood } \\
\text { mechanism }\end{array}$ & $\begin{array}{l}\text { Flood } \\
\text { severity } \\
\text { metric }\end{array}$ & $\begin{array}{l}\text { MMF flood } \\
\text { mechanism }^{b}\end{array}$ & $\begin{array}{l}\text { Joint probability } \\
\text { approach }^{c}\end{array}$ & $\begin{array}{l}\text { Data sources and models/software } \\
\text { used (if applicable) }\end{array}$ & $\begin{array}{l}\text { Case study/ } \\
\text { focus area }\end{array}$ \\
\hline $\begin{array}{l}\text { Lonfat et al. } \\
2007\end{array}$ & $\begin{array}{l}\text { Coastal, } \\
\text { pluvial }\end{array}$ & Hurricane & $\begin{array}{l}\text { Precipitation- } \\
\text { induced runoff }\end{array}$ & N/A & $\begin{array}{l}\text { Precipitation- } \\
\text { site or rainfall } \\
\text { runoff } \\
\text { processes_river }\end{array}$ & $\begin{array}{l}\text { N/A } \\
\text { (PHRaM) }\end{array}$ & $\begin{array}{l}\text { Gridded rainfall data (rain gauges), } \\
\text { radar data }\end{array}$ & $\begin{array}{l}\text { All storms that } \\
\text { made landfall along } \\
\text { US coasts in } 2004\end{array}$ \\
\hline $\begin{array}{l}\text { Lu et al. } \\
2018\end{array}$ & $\begin{array}{l}\text { Coastal, } \\
\text { pluvial }\end{array}$ & $\mathrm{TC}$ & $\begin{array}{l}\text { Runoff- } \\
\text { induced } \\
\text { flooding }\end{array}$ & Discharge & $\begin{array}{l}\text { Precipitation- } \\
\text { site or rainfall } \\
\text { runoff } \\
\text { processes-river }\end{array}$ & $\begin{array}{l}\text { N/A } \\
\text { (process- and physics- } \\
\text { based model of } \\
\text { hurricane-induced } \\
\text { rainfall) }\end{array}$ & $\begin{array}{l}\text { Outputs from WRF model } \\
\text { Models/software: CUENCAS }\end{array}$ & $\begin{array}{l}\text { Hurricanes Isabel } \\
\text { (2003) and Irene } \\
\text { (2011), Delaware } \\
\text { River Basin }\end{array}$ \\
\hline $\begin{array}{l}\text { Masina et al. } \\
2015\end{array}$ & Coastal & $\begin{array}{l}\text { Meteorological } \\
\text { conditions (strong } \\
\text { onshore winds, } \\
\text { low atmospheric } \\
\text { pressure systems), } \\
\text { astronomical } \\
\text { forces }\end{array}$ & $\begin{array}{l}\text { Sea level, } \\
\text { wave }\end{array}$ & $\begin{array}{l}\text { PWL, } \\
\text { significant } \\
\text { wave height }\end{array}$ & $\begin{array}{l}\text { Storm surge, } \\
\text { wave, tide }\end{array}$ & $\begin{array}{l}\text { Copula-based } \\
\text { approach }\end{array}$ & $\begin{array}{l}\mathrm{SWH} \text {, mean and peak wave period, } \\
\text { average water temperature, direction of } \\
\text { wave }\end{array}$ & $\begin{array}{l}\text { Ravenna coast in } \\
\text { Italy }\end{array}$ \\
\hline $\begin{array}{l}\text { Moftakhari } \\
\text { et al. } 2017\end{array}$ & $\begin{array}{l}\text { Coastal, } \\
\text { fluvial }\end{array}$ & $\begin{array}{l}\text { Storms, } \\
\text { astronomical } \\
\text { forces, SLR } \\
\text { forcing }\end{array}$ & $\begin{array}{l}\text { Fluvial flow, } \\
\text { surge, tide, } \\
\text { SLR }\end{array}$ & Water level & $\begin{array}{l}\text { Rainfall runoff } \\
\text { processes - river, } \\
\text { storm surge, tide, } \\
\text { SLR }\end{array}$ & $\begin{array}{l}\text { Copula-based } \\
\text { approach }\end{array}$ & $\begin{array}{l}\text { Hourly coastal water levels, daily river } \\
\text { flow, future SLR projections }\end{array}$ & $\begin{array}{l}\text { Multiple coastal } \\
\text { estuaries }\end{array}$ \\
\hline $\begin{array}{l}\text { Orton et al. } \\
2016\end{array}$ & Coastal & $\begin{array}{l}\text { TCs, extratropical } \\
\text { cyclones }\end{array}$ & Storm tide & Water level & $\begin{array}{l}\text { Storm surge, } \\
\text { wave, tide }\end{array}$ & $\begin{array}{l}\text { Statistical analysis } \\
\text { using the results of the } \\
\text { physical models, } \\
\text { extreme value analysis }\end{array}$ & $\begin{array}{l}\text { Extratropical storm set and tide gauge } \\
\text { data, historical TC data }\end{array}$ & New York Harbor \\
\hline $\begin{array}{l}\text { Orton et al. } \\
2018\end{array}$ & $\begin{array}{l}\text { Coastal, } \\
\text { fluvial }\end{array}$ & $\begin{array}{l}\text { Tropical, wet } \\
\text { extratropical, and } \\
\text { extratropical } \\
\text { cyclones; SLR } \\
\text { forcing }\end{array}$ & $\begin{array}{l}\text { Storm tide, } \\
\text { river flow, } \\
\text { SLR }\end{array}$ & Water level & $\begin{array}{l}\text { Rainfall runoff } \\
\text { processes-river, } \\
\text { storm surge, tide, } \\
\text { SLR }\end{array}$ & $\begin{array}{l}\text { Statistical analysis } \\
\text { involving combination } \\
\text { of numerical } \\
\text { modeling, Bayesian- } \\
\text { motivated approaches, } \\
\text { extreme value analysis }\end{array}$ & $\begin{array}{l}\text { HURDAT2 TC data, USGS river gauge } \\
\text { flow data, meteorological reanalysis } \\
\text { data } \\
\text { Models/software: Stevens ECOM 3D } \\
\text { hydrodynamic model }\end{array}$ & $\begin{array}{l}\text { Hudson River, } \\
\text { United States }\end{array}$ \\
\hline $\begin{array}{l}\text { Petroliagkis } \\
2018\end{array}$ & $\begin{array}{l}\text { Coastal, } \\
\text { fluvial }\end{array}$ & Weather event & $\begin{array}{l}\text { Storm surge, } \\
\text { wave }\end{array}$ & N/A & $\begin{array}{l}\text { Rainfall runoff } \\
\text { processes - river, } \\
\text { storm surge, } \\
\text { wave }\end{array}$ & $\begin{array}{l}\text { N/A } \\
\text { (analysis of statistical } \\
\text { dependence between } \\
\text { quantities) }\end{array}$ & $\begin{array}{l}\text { Hindcasted wind, pressure field data } \\
\text { Models/software: Delf3D-Flow }\end{array}$ & $\begin{array}{l}32 \text { rivers along } \\
\text { European coasts }\end{array}$ \\
\hline $\begin{array}{l}\text { Serafin et al. } \\
2019\end{array}$ & $\begin{array}{l}\text { Coastal, } \\
\text { fluvial }\end{array}$ & $\begin{array}{l}\text { Oceanographic } \\
\text { and riverine } \\
\text { processes }\end{array}$ & $\begin{array}{l}\text { Fluvial (river) } \\
\text { flow, coastal } \\
\text { water level }\end{array}$ & Water levels & $\begin{array}{l}\text { Rainfall runoff } \\
\text { processes-river, } \\
\text { storm surge, } \\
\text { wave }\end{array}$ & $\begin{array}{l}\text { N/A } \\
\text { (process model } \\
\text { involving numerical } \\
\text { model, machine } \\
\text { learning, probabilistic } \\
\text { simulation model) }\end{array}$ & $\begin{array}{l}\text { Hourly discharge and stage } \\
\text { observations; hourly stillwater level } \\
\text { Models/software: HEC-RAS }\end{array}$ & Washington coast \\
\hline $\begin{array}{l}\text { Sui and } \\
\text { Koehler } \\
2001\end{array}$ & Fluvial & $\begin{array}{l}\text { Precipitation- } \\
\text { producing events }\end{array}$ & $\begin{array}{l}\text { Precipitation } \\
\text { on snow and } \\
\text { snow melt }\end{array}$ & $\begin{array}{l}\text { Runoff } \\
\text { depth, peak } \\
\text { discharge }\end{array}$ & $\begin{array}{l}\text { Rainfall runoff } \\
\text { processes - river, } \\
\text { rain-on-snow } \\
\text { events, snowmelt } \\
\end{array}$ & $\begin{array}{l}\text { N/A } \\
\text { (statistical analysis } \\
\text { [EVA] of rain-on- } \\
\text { snow events) }\end{array}$ & $\begin{array}{l}\text { Average monthly and annual } \\
\text { precipitation data, snow depth and } \\
\text { snow water equivalent data; discharge }\end{array}$ & $\begin{array}{l}\text { A forest region, } \\
\text { Southern Germany }\end{array}$ \\
\hline $\begin{array}{l}\text { Svensson } \\
\text { and Jones } \\
2002\end{array}$ & $\begin{array}{l}\text { Coastal, } \\
\text { fluvial }\end{array}$ & $\begin{array}{l}\text { Mid-latitude } \\
\text { cyclones }\end{array}$ & $\begin{array}{l}\text { Sea surge, } \\
\text { precipitation- }\end{array}$ & $\begin{array}{l}\text { Flow and } \\
\text { surge } \\
\text { residuals }\end{array}$ & $\begin{array}{l}\text { Rainfall runoff } \\
\text { processes - river, }\end{array}$ & N/A & $\begin{array}{l}\text { Daily mean river flows; daily } \\
\text { precipitation observations; sea surge } \\
\text { and total sea levels }\end{array}$ & Eastern Britain \\
\hline
\end{tabular}




\begin{tabular}{|c|c|c|c|c|c|c|c|c|}
\hline Reference & $\begin{array}{l}\text { Flood } \\
\text { type }\end{array}$ & $\begin{array}{l}\text { Flood-forcing } \\
\text { phenomena }^{a}\end{array}$ & $\begin{array}{l}\text { Flood } \\
\text { mechanism }\end{array}$ & $\begin{array}{l}\text { Flood } \\
\text { severity } \\
\text { metric }\end{array}$ & $\begin{array}{l}\text { MMF flood } \\
\text { mechanism }^{b}\end{array}$ & $\begin{array}{l}\text { Joint probability } \\
\text { approach }^{c}\end{array}$ & $\begin{array}{l}\text { Data sources and models/software } \\
\text { used (if applicable) }\end{array}$ & $\begin{array}{l}\text { Case study/ } \\
\text { focus area }\end{array}$ \\
\hline & & & $\begin{array}{l}\text { induced } \\
\text { runoff, tide }\end{array}$ & & $\begin{array}{l}\text { storm surge, } \\
\text { wave, tide }\end{array}$ & $\begin{array}{l}\text { (analysis of statistical } \\
\text { dependence between } \\
\text { [extremal] quantities) }\end{array}$ & & \\
\hline $\begin{array}{l}\text { Svensson } \\
\text { and Jones } \\
2004\end{array}$ & $\begin{array}{l}\text { Coastal, } \\
\text { fluvial }\end{array}$ & $\begin{array}{l}\text { Mid-latitude } \\
\text { cyclones }\end{array}$ & $\begin{array}{l}\text { Sea surge, } \\
\text { precipitation- } \\
\text { induced } \\
\text { runoff, tide }\end{array}$ & $\begin{array}{l}\text { Flow and } \\
\text { surge } \\
\text { residuals }\end{array}$ & $\begin{array}{l}\text { Rainfall runoff } \\
\text { processes-river, } \\
\text { storm surge, } \\
\text { wave, tide }\end{array}$ & $\begin{array}{l}\text { N/A } \\
\text { (analysis of statistical } \\
\text { dependence between } \\
\text { [extremal] quantities) }\end{array}$ & $\begin{array}{l}\text { Hourly sea surge and total sea level, } \\
\text { river flow data, precipitation data }\end{array}$ & $\begin{array}{l}\text { Coastal areas in } \\
\text { south and west } \\
\text { Britain }\end{array}$ \\
\hline $\begin{array}{l}\text { Tebaldi et al. } \\
2012\end{array}$ & Coastal & $\begin{array}{l}\text { Storms, SLR } \\
\text { forcing, } \\
\text { astronomic forces }\end{array}$ & $\begin{array}{l}\text { Storm, tide, } \\
\text { SLR }\end{array}$ & Water level & $\begin{array}{l}\text { Storm surge, } \\
\text { wave, tide, SLR }\end{array}$ & $\begin{array}{l}\text { N/A } \\
\text { (EVA considering } \\
\text { impacts of SLR on } \\
\text { water levels) }\end{array}$ & Hourly and monthly tide records & $\begin{array}{l}\text { Coasts of the } \\
\text { contiguous United } \\
\text { States }\end{array}$ \\
\hline $\begin{array}{l}\text { Toro et al. } \\
2008\end{array}$ & Coastal & Hurricane & Storm surge & $\begin{array}{l}\text { Water level } \\
\text { (elevation) }\end{array}$ & Storm surge & $\begin{array}{l}\text { (compares JPM and } \\
\text { JPM-OS methods) }\end{array}$ & Historical/synthetic storm data & Mississippi coast \\
\hline $\begin{array}{l}\text { Van den } \\
\text { Hurk et al. } \\
2015\end{array}$ & $\begin{array}{l}\text { Coastal, } \\
\text { fluvial }\end{array}$ & $\begin{array}{l}\text { Meteorological } \\
\text { condition, } \\
\text { astronomical } \\
\text { forcing }\end{array}$ & $\begin{array}{l}\text { Storm surge } \\
\text { and } \\
\text { precipitation- } \\
\text { induced } \\
\text { runoff, tide }\end{array}$ & Water level & $\begin{array}{l}\text { Rainfall runoff } \\
\text { processes-river, } \\
\text { storm surge, } \\
\text { wave, tide }\end{array}$ & $\begin{array}{l}\text { Empirical joint } \\
\text { distributions } \\
\text { (statistical and } \\
\text { process-based method } \\
\text { using RCM) }\end{array}$ & $\begin{array}{l}\text { Observations from in situ stations and } \\
\text { rainfall radar data, local surge data }\end{array}$ & Netherlands \\
\hline $\begin{array}{l}\text { Vitousek et } \\
\text { al. } 2017\end{array}$ & Coastal & $\begin{array}{l}\text { Coastal storms/ } \\
\text { meteorological } \\
\text { conditions, } \\
\text { astronomical } \\
\text { forces, SLR } \\
\text { forcing }\end{array}$ & $\begin{array}{l}\text { Wave (runup } \\
=\text { setup }+ \\
\text { swash), storm } \\
\text { surge, tide, } \\
\text { SLR }\end{array}$ & $\begin{array}{l}\text { Total water } \\
\text { level }\end{array}$ & $\begin{array}{l}\text { Rainfall runoff } \\
\text { processes-river, } \\
\text { storm surge, } \\
\text { wave, tide, SLR }\end{array}$ & $\begin{array}{l}\text { N/A } \\
\text { (EVA considering } \\
\text { impacts of SLR on } \\
\text { water levels) }\end{array}$ & Reanalysis data and model results & Global \\
\hline $\begin{array}{l}\text { Wadey et al. } \\
2015\end{array}$ & Coastal & $\begin{array}{l}\text { Winter sea storm, } \\
\text { astronomical } \\
\text { forces }\end{array}$ & $\begin{array}{l}\text { Storm surge, } \\
\text { wave, tide }\end{array}$ & $\begin{array}{l}\text { Sea level, } \\
\text { significant } \\
\text { wave height }\end{array}$ & $\begin{array}{l}\text { Storm surge, } \\
\text { wave, tide }\end{array}$ & $\begin{array}{l}\text { Parametric joint } \\
\text { distribution (bivariate } \\
\text { normal distribution) }\end{array}$ & Tide gauge records and wave buoy data & $\begin{array}{l}\text { UK coastal regions } \\
\text { (Sefton in northwest } \\
\text { coast, Suffolk in } \\
\text { east coast) }\end{array}$ \\
\hline $\begin{array}{l}\text { Wahl et al. } \\
2015\end{array}$ & $\begin{array}{l}\text { Coastal, } \\
\text { pluvial }\end{array}$ & Hurricane & $\begin{array}{l}\text { Storm surge } \\
\text { and } \\
\text { precipitation }\end{array}$ & N/A & $\begin{array}{l}\text { Storm surge, } \\
\text { Precipitation-- } \\
\text { site or rainfall } \\
\text { runoff } \\
\text { processes-river }\end{array}$ & $\begin{array}{l}\text { Copula-based } \\
\text { approach }\end{array}$ & $\begin{array}{l}\text { Storm surge; mean daily precipitation } \\
\text { data }\end{array}$ & $\begin{array}{l}\text { Contiguous United } \\
\text { States }\end{array}$ \\
\hline $\begin{array}{l}\text { Wang et al. } \\
2009\end{array}$ & Fluvial & N/A & $\begin{array}{l}\text { Runoff- } \\
\text { induced } \\
\text { flooding }\end{array}$ & Discharge & $\begin{array}{l}\text { Rainfall runoff } \\
\text { processes-river }\end{array}$ & $\begin{array}{l}\text { Copula-based } \\
\text { approach } \\
\text { (Archimedean } \\
\text { copulas) } \\
\end{array}$ & $\begin{array}{l}\text { Daily/hourly observational data for } \\
\text { flow rate }\end{array}$ & $\begin{array}{l}\text { Des Moines River, } \\
\text { Iowa }\end{array}$ \\
\hline $\begin{array}{l}\text { Ward et al. } \\
2018\end{array}$ & $\begin{array}{l}\text { Coastal, } \\
\text { fluvial }\end{array}$ & $\begin{array}{l}\text { Coastal and inland } \\
\text { storms }\end{array}$ & $\begin{array}{l}\text { Surge, river } \\
\text { flow }\end{array}$ & $\begin{array}{l}\text { Water level, } \\
\text { (skew surge), } \\
\text { peak } \\
\text { discharge }\end{array}$ & $\begin{array}{l}\text { N/A } \\
\text { (rainfall runoff } \\
\text { processes-river, } \\
\text { storm surge, } \\
\text { wave) }\end{array}$ & Copula-based method & $\begin{array}{l}\text { Observations of high sea levels and } \\
\text { high river discharge }\end{array}$ & Global \\
\hline $\begin{array}{l}\text { Zhang et al. } \\
2011\end{array}$ & Coastal & $\begin{array}{l}\text { Earthquake in } \\
\text { water bodies, } \\
\text { astronomical } \\
\text { forces }\end{array}$ & Tsunami, tide & $\begin{array}{l}\text { Wave runup, } \\
\text { inundation } \\
\text { extent }\end{array}$ & Tsunami, tide & $\begin{array}{l}\text { N/A } \\
\text { (process-based, } \\
\text { numerical model } \\
\text { addressing interactions } \\
\text { of tides and tsunamis) }\end{array}$ & $\begin{array}{l}\text { Observed tide and wave data } \\
\text { Models/software: SELFEE }\end{array}$ & $\begin{array}{l}\text { Prince William } \\
\text { Sound Earthquake, } \\
\text { Gulf of Alaska }\end{array}$ \\
\hline
\end{tabular}




\begin{tabular}{|c|c|c|c|c|c|c|c|c|}
\hline Reference & $\begin{array}{l}\text { Flood } \\
\text { type }\end{array}$ & $\begin{array}{l}\text { Flood-forcing } \\
\text { phenomena }^{a}\end{array}$ & $\begin{array}{l}\text { Flood } \\
\text { mechanism }\end{array}$ & $\begin{array}{l}\text { Flood } \\
\text { severity } \\
\text { metric }\end{array}$ & $\begin{array}{l}\text { MMF flood } \\
\text { mechanism }^{b}\end{array}$ & $\begin{array}{l}\text { Joint probability } \\
\text { approach }^{c}\end{array}$ & $\begin{array}{l}\text { Data sources and models/software } \\
\text { used (if applicable) }\end{array}$ & $\begin{array}{l}\text { Case study/ } \\
\text { focus area }\end{array}$ \\
\hline $\begin{array}{l}\text { Zheng et al. } \\
2013\end{array}$ & $\begin{array}{l}\text { Coastal, } \\
\text { pluvial }\end{array}$ & Cyclonic systems & $\begin{array}{l}\text { Storm surge } \\
\text { and } \\
\text { precipitation }\end{array}$ & N/A & $\begin{array}{l}\text { Storm surge, } \\
\text { precipitation-- } \\
\text { site or rainfall } \\
\text { runoff } \\
\text { processes-river }\end{array}$ & $\begin{array}{l}\text { N/A } \\
\text { (dependence study } \\
\text { involving bivariate } \\
\text { logistic threshold- } \\
\text { excess model) }\end{array}$ & $\begin{array}{l}\text { Processed tide level data daily } \\
\text { precipitation data }\end{array}$ & Australian coast \\
\hline $\begin{array}{l}\text { Zheng et al. } \\
2014\end{array}$ & $\begin{array}{l}\text { Coastal, } \\
\text { fluvial }\end{array}$ & $\begin{array}{l}\text { Hurricane, } \\
\text { meteorological } \\
\text { conditions }\end{array}$ & $\begin{array}{l}\text { Runoff- } \\
\text { induced } \\
\text { flooding and } \\
\text { surge }\end{array}$ & Flood level & $\begin{array}{l}\text { Rainfall runoff } \\
\text { processes - river, } \\
\text { storm surge }\end{array}$ & $\begin{array}{l}\text { N/A } \\
\text { (extremal dependence } \\
\text { study using multiple } \\
\text { statistical assessments) }\end{array}$ & $\begin{array}{l}\text { Synthetic data sets, daily rainfall } \\
\text { gauges and the storm tide gauge (case } \\
\text { study) }\end{array}$ & $\begin{array}{l}\text { Hawkesbury- } \\
\text { Nepean catchment, } \\
\text { north of Sydney, } \\
\text { Australia }\end{array}$ \\
\hline $\begin{array}{l}\text { Zhong et al. } \\
2013\end{array}$ & $\begin{array}{l}\text { Coastal, } \\
\text { fluvial }\end{array}$ & $\begin{array}{l}\text { Astronomical } \\
\text { forces, } \\
\text { meteorological } \\
\text { conditions, SLR } \\
\text { forcing, operations }\end{array}$ & $\begin{array}{l}\text { Astronomical } \\
\text { tide, wind- } \\
\text { induced storm } \\
\text { surge, fluvial } \\
\text { (river) flow }\end{array}$ & Water levels & $\begin{array}{l}\text { Precipitation- } \\
\text { site or rainfall } \\
\text { runoff } \\
\text { processes-river, } \\
\text { storm surge, } \\
\text { wave, tide, } \\
\text { snowmelt, river } \\
\text { structure } \\
\text { operations, SLR }\end{array}$ & $\begin{array}{l}\text { Copula-based } \\
\text { approach (also used } \\
\text { Monte Carlo } \\
\text { simulation) }\end{array}$ & $\begin{array}{l}\text { Observed sea level, predicted } \\
\text { astronomic tidal level, observed } \\
\text { discharges }\end{array}$ & $\begin{array}{l}\text { Lower Rhine Delta, } \\
\text { Europe }\end{array}$ \\
\hline
\end{tabular}

${ }^{a}$ In this table, the entry "N/A" is used to indicate that information was not explicitly stated in the subject paper or that the information is otherwise not available or applicable for the study. In some cases, the flood-forcing phenomena listed in this table are based on the judgement of this report's authors regarding the flood-forcing that is relevant to the process under consideration in a particular + study.

a Different terminology is used across the literature to describe flood-forcing phenomena, mechanisms, and severity (including multiple terms used to describe similar metrics). In this table, terms used to describe flood-forcing phenomena, mechanisms, and severity metrics are taken from the source papers. To link to the MMF Framework and terminology, the flood mechanism as described in that terminology is shown in this column.

${ }^{c}$ The column identifies which of the joint probability approaches introduced in Section 3.3 are applicable to the study being summarized. When the study does not use one of the approaches noted in Section 3.3, the statistical method is identified as "N/A" (not applicable) and a note is included regarding the alternate focus of the paper. Studies not directly related to statistical methods are included in this table because they are judged to provide information/insights, "building blocks," or formulations that may potentially be relevant to addressing MMFs. 


\section{CRITICAL REVIEW OF EXISTING PRACTICE AND RESEARCH}

The subsections that follow provide insights resulting from the critical assessment of existing approaches, with particular emphasis on identifying key themes as well as issues and challenges of relevance to the assessment of MMFs at nuclear facilities. Relevant insights include the following:

SITE-SPECIFIC ASSESSMENTS (Section 5.1): The majority of existing studies have involved analysis of site-specific data. Therefore, quantitative conclusions from existing studies may not be directly generalizable or applicable to other locations. Instead, extrapolation of insights must focus on broader, thematic issues.

DEFINITION OF FLOOD SEVERITY METRICS (Section 5.2): In existing studies, flood severity metrics are defined in various ways, even when the same (or similar) flood-forcing phenomena or flood mechanisms are considered. Even when metrics are physically equivalent between one or more studies, different terminology may be used to define and describe those metrics.

MODELING CONSIDERATIONS (Section 5.3): The following subsections describe the range of modeling considerations addressed in existing studies:

- Return Periods Considered in Existing Assessments: Existing studies have generally focused on hazards associated with return periods of 5-100 years (a few studies extend to 500-1,000 years). This range does not reach the length of return periods relevant to NPPs. Therefore, future work that builds on existing studies will need to include careful consideration of unique issues that arise when working with hazards associated with long return periods.

- Length of Record and Characteristics of Available Data Series: The length of record and characteristics (e.g., spatial and temporal resolution) of the data series used in a statistical assessment of flood frequencies can affect the validity and reliability of results, especially for studies targeting long return periods. Therefore, explicitly addressing data limitations in a probabilistic assessment of MMFs (e.g., via uncertainty analysis for bias corrections) may be necessary. Expansion of the data record through model simulation provides a mechanism for addressing some data limitations.

- Statistical Modeling Choices: Numerous modeling decisions must be made in performing probabilistic assessments that rely on statistical analysis for development of model input. These decisions lead to epistemic uncertainties that can have meaningful impacts on the results of statistical assessments.

- Assumptions Regarding Concurrence of Extrema: When extending conventional PFHA techniques based on EVA methods to the assessment of MMFs, a challenge arises because extrema associated with multiple flood mechanisms or severity measures typically do not coincide temporally. That is, when one random quantity is in the extremal state, the other quantity is typically in a non-extremal state. PFHA methods for MMFs must then account for this lack of concurrence.

- Model Validation: Validation of numerical, surrogate, probabilistic, and other models used in MMF studies remains a challenge because of a scarcity of data, which is particularly true for assessments focusing on severe events. 
GAPS AND CHALLENGES (Section 5.4): Numerous challenges and gaps were identified related to the existing literature, including inconsistencies in terminology (and the associated mathematical implications), the limited number of studies focusing on development of conventional hazard curves or surfaces, and a lack of a comprehensive framework for analyzing the range of potential sources of dependency among quantities and for treating temporal non-stationarities.

Additional discussion of each of those insights is provided in the subsections that follow. Furthermore, commentary is provided in conjunction with each subsection describing the potential implications of the insight on future work to be performed under this project.

\subsection{SITE-SPECIFIC ASSESSMENTS}

The majority of existing studies have involved the analysis of site-specific data. Therefore, quantitative conclusions from existing studies may not be directly generalizable or applicable to other locations. Instead, extrapolation of insights must focus on broader, thematic issues. Additional discussion is provided in this section.

A significant component of analyzing MMFs involves characterizing the dependence between variables (e.g., flood severity metrics resulting from one or more flood mechanisms). This dependence between variables is affected by hydraulic, hydrologic, and meteorological factors (Hawkes 2008), as well as other environmental factors and topographic/bathymetric features that vary from one location to another. MMF analysis involving empirical data related to these quantities will inevitably yield site-specific results. Therefore, a significant portion of the literature identified as part of this project relates to site-specific studies. Specific study regions are noted in the relevant column of Table 4.1. However, only a limited number of studies analyze joint probabilities and/or dependence among variables on a larger spatial scale. The few studies that address these broader geographic regions typically focus on identifying how patterns and the levels of dependence among variables range across locations. One example is the work performed by Wahl et al. (2015) in which dependence between surge and precipitation was investigated for the contiguous United States. The study found spatial variation in dependence between storm surge and precipitation across the country. Svensson and Jones (2004) also investigated the dependence between sea surge, river flow, and precipitation in south and west Britain to analyze spatial changes in dependence.

Considering the site-specific nature of the results related to analyzing the dependence between variables associated with MMFs, generalizing or spatially extrapolating specific conclusions is challenging (and perhaps technically inappropriate) regarding the magnitude and characteristics of dependence among variables from a site-specific study. Therefore, site-specific conclusions are not emphasized in this report (e.g., for consideration in subsequent project activities). This report and the assessment that follows do not focus on analysis of location-specific quantitative results, but instead focus on a broader, more thematically oriented approach. In particular, the assessment that follows focuses on general methods and on understanding the degree to which they are sufficiently flexible to be applied to the wide range of MMFs that are expected at NPPs.

\subsection{DEFINITION OF FLOOD SEVERITY METRICS}

Flood severity metrics are diversely defined in existing studies, even when considering the same (or similar) flood-forcing phenomena or flood mechanisms and metrics that are physically equivalent between one or more studies.

The definition and specification of the flood severity metrics of relevance to a particular study naturally change the interpretation of what is considered a flood hazard. In the current literature, no unique definition exists for a flood severity metric, even in assessing hazards for a particular hazard group or 
hazard mechanism. For example, in some studies, flood height is the relevant flood severity metric (Bass and Bedient 2018; Bevacqua et al. 2017; Bender et al. 2016). Other common severity metrics include volumetric measures (e.g., discharge) and durations (e.g., Gilja et al. 2018). However, other works focus on flood severity metrics in a manner that goes beyond physical measures. For example, Lian et al. (2012) defined a flood severity metric (the "flood severity index") that is interpreted as the ratio of the flooded length of the river to the total length of the river. In another work, Archetti et al. (2011) used flooded nodes of an urban drainage network to define flood risk.

Even when the flood severity metric used in one study is physically equivalent to that used in another study, the terminology used by the studies may differ substantially. Although this circumstance is a natural result of differing study focuses, this diversity in terminology terms can lead to challenges in identifying related literature and building off existing studies. Thus, although the development of a definition of a unique flood severity metric that is relevant for all studies is not feasible, that lack of a common/consistent language may create some challenges relative to sharing information and comparing insights across studies. In the context of this report, flood severity metrics will be defined in the context of hazard parameters of primary relevance to NPP design or analysis (i.e., flood elevation or depth).

Because the focus of this project is on the probabilistic assessment of combinations of flood mechanisms (rather than at other tiers of the hierarchy in Figure 2-7), combinations of flood severity metrics (e.g., flood elevation and duration of inundation) are not a focus.

\subsection{MODELING CONSIDERATIONS}

The following subsections describe the range of modeling considerations addressed in reviewed studies.

\subsubsection{Return Periods Considered in Existing Assessments}

NPPs are somewhat unique in the length of return periods considered as part of hazard assessment, with most NPP-related probabilistic flood hazard estimates focusing on long return periods (e.g., 10,000 years or longer). Most other noncritical infrastructure systems are designed for hazards associated with significantly shorter return periods. Existing literature has not focused on assessment of hazards in the context of the design/analysis of nuclear facilities, but rather, the literature typically focuses on shorter return periods. For example, Masina et al. (2015) considered assessment of hazards with a return period of 100 years, Lian et al. (2012) considered return periods of 5 to 100 years, and Kao and Chang (2012) considered return periods of up to 200 years. Moftakhari et al. (2017), using data for several estuaries in the United States, considered hazards associated with 5 to 50 year return periods. One of the few studies that considered longer return periods is the work by Gilja et al. (2018), which conducted a joint probability analysis related to flood hazards at river confluences by considering a return period of 1,000 years. Orton et al. (2018) analyzed the combination of storm tides and riverine flow for a return period of 1,000 years, and Orton et al. (2016) considered longer return periods in assessing hazard contributions from both extratropical and tropical events.

Considering the focus of most existing studies is on (relatively) short return periods, future work using the methods proposed in those works will need to include careful consideration of technical issues that arise in working with hazards associated with long return periods (e.g., the effect of epistemic uncertainties, nonlinearity in phenomenological processes, and physical upper limits).

\subsubsection{Length of Record and Characteristics of Available Data Series}

Data series record lengths can affect the validity and reliability of statistical flood frequency assessments, especially for studies targeting long return periods. Unfortunately, in many locations, complete records of long duration are simply not available. Some studies have proceeded in light of limited data; for example, 
Masina et al. (2015) used six years of data related to sea level (i.e., PWL) and waves (i.e., SWH and direction) to estimate the joint probability of water levels and waves. However, researchers have typically employed alternative strategies to generate results that are more robust in data-sparse situations. One of these strategies is generating synthetic data. Different techniques exist for synthetic data generation, including Monte Carlo methods (Hawkes et al. 2002; Wang 2016; Zhong et al. 2013) and leveraging output from numerical models (e.g., the WRF model [Lu et al. 2012]).

In addition to challenges arising from limited record length and varying degrees of completeness, further challenges arise from the resolution of data. For example, for considering precipitation, river discharge, and tidal gauge data series, often only averaged metrics (e.g., mean daily discharge) are available. The limits of the data can lead to missed peaks and can result in a low bias when used in, for example, EVAs. Of course, the use of mean data over more refined data (e.g., "instantaneous" data) is typically simply due to the availability of one type of data over another. For example, Wahl et al. (2015) used mean daily precipitation data, and Bender et al. (2016), Svensson and Jones (2002, 2004), and Zhong et al. (2013) used daily mean discharge time series.

In developing probabilistic assessments for MMFs, using averaged data may be necessary because more temporally refined data may not be available. However, in such cases, care should be taken to understand the potential bias that may be introduced by the use of average data (e.g., the low bias may be more pronounced in watersheds with shorter times of concentration and thus more rapidly changing time series). In cases in which potential differences exist between results that may be generated using average or using instantaneous data, correction factors may need to be considered in the analysis.

\subsubsection{Statistical Modeling Choices}

In performing probabilistic assessments that rely on statistical analysis for the development of model input (e.g., development of distributions for probabilistic characterization of the variability associated with one or more random variables), numerous modeling decisions are required. The decisions may include identification, processing, and filtering of data sets; selection of distributions and estimation of associated parameters; and the development, calibration, and validation of numerical models. Generally, little guidance is available to support such modeling decisions, particularly for the development of hazard assessments associated with the range of return periods of relevance to nuclear facilities. Although some guidance is available for shorter return periods (e.g., England et al. [2018] provides explicit guidelines for treatment of data, distribution selection, and parameter estimation), such guidance remains focused on univariate assessments rather than MMFs. The modeling decisions taken as part of statistical and probabilistic assessments can have a significant effect on estimated frequencies. No definitive decision metric or statistical criteria exists for distribution selection. However, statistical tests can be used to eliminate distributions from further consideration and various goodness-of-fit metrics can provide insights regarding relative measures. Moreover, physical considerations (e.g., physical process limits) and other considerations (e.g., preference for conservative decision-making in distribution selection) may be helpful informing distribution selection.

The epistemic uncertainties associated with statistical modeling decisions continue to aggregate when an assessment is extended from univariate to multivariate. As noted in Section 3.3.2, copula modeling has been widely used for bivariate and multivariate analyses involving MMFs. Copulas are commonly used because they are relatively simple to apply and offer flexibility in functional forms, particularly in the form of the marginal distributions. However, similar to univariate assessments, the functional form of the copula is a potentially significant modeling decision. The choice of copula type for multivariate analysis involving MMFs is often based on common practice rather than a theoretical basis. Although various goodness-of-fit metrics have been employed in the literature (De Michele et al. 2007; Kao and Chang 2012; Lian et al. 2012; Masina et al. 2015), there continues to be a lack of robust criteria and a general 
process to decide on a candidate copula method (e.g., to select a best fit or understand the appropriateness of one copula function over another). Moreover, the basis for selection of one copula function over another in any particular study is often not clearly defined. In most studies, the stated goal is not usually to describe how the best copula can be chosen, but rather to define an overall procedure (under the assumption that the best or an acceptable copula is chosen). Table 5.1 shows the various types of copula functions used in existing literature related to MMF. This table also provides the reason for selecting the type of copula for analysis in each particular study. Modeling decisions associated with epistemic uncertainties extend beyond the noted challenges related to the assumed functional form of marginal distributions and copula functions. For example, a lack of a general process exists for defining how threshold values can be defined for consideration in extremal analysis involving analysis of partial duration data series. In most studies, threshold levels are defined based on expert judgement or other expert defined methods. Tebaldi et al. (2012) conducted a PoT analysis by selecting a threshold related to the 99th percentile based on trial and error. Zhong et al. (2013) defined a fixed threshold for the peak surge residual. Kjeldsen et al. (2010) used a threshold related to 5\% of the 2-year return period rainfall.

Although many of the mentioned issues are relevant to univariate assessments, further considerations become relevant in the context of multivariate assessments. For example, Hawkes (2008) explained that "sometimes, when dependence exists, it is more marked amongst the higher observed values (stormy conditions) than amongst the lower values." This explanation implies that the choice of threshold value will affect the degree of dependence between variables, which adds to the importance of selected threshold value not only from the perspective of quantity of useful data available for analysis, but also from the perspective of the degree of dependence between variables.

Therefore, future work under this project that uses statistical assessments is expected to include consideration of the effects of statistical modeling choices leading to epistemic uncertainties in analysis results. Potential strategies for addressing these uncertainties include sensitivity studies and the application of established approaches for identifying and addressing epistemic uncertainties (e.g., using Bayesian approaches or logic trees).

Table 5.1. Summary of copulas used in literature and basis for selection.

\begin{tabular}{|c|c|c|}
\hline Reference & Type of copula used & Reason for selection \\
\hline Masina et al. (2015) & $\begin{array}{l}\text { - } \\
\text { - } \\
\text { - } \\
\text { Archimedreme value (EV) } \\
\text { Archimax, which encompass the EV and } \\
\text { - Metaelliptical, including } \\
\circ \quad \text { Gaussian } \\
\circ t \\
\text { - Miscellaneous, including } \\
\text { o Farlie-Gumbel-Morgenstern }\end{array}$ & $\begin{array}{l}\text { Several parametric copula } \\
\text { families were applied to cover a } \\
\text { wide range of possible patterns } \\
\text { for dependencies between } \\
\text { variables }\end{array}$ \\
\hline Kao and Chang (2012) & - Gaussian & $\begin{array}{l}\text { This type of copula was selected } \\
\text { because it was considered to be } \\
\text { well-accepted in the literature }\end{array}$ \\
\hline $\begin{array}{l}\text { Gilja, Ocvirk, and } \\
\text { Kuspilić (2018) }\end{array}$ & - Archimedean Gumbel-Hougaard & $\begin{array}{l}\text { These types of copulas were } \\
\text { selected because they are the } \\
\text { most frequently used one- } \\
\text { parameter Archimedean copulas } \\
\text { in the literature }\end{array}$ \\
\hline Bender et al. (2016) & $\begin{aligned} & \text { - Three Archimedean family, including } \\
& \circ \text { Clayton Archimedean } \\
& \circ \text { Frank Archimedean } \\
& \circ \text { Gumbel Archimedean }\end{aligned}$ & $\begin{array}{l}\text { These types of copula were } \\
\text { selected because they are } \\
\text { relatively easy to construct, }\end{array}$ \\
\hline
\end{tabular}




\begin{tabular}{|c|c|c|}
\hline Reference & Type of copula used & Reason for selection \\
\hline & & $\begin{array}{l}\text { flexible, and capable of covering } \\
\text { the full range of tail dependence }\end{array}$ \\
\hline $\begin{array}{l}\text { Lian, Xu, and Ma } \\
\text { (2012) }\end{array}$ & $\begin{array}{ll}- & \text { Gaussian } \\
- & t \\
- & \text { Clayton } \\
- & \text { Frank } \\
- & \text { Gumbel } \\
\end{array}$ & $\begin{array}{l}\text { These types of copula were } \\
\text { selected because they are widely } \\
\text { used in hydrology }\end{array}$ \\
\hline $\begin{array}{l}\text { Zhong, Overloop, and } \\
\text { Gelder (2013) }\end{array}$ & $\begin{array}{ll}- & \text { Gumbel } \\
- & \text { Gaussian }\end{array}$ & $\begin{array}{l}\text { A Gumbel copula was selected to } \\
\text { describe the dependency for high } \\
\text { river flows because it exhibits a } \\
\text { stronger dependency in the } \\
\text { positive tail. No basis was } \\
\text { identified for selection of } \\
\text { Gaussian copula }\end{array}$ \\
\hline Wahl et al. (2015) & $\begin{array}{l}\text { Three EVfamily, including } \\
\circ \quad \text { Gumbel } \\
\circ \quad \text { Galambos } \\
\circ \quad \text { Hüsler-Reiss } \\
\text { - Archimedean family, including } \\
\circ \quad \text { Clayton } \\
\circ \quad \text { Gumbel } \\
\text { (Gumbel belongs to both classes) }\end{array}$ & $\begin{array}{l}\text { No basis was identified for } \\
\text { selection for the choice of these } \\
\text { copula types }\end{array}$ \\
\hline $\begin{array}{l}\text { Moftakhari et al. } \\
(2017)\end{array}$ & $\begin{array}{l}\text { O Archimedean family, including } \\
\circ \quad \text { Ali-Mikhail-Haq } \\
\circ \text { Clayton } \\
\circ \text { Frank } \\
\circ \text { Gumbel } \\
\circ \text { Joe } \\
\text { - } \quad \text { Elliptical family, including } \\
\circ \quad \text { Normal } \\
\circ \quad t \\
\text { - EV family, including } \\
\circ \quad \text { Galambos } \\
\circ \quad \text { Hüsler-Reiss } \\
\circ \quad \text { Tawn } \\
\text { Farlie-Gumbel-Morgenstern }\end{array}$ & $\begin{array}{l}\text { These copula families were } \\
\text { considered to cover a wide } \\
\text { variety of dependencies that can } \\
\text { exist between variables }\end{array}$ \\
\hline $\begin{array}{l}\text { De Michele et al. } \\
\text { (2007) }\end{array}$ & $\begin{array}{ll}\text { - } & \text { Ali-Mikhail-Haq } \\
\text { - } & \text { Frank } \\
\text { - } & \text { Gumbel }\end{array}$ & $\begin{array}{l}\text { These copula families commonly } \\
\text { used in literature were selected to } \\
\text { cover a wide range of } \\
\text { dependencies that can exist } \\
\text { between variables }\end{array}$ \\
\hline
\end{tabular}

\subsubsection{Assumptions Regarding Concurrence of Extrema}

Univariate statistical assessments to support PFHA often use EVA based on annual maximum series in which distributions are fit to a data series that contains a single annual maxima value for every year contained in the overall data set. However, challenges arise in seeking to extend these concepts to multivariate assessments because in considering multiple random variables corresponding to multiple flood-forcing phenomena, flood mechanisms, or flood severity metrics, the occurrence of the annual maxima for one variable may not (and likely will not) coincide with the occurrence of the annual maxima for the other variable. Bender et al. (2016) noted that "it might even be that the simultaneous occurrence is physically impossible or at least very unlikely." 
Nonetheless, one of the common strategies for probabilistic assessment of MMFs is to conduct multivariate analysis by considering pairs of data related to annual maximum values of the involved variables (i.e., by assuming that the annual maxima of variables coincide). Some examples are the work by Gilja et al. (2018) in which pairs of annual maximum discharge were used for joint probability analysis related to flood hazard at river confluences by using a copula method. Also, Wang (2016) and Wang et al. (2009) used annual peak discharge data related to upstream tributaries of river confluence. Svensson and Jones $(2002,2004)$ also conducted extremal dependence analysis based on an extremal dependence measure, which was defined as the probability of one variable's being extreme, conditioned on the other variable's being extreme.

Given that extremal values may be unlikely to occur at the same time, some researchers have employed different approaches to analyze pairs of annual extremal values of involved variables. Typically, these approaches involve identifying the extremal (e.g., annual maxima) value for one quantity (e.g., $Y_{1}$ ) and then selecting the contemporaneous value of the other quantity (e.g., $Y_{2}$ ); for instance, if $t_{\text {ext }, 1}$ refers to the time at which the extreme value of $Y_{1}$ occurs, the quantity of $Y_{2}$ would be extracted at time $t_{\text {ext, } 1}$. Extensions to this approach may consider a "buffer" around $t_{\text {ext }, 1}$ so that rather than taking the value of $Y_{2}$ at exactly $t_{\text {ext }, 1}$, the maximum value of $Y_{2}$ is taken within an interval $t_{\text {ext }, 1} \pm \Delta t$, where $\Delta t$ is often taken as one day.

For example, Masina et al. (2015) considered peak sea level due to surge/tides and contemporary SWHs. To analyze the compounding effects of SLR and fluvial flooding, Moftakhari et al. (2017) analyzed the annual maximum fluvial flow and the corresponding maximum coastal water level measured within one day of the flood peak. To analyze compound floods, Wahl et al. (2015) used the highest annual storm surge and the highest precipitation within a time range of \pm 1 day, and also the highest annual precipitation and corresponding highest storm surge within \pm 1 day. For analyzing the joint impact of rainfall and tidal level, Lian et al. (2012) considered maximum annual $24 \mathrm{~h}$ rainfall and the highest tidal level during the time window corresponding to that rainfall. In a study focused on fluvial flooding, Kao and Chang (2012) confirmed that pairs of annual peak data for two variables may correspond to floods at different times during the year. They used pairs of data related to high flows (top 20\% of flow pairs) instead of peak annual pairs. Bender et al. (2016) worked with data pairs in which the maximum value of one variable was considered along with the simultaneously measured value of a second variable (and vice versa). The study demonstrated that results related to the proposed approach were distinctively different from the results of the conservative method of considering the simultaneous occurrence of annual maximum values related to both variables.

Overall, as noted in previous paragraphs, the most common approach for addressing MMFs is via assessments using annual maxima series without assuming the peaks coincide include the following strategies:

- Considering the annual peak value of the first variable and simultaneous value of the second variable and vice versa (Masina et al. 2015 and Bender et al. 2016)

- Considering the annual peak value for the first variable and the corresponding highest value for the second variable within an appropriate time span (e.g., \pm 1 day) so that they can be considered dependent (Wahl et al. 2015)

In the second case, an additional modeling decision arises from the need to select the appropriate time window for consideration of dependence events. For some random quantities of interest, data may only be available for annual maximum values (rather than at more refined time intervals), which may limit the flexibility of analysis that can be performed in some locations. Moreover, even when time series 
information is available, as noted in Section 5.3.2, data may be available only at insufficient discretization so that true maximum values over an interval may be missed.

\subsubsection{Model Validation}

Validation of numerical, surrogate, probabilistic, and other models used in MMF studies remains a challenge because of the scarcity of data. In most studies in identified literature, models and results were validated using data related to one event. For example, Archetti et al. (2011) developed flood probability charts for an urban drainage network and compared them with the time series of one year of rainfall-sea level. Gilja et al. (2018) compared the estimated trend of peak discharge obtained from bivariate copulas with measured values of a flood event that occurred in 2014. Demonstration of good performance for one flood event does not necessarily provide high confidence in good performance of the model for other flood events. For a PFHA involving the prediction of severe hazards associated with long return periods, the model and results should ideally be validated for at least several different sets of observed data related to different severities, time periods, and flood events. However, this validation must be balanced against the need to use historical events in building the model (e.g., training empirical or calibrating numerical models).

\subsection{GAPS AND CHALLENGES}

The following subsections describe numerous challenges and gaps that were identified related to existing literature, particularly when assessed from the perspective of issues of relevance to flooding hazards at

NPPs. These gaps and challenges include inconsistencies in terminology (and the associated mathematical implications); the limited number of studies focusing on the development of conventional hazard curves or surfaces; a lack of a comprehensive framework for analyzing the range of potential sources of dependency between quantities; the limited number of process variables explicitly modeled in existing studies; and the treatment of temporal non-stationarities. Additional gaps were also articulated in Section 3 in conjunction with the overall summary of available literature. Those gaps focused primarily on topics (e.g., specific flood hazard mechanisms) not addressed in the identified literature.

\subsubsection{Inconsistency in Terminology}

The existing literature is relatively fragmented in the use of terminology related to MMFs. The fragmentation can lead to challenges in identifying relevant literature and applying it to specific applied and research problems. Moreover, it has important implications for the development of mathematical details related to the probabilistic assessment of hazards, as well as the presentation of the results of those assessments.

Of particular note is "joint probability analysis" (or a closely related terminology variant), which is often used in the context of assessing MMFs. In this report, "joint probability" has been defined within the context of multiple random variables related to the Boolean "and" scenario (see Section 3.2.2). However, although the phrase "joint probability analysis" is widely used, diversity exists in the way that "joint" is mathematically defined in studies. In particular, in the context of bivariate assessments, studies have defined "joint hazards" to mean cases in which the following are true:

1. the two hazard relevant variables (e.g., parameters related to flood mechanisms or flood severity metrics) are both exceeded (Boolean "and" scenario),

2. either hazard relevant variable is exceeded (Boolean "or" scenario), or 
3. one variable (e.g., flood severity metric) is exceeded, given that another variable equals a specified value or exceeds a specified threshold (conditional scenario).

Similar extensions can be considered within the context of more than two variables. Moreover, these definitions may consider "joint occurrence" to imply a temporally simultaneous occurrence or may consider occurrence within some defined time window.

Hawkes (2008) identified a comprehensive bibliography related to definition and how joint probability should be applied in the United Kingdom (e.g., Coles and Tawn 1991, 1994; Hawkes 2006; Hawkes et al. 2002). However, outside of those studies, there remains diversity in definitions. For example, Gilja et al. (2018), Wang (2016), Wang et al. (2009), and Svensson and Jones (2002, 2004) use "joint -probability analysis" to refer to extremal analysis in which both variables are at an extremal level. However, other studies use this phrase to refer to the simultaneous occurrence of one variable conditioned on another variable's being an extreme value (Bender et al. 2016; Lian et al. 2012; Masina et al. 2015). Other work has considered the analysis of the extreme value of one variable and highest value of the second variable within (usually) \pm 1 day (Wahl et al. 2015). Moftakhari et al. (2017) used an "or" scenario logic in defining hazards.

\subsubsection{Presentation of Results}

Hazard curves are one of the most common ways of presenting the results of a conventional PFHA, for example, as generated by the USGS flood frequency tool PEAK-FQ (USGS 2018) or as part of the North Atlantic Comprehensive Coastal Study of storm surge hazards (USACE 2015; see Section 3.3.4 for additional information regarding development of hazard curves). However, probabilistic assessment of MMFs leads to challenges in generating hazard curves due to the presence of more than one flood mechanism or flood severity metric in the analysis, which is exacerbated by the challenges in defining "joint hazards."

Only a limited number of existing studies present results in the form of conventional hazard curves (i.e., a plot with one axis corresponding to a flood severity metric and the other showing the probability of exceedance or return period). For example, Orton et al. $(2016,2018)$ presented the results of a study related to the combined effects of TC and ETC as flood exceedance curves showing water levels for different return periods. Bass and Bedient (2018) presented the results in the form of inundation area versus return period. Bevacqua et al. (2017) presented the results as water level versus return period, along with some measures of uncertainty. Other studies provide information in the form of graphs but not necessarily conventional hazard curves. For example, Lian et al. (2012) presented graphs related to the joint probability of precipitation and tide. To analyze the increasing risk of compound flooding from storm surge and rainfall for major US cities, Wahl et al. (2015) presented the results in terms of the spatial variability of the dependency between storm surge and precipitation. Gilja et al. (2018) provided scatter plots of measured data pairs and simulated values generated from the copula model for the river confluence under study by considering different return periods. To analyze the joint probability of waves and water levels, Hawkes et al. (2002) provided joint exceedance curves of wave heights and water levels for different return periods and different locations.

\subsubsection{Lack of a Comprehensive Framework for Analyzing Dependence among Variables}

An important aspect of assessing MMFs is understanding and capturing dependence among variables of interest. Several factors affect the dependence among variables involved in MMF analysis, including spatial factors, temporal factors, and selected threshold values. Spatial factors include the spatial extent of flood-forcing phenomena, as well as location-specific factors (e.g., topography and bathymetry) that vary from one place to another but that may affect the occurrence and degree of dependence between flood 
mechanisms or other related quantities (e.g., see the work by Svensson and Jones 2002, 2004; Wahl et al. 2015). Temporal changes in dependence among variables can be captured in terms of seasonal, annual, and long-term variations. For example, Bender et al. (2016), Gilja et al. (2018), Moftakhari et al. (2017), Wang (2016), and Wang et al. (2009) considered annual data in investigating dependence. Consideration of annual metrics can mask the seasonal dependence among variables, which is especially important where conditions change with season. Hawkes (2008) considered short-term, midterm (seasonal) and long-term dependence in joint probability analysis. Svensson and Jones $(2002,2004)$ conducted a seasonal analysis for dependence among sea surge, river flow, and precipitation in south and west Britain. Masina et al. (2015) considered seasonal analysis for dependence to estimate the joint probability of water levels and waves in a coastal area in Italy by using a copula-based approach. Some researchers have also analyzed changes in dependence over time (Hawkes 2008; Wahl et al. 2015). The choice of threshold values also can change dependence levels among variables; for example, a higher threshold value used in defining extrema may be associated with differing dependencies among variables (Hawkes 2008).

Despite the recognition of these factors, the existing literature (and guidance) lacks a comprehensive framework for addressing and analyzing the dependence among variables, and most studies have addressed only one source of dependency. For contexts in which multiple sources of dependencies may be relevant (e.g., when considering potential changes in hazards over time or seeking to capture dependencies under severe conditions), additional research may be required to understand how multiple sources of dependencies may interact or compound.

\subsubsection{Limited Scope of Variables Included in Existing Models}

A review of existing literature related to the hazard of MMFs indicates that frequently, a limited number of process variables (i.e., variables related to flood-forcing phenomena or the flood mechanisms that contribute to a particular flood severity metric) are explicitly considered in some studies. Although the variables included in existing studies are often sufficient for the purposes of the studies, the limited explicit consideration of a broad range of process variables can affect the degree to which those models are able to incorporate process knowledge that extends beyond the often limited historical record (e.g., as is often done in using Bayesian-motivated approaches to consider severe event conditions that have not been observed). The following discussion describes how existing studies can be expanded to more explicitly consider a broader suite of process variables via development of graphical models (Bayesian networks) for several example applications.

Archetti et al. (2011) explored the effects of precipitation and sea level on the operations of a sewer system during storm events. In the study, flood severity was measured as the number of flooded nodes in the sewer network. The study involved a copula analysis of data from a tidal gage and a rain gage. Tidal gage data provided sea water levels at the sewer network outfall and included the effects of tides, storm surge, and wave setup. An analysis of a 1-year time series (69 rain events) containing rainfall and sea water levels was used to drive a simulation model. The statistical analysis contained in the paper developed a copula on the two flood mechanism variables (sea water level and precipitation quantity), and the simulation study estimated the flood severity metric (number of flooded nodes in the sewer system) as a result of changes in those two variables. Although the study included the statistical analysis of two variables associated with flood mechanisms and one variable representing a flood severity metric, other relevant variables related to flood-forcing phenomena and flood mechanisms were not explicitly modeled. For example, Figure 5-1a provides a graphical illustration of the flood-forcing phenomena and flood mechanisms that are applicable to the process of interest for Archetti et al. (2011). ${ }^{20}$ In Figure 5-1, shaded nodes represent the variables explicitly modeled by Archetti et al. (2011), and white nodes represent

\footnotetext{
${ }^{20}$ This graphical model was developed by the authors of the current report as an interpretation of the process modeled by Archetti et al. (2011) and does not represent the work or interpretation of Archetti et al. (2011).
} 
variables that are not explicitly included in their statistical assessment. Although the data series considered by Archetti et al. (2011) reflect the impacts of storms, the occurrence of storms and storm characteristics are not modeled. Similarly, although sea levels reflected in the tidal gage record used by Archetti et al. (2011) include the effects of tides, storm surge, and waves, the constituent impacts from tide, waves, and storm surge (and the resulting storm tide) are not individually or explicitly modeled. Figure 5-1b provides a simplified model reflecting only the variables included in the study.

Lian et al. (2012) explored the effects of rainfall and tide levels on flood severity (characterized by the ratio of the river's flood length to its total length). A data series was developed containing pairwise observations of the annual maxima 24 hour rainfall and the coincident highest sea level during the day on which the annual maxima occurred. ${ }^{21}$ A copula was fit to the data series to develop a joint distribution. Additionally, a hydrodynamic model was developed that predicted flood severity as a function of rainfall and tidal levels. In particular, rainfall amounts were translated into model inflow boundary conditions (rainfall runoff hydrographs), and sea levels were translated into outlet boundary conditions. Once again, although Lian et al. (2012) included the statistical analysis of two variables associated with flood mechanisms and one variable representing a flood severity metric, other relevant variables related to flood-forcing phenomena and flood mechanisms were not explicitly modeled. Figure 5-2a provides a graphical illustration of the flood-forcing phenomena and flood mechanisms applicable to the process of interest in Lian et al. (2012). ${ }^{22}$ For example, although the data series considered in Lian et al. (2012) reflects typhoon impacts, the occurrence of typhoons and their associated characteristics were not modeled. Similarly, although sea levels reflected in the tidal gage record used by Lian et al. (2012) included the effects of tides and storm surge, constituent impacts from tide and storm surge were not individually modeled.

Although Archetti et al. (2011) and Lian et al. (2012) (and other cited literature; see Section 4) focus on modeling a subset of variables involved in processes leading to both precipitation and coastal flooding hazards, some works explicitly consider a broader suite of variables. For example, Bass and Bedient (2018) developed a surrogate model for estimating inundation levels as a function of tropical cyclone parameters in considering the contribution from rainfall runoff and storm surge (and associated interactions). In the study, high-fidelity simulations of storm surges and waves were coupled with inland hydraulic and hydrologic models to estimate inundation levels (output) as a function of tropical cyclone parameters (input). Input-output pairs were then used to train a surrogate model capable of predicting inundation levels as a function of tropical cyclone characteristics. The graphical representations of the quantities explicitly modeled in the numerical model are shown in Figure 5-3a, and the quantities explicitly modeled in the simplified surrogate model are shown in Figure 5-3b. Although the trained surrogate model provides a direct mapping between tropical cyclone characteristics and inundation levels, it can only implicitly capture the effects of multiple flood mechanisms (rainfall runoff, waves, storm surge, sea level) because it does not use input or generate output related to these quantities.

\footnotetext{
${ }^{21}$ Lian et al. (2012) refers to "tidal levels" rather than "sea levels." "Sea level" is used here because the authors of the current report have interpreted the water levels recorded by gages used in Lian et al. (2012) as containing the effects of tide as well as storm-induced surge and waves.

${ }^{22}$ This graphical model was developed by the authors of the current report as an interpretation of the process modeled by Lian et al. (2012) and does not represent the work or interpretation of Lian et al. (2012). Conventions regarding shading of nodes in Figure 5-2 remain consistent with those used previously in Figure 5-1.
} 


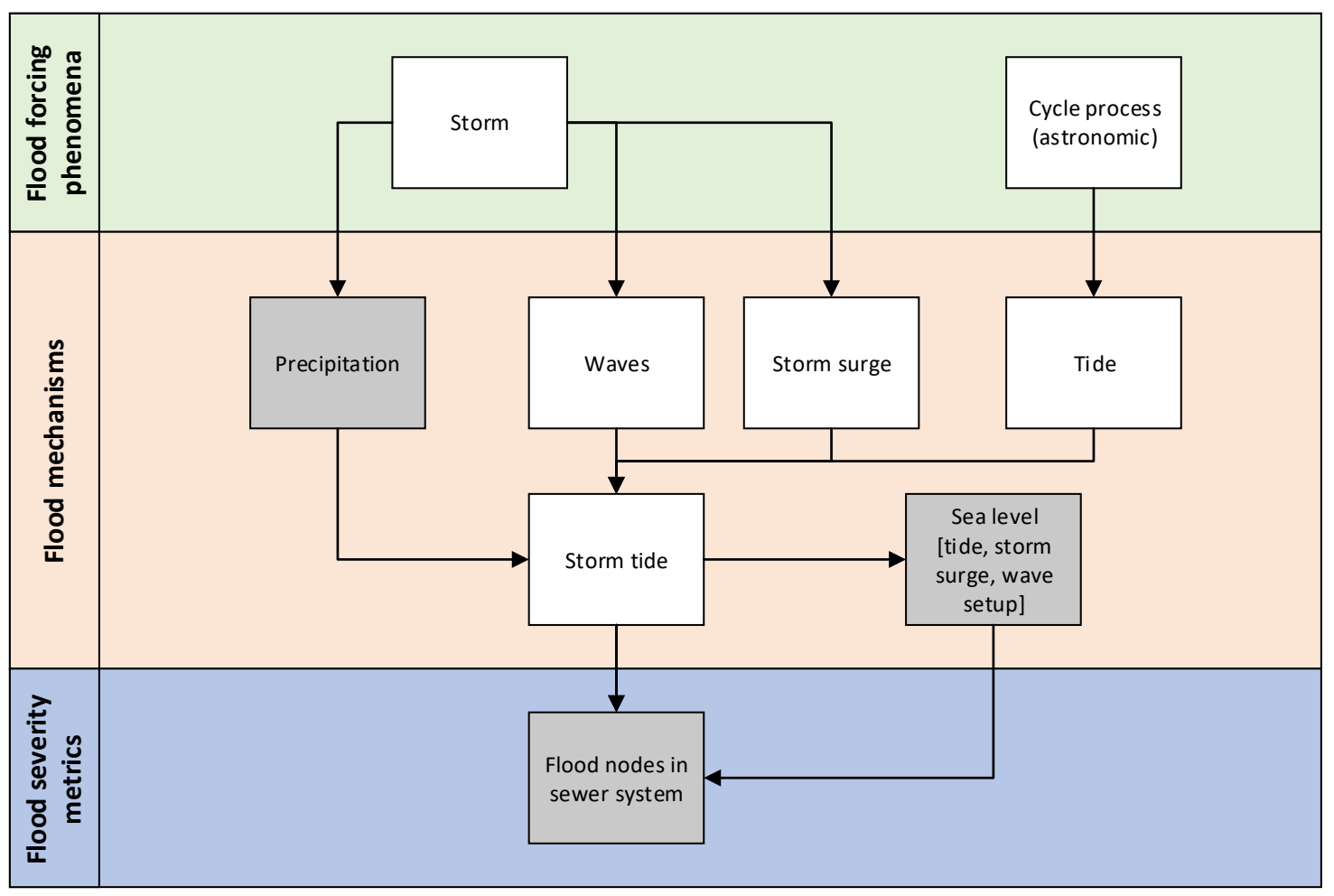

(a)

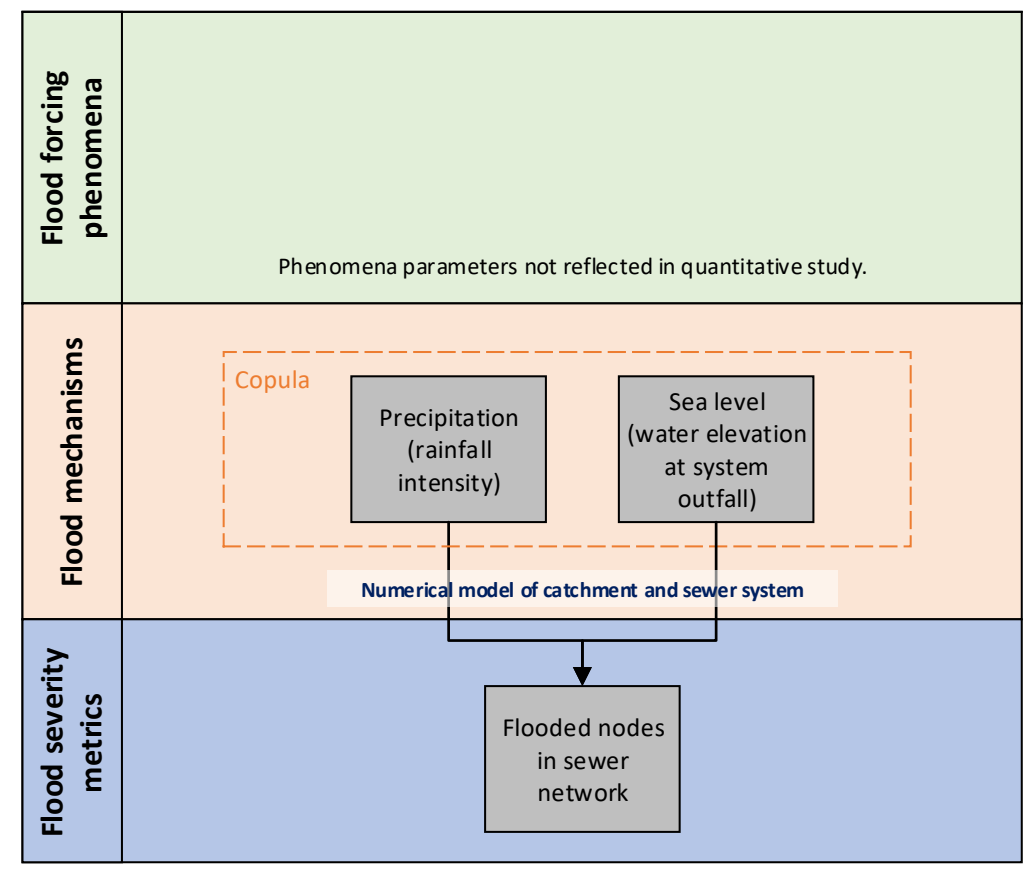

(b)

Figure 5-1. (a) Graphical model representing the process considered in Archetti et al. (2011). (b) Graphical model presenting variables included in model developed in Archetti et al. (2011). 


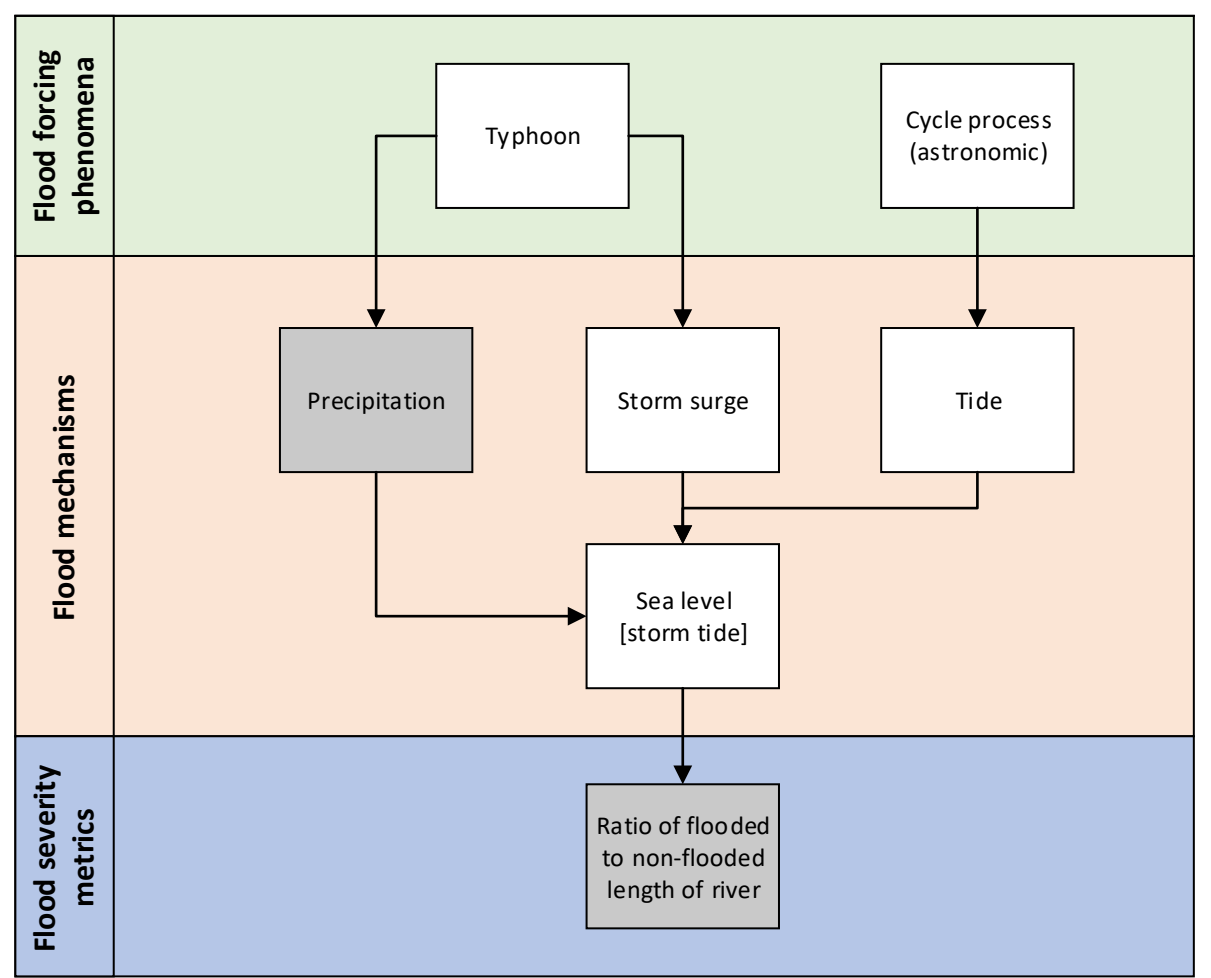

(a)

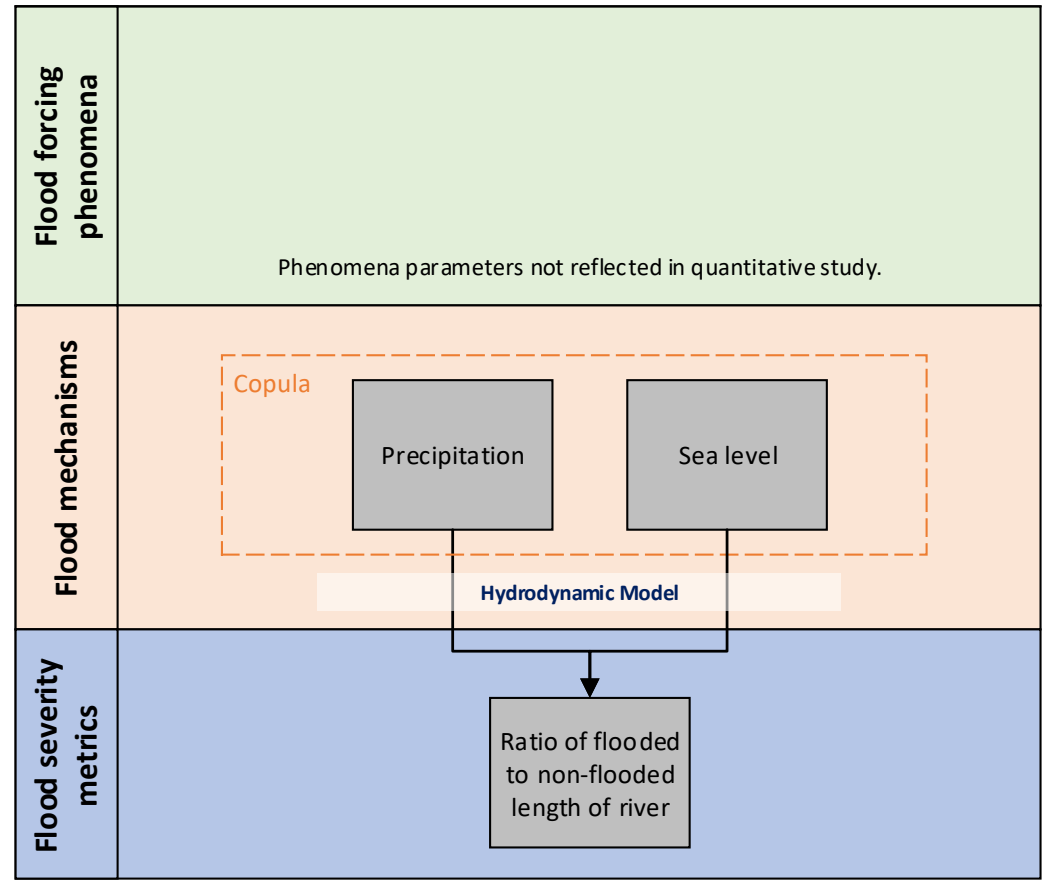

(b)

Figure 5-2. (a) Graphical model representing the process considered in Lian et al. (2012). (b) Graphical model presenting variables included in model developed in Lian et al. (2012). 


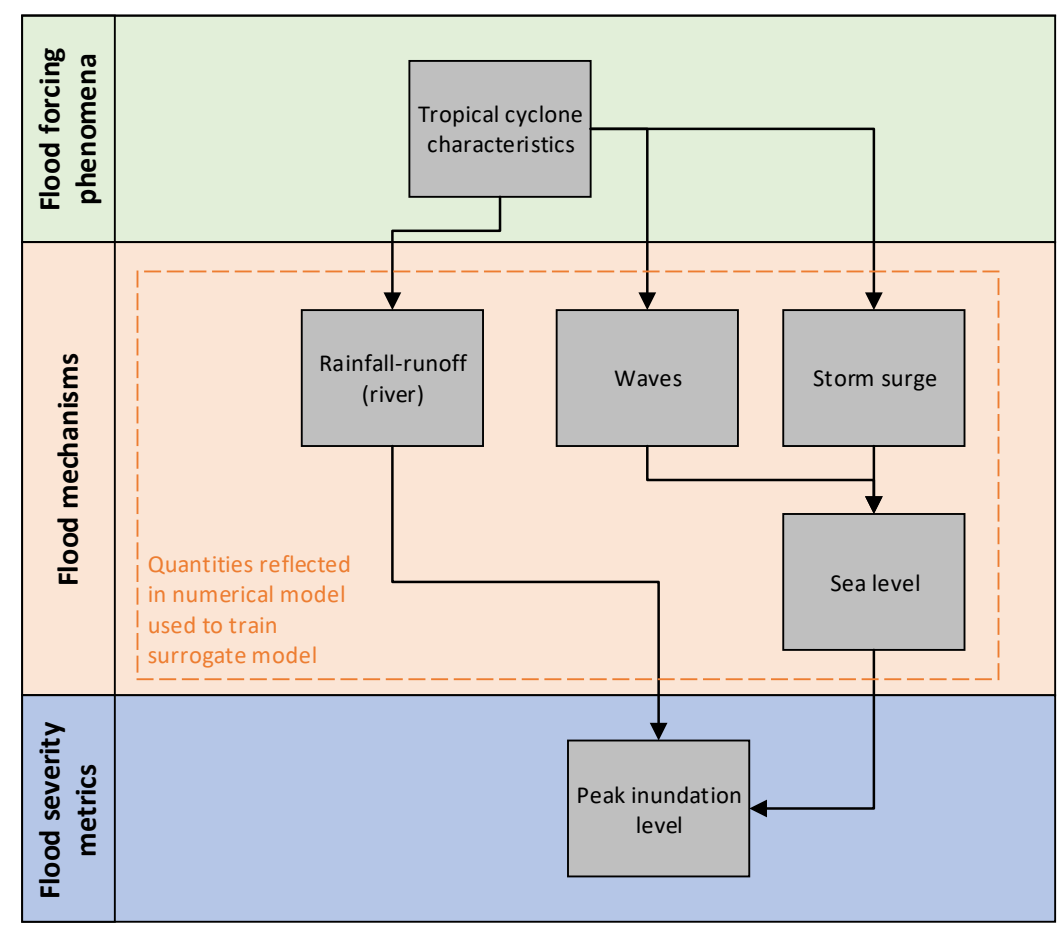

(a)

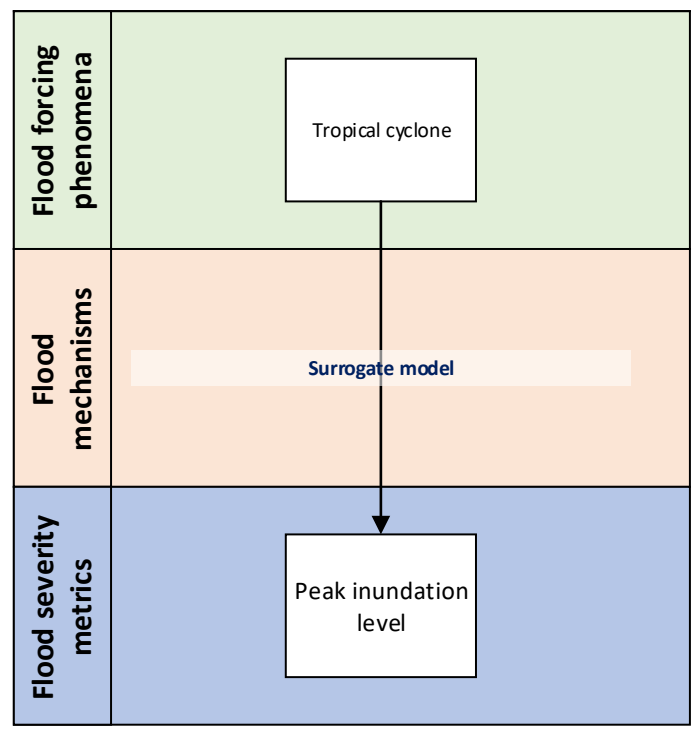

(b)

Figure 5-3. (a) Graphical model representing the process considered in Bass and Bedient (2018). (b) Graphical model presenting variables included in model developed in Bass and Bedient (2018)..

\subsubsection{Temporal Non-Stationarities}

Projected variations in climate and accelerated SLR, as well as changes in weather patterns due to global warming, may also affect the dependence among variables involved in MMF assessment. Explicit consideration of these factors requires a non-stationary framework for probabilistic assessment of MMFs. 
Wahl et al. (2015) demonstrated the existence of non-stationarity in the dependence between storm surge and precipitation for the contiguous United States and recommended MMF assessment in a non-stationary framework with linkages to the changing weather and climate. Moftakhari et al. (2017) quantified the increased probability of coastal inundation for 2030 and 2050 due to SLR and concluded that future SLR would exacerbate compound flood events. Kew et al. (2013) investigated the simultaneous occurrence of storm surge and river discharge for both current and future climate scenarios. Tebaldi et al. (2012) considered SLR through 2050 and investigated SLR impacts on storm surges along US coasts. The study showed that floods with only a $1 \%$ chance of annual occurrence currently will occur more frequently in the future. 


\section{SUMMARY AND NEXT STEPS}

This report provides a critical review of the current state of practice, with particular emphasis on assessing research and applied guidance from the perspective of NPP applicability. This report also provides background context regarding key components of PFHA and related mathematical formulations necessary to assess MMFs. The content of this report will later be incorporated when the full project results are documented in the form of an NRC NUREG/CR report. The following content highlights some of the key considerations for PFHA applications and next steps in the research project.

\subsection{CONSIDERATIONS FOR PROBABILISTIC FLOOD HAZARD ASSESSMENT APPLICATIONS}

Overall, the following three MMF-related considerations are needed for future PFHA applications.

- Site-specific nature of MMF assessment: Numerous studies were identified and reviewed as part of this project, many of which were highly site- or application-specific. The site-specific nature of existing studies means that quantitative conclusions from those studies may not be directly generalizable or applicable to other locations. Moreover, the range of hazards and geographic regions considered in the existing literature - as well as the diversity of flood-forcing phenomena, flooding mechanisms, and flood severity metrics considered in those studies-leads to challenges in drawing broad conclusions regarding specific relationships of interest to MMFs. Given the varying geographical, geological, hydrological, and climatic characteristics, each site is likely to be controlled by different flood-forcing phenomena and mechanisms and may need specific metrics. Nonetheless, the existing studies provide information regarding useful modeling approaches and tool sets for performing probabilistic MMF assessments.

- Choice of joint probability method: Based on insights from the existing literature, PFHA applications for MMF assessment may prioritize the use of copula-based and Bayesian-motivated approaches using both empirical and synthetic (simulation-derived) data sources. In particular, copula-based approaches are the most common approaches used in existing studies for the development of joint distributions. Although copulas provide numerous computational advantages (particularly their flexibility for accommodating a range of marginal distribution and dependency structures, as well as their relative ease of application), they have challenges. In particular, copulas are typically used to perform statistical analysis of empirical data, which is generally not directly associated with physical process considerations. Moreover, as with any statistically based approach (including direct estimation of parametric marginal and joint distributions), use of a copula-based approach requires that numerous modeling assumptions be made. These assumptions include decisions associated with processing of data, selection of marginal distributions, measures of dependence, and copula functional form, as well as parameter estimation techniques. These decisions can lead to important sources of epistemic uncertainty, the importance of which generally increases when long return periods are considered. Bayesian approaches provide a means of incorporating physical process knowledge through probabilistic, numerical, and other models.

- Data sufficiency and expansion through model simulation: In light of limited data and the potential for nonlinearities in physical processes when the severe events associated with long return periods are considered, an increased need exists to consider physical process knowledge in the probabilistic assessment of MMFs for NPPs. Data sufficiency is one main challenge of the univariate probabilistic assessment, and its importance is further highlighted given that long-term, multivariate observations will be needed to capture both the individual distributions and their dependence structures. When a situation allows, either physics- or surrogate-based models may be used to 
synthesize a large number of correlated variables to support further PFHA analysis. Bayesianmotivated approaches provide a structure for incorporating such knowledge into the probabilistic assessment. However, Bayesian approaches have not been broadly considered in existing studies related specifically to MMFs, although they have been used in probabilistic hazard assessments within other contexts. Therefore, their use in this project will represent an expansion of existing methods. Given the return periods of relevance to NPPs (which extend beyond those considered in most studies), further project activities will need to address several issues that have not been a focus of the majority of existing studies. These issues include the potential implications of the length of record and characteristics of available data series, assumptions regarding the occurrence of extrema, statistical modeling choices, and model validations for severe events.

\subsection{NEXT STEPS}

The information contained in this report serves as a foundation for subsequent project-related research activities, which will focus on the development of example case studies to illustrate best practices for quantifying probabilistic MMF hazards. Given the considerations provided in Section 6.1, these example case studies are expected to leverage empirical data and expanded, synthetic data generated from physical or surrogate modeling applications. Probabilistic models will be built using Bayesian-motivated and copula-based approaches. Copulas may be used directly to develop joint distributions on parameters of interest, or they may be used to build joint distributions that serve as input to a synthetic data generator or as part of a broader Bayesian model. Based on insights from this report's current state of practice review for MMF assessment, a work plan will be developed for performing example case studies.

Among others, the selection of scenarios and approaches is most critical. Presently, two scenarios are being considered for further study:

- Rain-on-snow events causing fluvial and pluvial flooding

- Storm surge and river flow causing fluvial, pluvial, and coastal flooding

The first scenario is motivated by the relevance to NPPs and the gap existing in the literature regarding rain-on-snow studies. However, the second case study is not associated with the scarcity of available studies. In fact, the literature gives much attention to MMFs caused by storm surge, river flow, and precipitation. Therefore, these case studies will use methods that are more mature, but which may not address all issues of relevance to NPPs. Consequently, data extensions and expansions will be needed to address the issues and range of return periods of relevance to NPPs and will be further explored in the future case studies. 


\section{REFERENCES}

Ang, A. H.-S., and Tang, W. H. (1984). Probability Concepts in Engineering Planning and Design, Vol. 2: Decision, Risk, and Reliability. John Wiley \& Sons Inc, New York.

Ang, A. H.-S., and Tang, W. H. (2007). Probability Concepts in Engineering: Emphasis on Applications to Civil and Environmental Engineering, 2nd Edition. John Wiley \& Sons.

ANS/ANSI. (1977). American National Standard - Standards for Determining Design Basis Flooding at Power Reactor Sites. ANSI ; N170-1976, The Society, La Grange Park, Ill.

ANSI/ANS. (1992). Determining Design Basis Flooding at Power Reactor Sites.

Archetti, R., Bolognesi, A., Casadio, A., and Maglionico, M. (2011). "Development of flood probability charts for urban drainage network in coastal areas through a simplified joint assessment approach." Hydrology and Earth System Sciences, 15(10), 3115-3122.

ASME/ANS. (2009). Addenda to ASME/ANS RA-S-2008 Standard for Level 1/Large Early Release Frequency Probabilistic Risk Assessment for Nuclear Power Plant Applications. American Nuclear Society, American Society of Mechanical Engineers, New York.

Baker, J. (2008). "An Introduction to Probabilistic Seismic Hazard Analysis (PSHA), Ver. 1.3."

Balakrishnan, N., and Lai, C. D. (2009). Continuous bivariate distributions. Springer, Dordrecht; New York.

Ball, J., Babister, M., Nathan, R., Weeks, W., Weinmann, E., Retallick, M., and Testoni, I. (2019). Australian Rainfall and Runoff: A Guide to Flood Estimation. Commonwealth of Australia (Geoscience Australia).

Bass, B., and Bedient, P. (2018). "Surrogate modeling of joint flood risk across coastal watersheds." Journal of Hydrology, 558, 159-173.

Bastian, K., Yeshewatesfa, H., and Schumann, A. (2010). "Probability Analysis of Hydrological Loads for the Design of Flood Control Systems Using Copulas." Journal of Hydrologic Engineering, 15(5), 360-369.

Bender, J., Wahl, T., Müller, A., and Jensen, J. (2016). "A multivariate design framework for river confluences." Hydrological Sciences Journal, 61(3), 471-482.

Benningfield, D. (2018). "Predicting Tides | Science and the Sea." <https://www.scienceandthesea.org/program/predicting-tides> (Accessed: Dec. 18, 2019).

Bensi, M., Der Kiureghian, A., and Straub, D. (2011). A Bayesian Network Methodology for Infrastructure Seismic Risk Assessment and Decision Support. Pacific Earthquake Engineering Research Center.

Bevacqua, E., Maraun, D., Hobæk Haff, I., Widmann, M., and Vrac, M. (2017). "Multivariate statistical modelling of compound events via pair-copula constructions: analysis of floods in Ravenna (Italy)." Hydrology and Earth System Sciences, 21(6), 2701-2723.

Bommier, E. (2014). "Peaks-Over-Threshold Modelling of Environmental Data." U.U.D.M. Project Report 2014:33.

Bücher, A., and Zhou, C. (2018). "A horse racing between the block maxima method and the peak-overthreshold approach." arXiv:1807.00282 [stat].

Bunya, S., Dietrich, J. C., Westerink, J. J., Ebersole, B. A., Smith, J. M., Atkinson, J. H., Jensen, R., Resio, D. T., Luettich, R. A., Dawson, C., Cardone, V. J., Cox, A. T., Powell, M. D., Westerink, H. J., and Roberts, H. J. (2010). "A High-Resolution Coupled Riverine Flow, Tide, Wind, Wind Wave, and Storm Surge Model for Southern Louisiana and Mississippi. Part I: Model Development and Validation." Monthly Weather Review, 138(2), 345-377.

Castellarin, A., Kohnova, S., Gaal, L., Fleig, A., Salinas, J. L., Toumazis, A., Kjeldsen, T. R., and Macdonald, N. (2012). "Review of applied-statistical methods for flood-frequency analysis in Europe." Publication - Report, <http://www.cost.eu/module/download/33272> (Jul. 22, 2019).

Chen, W.-B., and Liu, W.-C. (2014). "Modeling Flood Inundation Induced by River Flow and Storm Surges over a River Basin.” Water, 6(10), 3182-3199. 
Coles, S. (2001). An Introduction to Statistical Modeling of Extreme Values. Springer Series in Statistics, Springer-Verlag, London.

Coles, S. G., and Tawn, J. A. (1991). "Modelling Extreme Multivariate Events." Journal of the Royal Statistical Society. Series B (Methodological), 53(2), 377-392.

Coles, S. G., and Tawn, J. A. (1994). "Statistical Methods for Multivariate Extremes: An Application to Structural Design." Journal of the Royal Statistical Society. Series C (Applied Statistics), 43(1), $1-48$.

Corbella, S., and Stretch, D. D. (2013). "Simulating a multivariate sea storm using Archimedean copulas." Coastal Engineering, 76, 68-78.

Cunha, L. (2012). "Exploring the benefits of satellite remote sensing for flood prediction across scales." Iowa Research Online: https://ir.uiowa.edu/etd/2848.

De Michele, C., Salvadori, G., Passoni, G., and Vezzoli, R. (2007). "A multivariate model of sea storms using copulas." Coastal Engineering, 54(10), 734-751.

Der Kiureghian, A., and Ditlevsen, O. (2009). “Aleatory or epistemic? Does it matter?" Structural Safety, Risk Acceptance and Risk Communication, 31(2), 105-112.

Diermanse, F. L. M., and Geerse, C. P. M. (2012). "Correlation models in flood risk analysis." Reliability Engineering \& System Safety, ESREL 2010, 105, 64-72.

Engineers Australia. (2015). "Project 18 - Australian Rainfall and Runoff." <http://arr.ga.gov.au/revisionprojects/project-list/projects/project-18> (Jan. 24, 2019).

England, J. F., Cohn, T. A., Faber, B. A., Stedinger, J. R., Thomas Jr., W. O., Veilleux, A. G., Kiang, J. E., and Mason Jr., R. R. (2018). Guidelines for determining flood flow frequency-Bulletin 17C. Techniques and Methods, USGS Numbered Series, U.S. Geological Survey, Reston, VA, 168.

EPRI. (2015). Identification of External Hazards for Analysis in Probabilistic Risk Assessment. Electrical Power Research Institute.

FEMA. (2005a). "Wave Setup, Runup, and Overtopping." Guidelines and Specifications for Flood Hazard Mapping Partners.

FEMA. (2005b). FEMA Coastal Flood Hazard Analysis and Mapping Guidelines Focused Study Report Stillwater.

FEMA. (2014). "Emergency Management Institute (EMI) | AEMRC - Floodplain Management: Principles and Current Practices."

<https://training.fema.gov/hiedu/aemrc/courses/coursetreat/fm.aspx> (Jan. 18, 2019).

FEMA. (2015). "Coastal Wave Setup." Guidance for Flood Risk Analysis and Mapping, Federal Emergency Management Agency, Washington DC.

FEMA. (2016a). "Coastal Water Levels.” Guidance for Flood Risk Analysis and Mapping, Federal Emergency Management Agency, Washington DC.

FEMA. (2016b). "General Hydraulics Considerations." Guidance for Flood Risk Analysis and Mapping, Federal Emergency Management Agency, Washington DC.

FEMA. (2016c). "Hydraulics: One-Dimensional Analysis." Guidance for Flood Risk Analysis and Mapping, Federal Emergency Management Agency, Washington DC.

FEMA. (2016d). "Hydraulics: Two-Dimensional Analysis." Guidance for Flood Risk Analysis and Mapping, Federal Emergency Management Agency, Washington DC.

FEMA. (2016e). "Floodway Analysis and Mapping." Guidance for Flood Risk Analysis and Mapping, Federal Emergency Management Agency, Washington DC.

FEMA. (2016f). NDSP Biennial Report to Congress, Fiscal Years 2014-2015. Federal Emergency Management Agency, Washington DC.

FEMA. (2018a). "The National Flood Insurance Program | FEMA.gov." <https://www.fema.gov/nationalflood-insurance-program>.

FEMA. (2018b). "Guidelines and Standards for Flood Risk Analysis and Mapping | FEMA.gov." <https://www.fema.gov/guidelines-and-standards-flood-risk-analysis-and-mapping> (Accessed: Jan. 29, 2019). 
FEMA. (2018c). “Coastal Wave Runup and Overtopping.” Federal Emergency Management Agency, Washington DC.

FEMA. (2018d). "General Hydrologic Considerations." Guidance for Flood Risk Analysis and Mapping, Federal Emergency Management Agency, Washington DC.

FEMA. (2018e). "Ice-Jam Analyses and Mapping." Guidance for Flood Risk Analysis and Mapping, Federal Emergency Management Agency, Washington DC.

FEMA. (n.d.). "FEMA Common FAQ | FEMA.gov."

<https://www.fema.gov/faq?field_common_faq_keywords_value=Flood\%20Insurance\%20Maps $\% 20 \% 26 \% 20$ Information\&items_per_page $=40 \&$ page $=1>$ (Accessed: Dec. 4, 2019).

Galloway, G. E., Reilly, A., Ryoo, S., Riley, A., Haslam, Brody, S., Highfield, W., Gunn, J., Rainey, J., and Parker, S. (2018). The Growing Threat of Urban Flooding: A National Challenge.

Genest, C., and Favre, A.-C. (2007). "Everything You Always Wanted to Know about Copula Modeling but Were Afraid to Ask." Journal of Hydrologic Engineering, 12(4).

Gilja, G., Ocvirk, E., and Kuspilić, N. (2018). "Joint probability analysis of flood hazard at river confluences using bivariate copulas." Građevinar, 70(04), 267-275.

Griffis, V. W., and Stedinger, J. R. (2007). "Log-Pearson Type 3 Distribution and Its Application in Flood Frequency Analysis. I: Distribution Characteristics." Journal of Hydrologic Engineering, 12(5), 482-491.

Gumbel, E. J. (1958). Statistics of extremes. Columbia University Press, New York.

Haugh, M. (2016). "An Introduction to Copulas." < http://www.columbia.edu/ mh2078/QRM/Copulas.pdf>.

Hawkes, P. (2006). Use of Joint Probability Methods in Flood Management: A Guide to Best Practice. Defra - Flood Management Division, London.

Hawkes, P. J. (2008). "Joint probability analysis for estimation of extremes." Journal of Hydraulic Research, 46(sup2), 246-256.

Hawkes, P. J., Gonzalez-Marco, D., Sánchez-Arcilla, A., and Prinos, P. (2008). "Best practice for the estimation of extremes: A review." Journal of Hydraulic Research, 46(sup2), 324-332.

Hawkes, P. J., Gouldby, B. P., Tawn, J. A., and Owen, M. W. (2002). "The joint probability of waves and water levels in coastal engineering design." Journal of Hydraulic Research, 40(3), 241-251.

Hawkes, P., and Svensson, C. (2006). Joint Probability: Dependence Mapping and Best Practice: Technical report on dependence mapping. Defra - Flood Management Division, London.

IAEA. (1995). Treatment of External Hazards in Probabilistic Safety Assessment for Nuclear Power Plants: A Safety Practice. Safety Series Report, International Atomic Energy Agency, Vienna.

IAEA (2009), Safety Assessment for Facilities and Activities, General Safety Requirements No. GSR 4 (Rev. 1).

IAEA. (2010). Development and Application of Level 1 Probabilistic Safety Assessment for Nuclear Power Plants. Specific Safety Guide, International Atomic Energy Agency.

IAEA. (2011). Meteorological and Hydrological Hazards in Site Evaluation for Nuclear Installations. Specific Safety Guide, International Atomic Energy Agency, Vienna.

IAEA. (2016a). Site Evaluation for Nuclear Installations. Safety Requirements, International Atomic Energy Agency, Vienna.

IAEA (2016b), Safety Assessment for Facilities and Activities, General Safety Requirements No. GSR 4 (Rev. 1).

IAEA. (2018). Consideration of External Hazards in Probabilistic Safety Assessment for Single Unit and Multi-unit Nuclear Power Plants. Safety Series Report, International Atomic Energy Agency, Vienna.

Kao, S.-C., and Chang, N.-B. (2012). "Copula-Based Flood Frequency Analysis at Ungauged Basin Confluences: Nashville, Tennessee." Journal of Hydrologic Engineering, 17(7).

Kew, S. F., Selten, F. M., Lenderink, G., and Hazeleger, W. (2013). "The simultaneous occurrence of surge and discharge extremes for the Rhine delta." Natural Hazards and Earth System Sciences, 13(8), 2017-2029. 
Kjeldsen, T., Svensson, C., and Jones, D. (2010). "A joint probability approach to flood frequency estimation using Monte Carlo simulation.” Proceedings of the BHS Third International Symposium: Role of Hydrology in Managing Consequences of a Changing Global Environment, C. Kirby, ed., British Hydrological Society, Newcastle, 278-282.

Klerk, W. J., Winsemius, H. C., Verseveld, W. J. van, Bakker, A. M. R., and Diermanse, F. L. M. (2015). "The co-incidence of storm surges and extreme discharges within the Rhine-Meuse Delta." Environmental Research Letters, 10(3), 035005.

Knochenhauer, M., and Louko, P. (2003). Guidance for External Events Analysis. Swedish Nuclear Inspectorate (SKI.

Kowalik, Z., and Proshutinsky, A. (2010). "Tsunami-tide interactions: A Cook Inlet case study." Continental Shelf Research, Tides in Marginal Seas - A special issue in memory of Prof Alexei Nekrasov, 30(6), 633-642.

Langousis, A., and Veneziano, D. (2009). "Long-term rainfall risk from tropical cyclones in coastal areas." Water Resources Research, 45(11).

Leadbetter, M. R. (1983). "Extremes and local dependence in stationary sequences." Zeitschrift für Wahrscheinlichkeitstheorie und Verwandte Gebiete, 65(2), 291-306.

Leonard, M., Westra, S., Phatak, A., Lambert, M., Hurk, B. van den, McInnes, K., Risbey, J., Schuster, S., Jakob, D., and Stafford-Smith, M. (2014). "A compound event framework for understanding extreme impacts." Wiley Interdisciplinary Reviews: Climate Change, 5(1), 113-128.

Lian, J. J., Xu, K., and Ma, C. (2012). "Joint impact of rainfall and tidal level on flood risk in a coastal city with a complex river network: a case study for Fuzhou city, China." Hydrology and Earth System Sciences Discussions, 9(6), 7475-7505.

Lin, N., Smith, J. A., Villarini, G., Marchok, T. P., and Baeck, M. L. (2010). "Modeling Extreme Rainfall, Winds, and Surge from Hurricane Isabel (2003)." Weather and Forecasting, 25(5), 1342-1361.

Lonfat, M., Rogers, R., Marchok, T., and Marks, F. D. (2007). “A Parametric Model for Predicting Hurricane Rainfall." Monthly Weather Review, 135(9), 3086-3097.

Lu, C., Guo, S., Zenchao, H., and Tianyuan, L. (2012). "Flood Coincidence Risk Analysis Using Multivariate Copula Functions.” Journal of Hydrologic Engineering, 17(6), 742-755.

Lu, P., Lin, N., Emanuel, K., Chavas, D., and Smith, J. (2018). “Assessing Hurricane Rainfall Mechanisms Using a Physics-Based Model: Hurricanes Isabel (2003) and Irene (2011).” Journal of the Atmospheric Sciences, 75(7), 2337-2358.

Maddox, I. (2014). "Three Common Types of Flood Explained." <https://www.intermap.com/risks-ofhazard-blog/three-common-types-of-flood-explained> (Accessed: Jan. 17, 2019).

Madsen, H., Rasmussen, P. F., and Rosbjerg, D. (1997). "Comparison of annual maximum series and partial duration series methods for modeling extreme hydrologic events: 1. At-site modeling." Water Resources Research, 33(4), 747-757.

Mantilla, R., and Gupta, V. K. (2005). "A GIS numerical framework to study the process basis of scaling statistics in river networks.” IEEE Geoscience and Remote Sensing Letters, 2(4), 404-408.

Martyr, R. C., Dietrich, J. C., Westerink, J. J., Kerr, P. C., Dawson, Smith, J. M., Pourtaheri, H., Powell, N., Van Ledden, M., Tanaka, S., Roberts, H. J., Westerink, H. J., and Westerink, L. G. (2013). "Simulating Hurricane Storm Surge in the Lower Mississippi River under Varying Flow Conditions." Journal of Hydraulic Engineering, 139(5), 492-501.

Masina, M., Lamberti, A., and Archetti, R. (2015). "Coastal flooding: A copula based approach for estimating the joint probability of water levels and waves." Coastal Engineering, 97, 37-52.

Moftakhari, H. R., Salvadori, G., AghaKouchak, A., Sanders, B. F., and Matthew, R. A. (2017). "Compounding effects of sea level rise and fluvial flooding." Proceedings of the National Academy of Sciences, 114(37), 9785-9790.

Nelsen, R. B. (1994). "A Characterization of Farlie-Gumbel-Morgenstern Distributions via Spearman's RHO and Chi-Square Divergence." Sankhyā: The Indian Journal of Statistics, Series A (19612002), 56(3), 476-479. 
Nelsen, R.B. (1999). An Introduction to Copulas, Springer-Verlag, New York.

Nelsen, R. B. (2002). Properties and Applications of Copulas: A Brief Survey. < http://w4.stern.nyu.edu/ioms/docs/sg/seminars/nelsen.pdf >.

NOAA. (2006). NOAA Atlas 14: Precipitation-Frequency Atlas of the United States (Volume 2). National Oceanic and Atmospheric Administration.

NOAA. (2018). "Vertical Datums | Datums | National Geodetic Survey."

<https://www.ngs.noaa.gov/datums/vertical/> (Accessed: Dec. 18, 2019).

NOAA. (2019). “A tutorial on Datums." Vertical Datums Transformation, $<$ https://vdatum.noaa.gov/docs/datums.html> (Accessed:. 18, 2019).

NOAA. (n.d.-a). “Tides and Water Levels: What are Tides?" NOAA's National Ocean Service Education, $<$ https://oceanservice.noaa.gov/education/tutorial_tides/tides01_intro.html> (Accessed: Dec. 18, 2019).

NOAA. (n.d.-b). “The Battery, NY - Station ID: 8518750.” NOAA Tides \& Currents, <https://tidesandcurrents.noaa.gov/stationhome.html?id=8518750> (Accessed: Dec. 18, 2019).

NOAA. (n.d.-c). "Storm Surge Overview." <https://www.nhc.noaa.gov/surge/> (Accessed: Aug. 15, 2019).

NOAA. (n.d.-d). "NOAA Tides \& Currents - Tidal Datums." <https://tidesandcurrents.noaa.gov/datum_options.html> (Accessed: Dec. 17, 2019).

NOAA NHC. (2016). "The Alphabet Soup of Vertical Datums: Why MHHW is Mmm Mmm Good." Inside the Eye, Official Blog of the National Hurricane Center, $<$ https://noaanhc.wordpress.com/2016/01/29/the-alphabet-soup-of-vertical-datums-why-mhhw-ismmm-mmm-good/> (Dec. 18, 2019).

NOAA NHC. (n.d.). "Introduction to Storm Surge." $<$ https://www.nhc.noaa.gov/surge/surge_intro.pdf $>$ (Accessed: Dec. 18, 2019).

NTSLF. (2019). "Skew surges.” National Tidal and Sea Level Facility (NTSLF), <https://www.ntslf.org/storm-surges/skew-surges> (Accessed: Dec. 18, 2019).

Orton, P. M., Conticello, F. R., Cioffi, F., Hall, T. M., Georgas, N., Lall, U., Blumberg, A. F., and MacManus, K. (2018). "Flood hazard assessment from storm tides, rain and sea level rise for a tidal river estuary." Natural Hazards.

Orton, P. M., Hall, T. M., Talke, S. A., Blumberg, A. F., Georgas, N., and Vinogradov, S. (2016). “A validated tropical-extratropical flood hazard assessment for New York Harbor." Journal of Geophysical Research: Oceans, 121(12), 8904-8929.

Ozga-Zielinski, B., Ciupak, M., Adamowski, J., Khalil, B., and Malard, J. (2016). "Snow-melt flood frequency analysis by means of copula based 2D probability distributions for the Narew River in Poland." Journal of Hydrology: Regional Studies, 6, 26-51.

Papaioannou, G., Kohnová, S., Bacigál, T., Szolgay, J., Hlavčová, K., and Loukas, A. (2016). “Joint modelling of flood peaks and volumes: A copula application for the Danube River." Journal of Hydrology and Hydromechanics, 64(4), 382-392.

Petroliagkis, T. I. (2018). "Estimations of statistical dependence as joint return period modulator of compound events - Part 1: Storm surge and wave height." Natural Hazards and Earth System Sciences, 18(7), 1937-1955.

Petroliagkis, T. I., Voukouvalas, E., Disperati, J., and Bidlot, J. (2016). Joint Probabilities of Storm Surge, Significant Wave Height and River Discharge Components of Coastal Flooding Events; Utilising statistical dependence methodologies \& techniques. JRC Technical Reports.

Reguero, B. G., Menéndez, M., Méndez, F. J., Mínguez, R., and Losada, I. J. (2012). "A Global Ocean Wave (GOW) calibrated reanalysis from 1948 onwards." Coastal Engineering, 65, 38-55.

Serafin, K. A., and Ruggiero, P. (2014). "Simulating extreme total water levels using a time-dependent, extreme value approach." Journal of Geophysical Research: Oceans, 119(9), 6305-6329.

Serafin, K. A., Ruggiero, P., Parker, K., and Hill, D. F. (2019). "What's streamflow got to do with it? A probabilistic simulation of the competing oceanographic and fluvial processes driving extreme along-river water levels." Natural Hazards and Earth System Sciences, 19(7), 1415-1431. 
Sui, J., and Koehler, G. (2001). "Rain-on-snow induced flood events in Southern Germany." Journal of Hydrology, 252(1), 205-220.

Svensson, C., and Jones, D. A. (2002). "Dependence between extreme sea surge, river flow and precipitation in eastern Britain." International Journal of Climatology, 22(10).

Svensson, C., and Jones, D. A. (2004). "Dependence between sea surge, river flow and precipitation in south and west Britain." Hydrology and Earth System Sciences, 8(5), 973-992.

Svensson, C., and Jones, D. A. (2006). Joint Probability: Dependence between extreme sea surge, river flow and precipitation: A study in south and west Britain. Defra - Flood Management Division.

Tebaldi, C., Strauss, B. H., and Zervas, C. E. (2012). "Modelling sea level rise impacts on storm surges along US coasts." Environmental Research Letters, 7(1), 014032.

Toro, G. R. (2008). Joint Probability Analysis of Hurricane Flood Hazards for Mississippi, Final report in support of the FEMA-HMTAP flood study of the State of Mississippi (Rev. 1).

Toro, G. R., Resio, D. T., Divoky, D., Niedoroda, A. Wm., and Reed, C. (2010). "Efficient jointprobability methods for hurricane surge frequency analysis." Ocean Engineering, A Forensic Analysis of Hurricane Katrina's Impact: Methods and Findings, 37(1), 125-134.

Torres, J. M., Bass, B., Irza, N., Fang, Z., Proft, J., Dawson, C., Kiani, M., and Bedient, P. (2015). "Characterizing the hydraulic interactions of hurricane storm surge and rainfall-runoff for the Houston-Galveston region." Coastal Engineering, 106, 7-19.

Tyler, R., Emilia, S., Antonia, S., and Bedient, P. (2011). "Dynamic Modeling of Storm Surge and Inland Flooding in a Texas Coastal Floodplain." Journal of Hydraulic Engineering, 137(10), 11031110.

USACE. (1993). Engineering and Design - Hydrologic Frequency Analysis. U.S. Army Corps of Engineers.

USACE. (1995). Engineering and Design - Hydrologic Engineering Requirements for Flood Damage Reduction Studies. U.S. Army Corps of Engineers.

USACE. (2008). Director's Policy Memorandum Civil Works Programs. U.S. Army Corps of Engineers.

USACE. (2015). "North Atlantic Coast Comprehensive Study." <http://www.nad.usace.army.mil/CompStudy.aspx> (Dec. 29, 2017).

USACE. (2018). Engineering and Design - Hydrologic Analysis of Interior Areas. U.S. Army Corps of Engineers.

USBR. (2017). "Dam Safety Office | Security, Safety and Law Enforcement Office | Bureau of Reclamation." <https://www.usbr.gov/ssle/damsafety/risk/methodology.html> (Jan. 29, 2019).

USBR, and USACE. (2017). "Dam Safety Risk Analysis Best Practices Training Manual." US Bureau of Reclamation, US Army Corps of Engineers, Denver and Washington, DC.

USGS. (2018). "PeakFQ - Flood-Frequency Analysis." < https://water.usgs.gov/software/PeakFQ/> (Dec. 3, 2019).

USNRC. (1977). Regulatory Guide 1.59 - Design Basis Floods for Nuclear Power Plants.

USNRC. (2007a). "NRC: Standard Review Plan for the Review of Safety Analysis Reports for Nuclear Power Plants: LWR Edition - Site Characteristics and Site Parameters (NUREG-0800, Chapter 2)." $<$ https://www.nrc.gov/reading-rm/doc-collections/nuregs/staff/sr0800/ch2/> (Jan. 17, 2019).

USNRC. (2007b). NRC: Standard Review Plan for the Review of Safety Analysis Reports for Nuclear Power Plants: LWR Edition - Site Characteristics and Site Parameters (NUREG-0800, Chapter 2).

USNRC. (2011). Design-Basis Flood Estimation for Site Characterization at Nuclear Power Plants in the United States of America (NUREG/CR-7046).

USNRC. (2012). Guidance for Performing the Integrated Assessment for External Flooding.

USNRC. (2014). Probabilistic Flood Hazard Assessment Research Plan.

USNRC. (2018a). Strategic Plan, Fiscal Years 2018-2022.

USNRC. (2018b). "Plant-Specific Japan Lessons-Learned Activities." <https://www.nrc.gov/reactors/operating/ops-experience/japan-dashboard/japan-plants.html> (Accessed: Aug. 29, 2019). 
USNRC. (2018c). Federal Register Notice: Proposed Revisions to Standard Review Plan Section 2.4.6, Tsunami Hazards; Section 2.4.9, Channel Migration or Diversion; and Section 2.3.3, Onsite Meteorological Measurements Program. NRC-2018-0176, 49132-49138.

van den Hurk, B., van Meijgaard, E., de Valk, P., van Heeringen, K.-J., and Gooijer, J. (2015). “Analysis of a compounding surge and precipitation event in the Netherlands." Environmental Research Letters, 10(3), 035001.

Vitousek, S., Barnard, P. L., Fletcher, C. H., Frazer, N., Erikson, L., and Storlazzi, C. D. (2017). "Doubling of coastal flooding frequency within decades due to sea-level rise." Scientific Reports, 7(1), 1399.

Wadey, M. P., Brown, J. M., Haigh, I. D., Dolphin, T., and Wisse, P. (2015). “Assessment and comparison of extreme sea levels and waves during the 2013/14 storm season in two UK coastal regions." Natural Hazards and Earth System Sciences, 15(10), 2209-2225.

Wahl, T., Jain, S., Bender, J., Meyers, S. D., and Luther, M. E. (2015). "Increasing risk of compound flooding from storm surge and rainfall for major US cities." Nature Climate Change, 5(12), $1093-1097$.

Wang, C. (2016). "A joint probability approach for coincidental flood frequency analysis at ungauged basin confluences." Natural Hazards, 82(3), 1727-1741.

Wang, C., Chang, N.-B., and Yeh, G.-T. (2009). "Copula-based flood frequency (COFF) analysis at the confluences of river systems." Hydrological Processes, 23(10), 1471-1486.

Ward, P. J., Couasnon, A., Eilander, D., Haigh, I. D., Hendry, A., Muis, S., Veldkamp, T. I. E., Winsemius, H. C., and Wahl, T. (2018). "Dependence between high sea-level and high river discharge increases flood hazard in global deltas and estuaries." Environmental Research Letters, 13(8), 084012.

Xu, K., Ma, C., Lian, J., and Bin, L. (2014). "Joint Probability Analysis of Extreme Precipitation and Storm Tide in a Coastal City under Changing Environment." PLOS ONE, 9(10), e109341.

Yue, S. (2001). "A bivariate gamma distribution for use in multivariate flood frequency analysis." Hydrological Processes, 15(6), 1033-1045.

Yue, S., Ouarda, T. B. M. J., Bobée, B., Legendre, P., and Bruneau, P. (1999). “The Gumbel mixed model for flood frequency analysis." Journal of Hydrology, 226(1), 88-100.

Zhang, L., and Singh, V. P. (2006). "Bivariate Flood Frequency Analysis Using the Copula Method." Journal of Hydrologic Engineering, 11(2), 150-164.

Zhang, Y. J., Witter, R. C., and Priest, G. R. (2011). "Tsunami-tide interaction in 1964 Prince William Sound tsunami." Ocean Modelling, 40(3), 246-259.

Zheng, F., Westra, S., Leonard, M., and Sisson, S. A. (2014). "Modeling dependence between extreme rainfall and storm surge to estimate coastal flooding risk." Water Resources Research, 50(3), 2050-2071.

Zheng, F., Westra, S., and Sisson, S. A. (2013). "Quantifying the dependence between extreme rainfall and storm surge in the coastal zone." Journal of Hydrology, 505, 172-187.

Zhong, H., van Overloop, P.-J., and van Gelder, P. H. A. J. M. (2013). “A joint probability approach using a 1-D hydrodynamic model for estimating high water level frequencies in the Lower Rhine Delta." Natural Hazards and Earth System Sciences, 13(7), 1841-1852. 
APPENDIX A. SUMMARY OF CURRENT US AND INTERNATIONAL MULTI-MECHANISM FLOOD ASSESSMENT PRACTICE 



\section{APPENDIX A. SUMMARY OF CURRENT US AND INTERNATIONAL MMF ASSESSMENT PRACTICE}

This appendix describes the current practice for estimation of hazards from combinations of flood mechanisms, as defined in existing guidance and standards used by the nuclear industry, and summarizes guidance and documents used by federal agencies in the United States. The current practice in this field generally focuses on single-mechanism flood hazard assessments, and although some documentation acknowledges MMF hazards, it generally lacks analytical frameworks and guidance for MMF assessment. Additionally, much of the existing documentation focuses on deterministic approaches rather than probabilistic approaches for flood hazard assessment.

Although the existing guidance and standards referenced in this appendix use varying terminology, the following sections use the terminology described in the main body of this report to maintain consistency across the literature.

\section{A.1 NUCLEAR APPLICATIONS}

\section{A.1.1 NRC GUIDANCE AND STANDARDS}

For US commercial nuclear power facilities, Regulatory Guide 1.59 (RG 1.59), "Design-Basis Floods for Nuclear Power Plants" (USNRC 1977), describes the design basis floods that NPPs should be designed to withstand. In turn, RG 1.59 endorses (with limited exceptions) the ANS/ANSI Standard N170-1976, "American National Standard for Determining Design Basis Flooding at Power Reactor Sites" (ANS/ANSI 1977). An update to N170-1976 (identified as ANS/ANSI-2.8-1992) was published in 1992 (ANSI/ANS 1992) and was subsequently withdrawn in 2002, consistent with normal publishing practices for standards. NRC staff is currently revising RG 1.59. To support efforts to update RG1.59, NRC issued NUREG/CR-7046, "Design-Basis Flood Estimation for Site Characterization at Nuclear Power Plants in the United States of America" in November 2011 (USNRC 2011). In addition to the regulatory guidance intended for use by applicants, the Standard Review Plan (SRP) provides guidance to NRC for the evaluation of analyses performed by applicants for commercial nuclear power facilities (USNRC 2007b). The SRP is currently being updated (USNRC 2018c).

The current guidance for flood hazard assessment used for siting of commercial NPPs in the United States (identified in the previous paragraph) remains primarily deterministic for the assessment of both individual and combinations of flood mechanisms. In the context of combinations of flooding mechanisms, ANS/ANSI-2.8-1992 and NUREG/CR-7046 identify deterministic scenarios that are deemed acceptable and sufficient for use in defining design bases at commercial nuclear facilities. These guidance documents adopt a deterministic, standards-based approach to flood hazard assessment that focuses on a limited number of prescribed scenarios involving combinations of mechanisms. Appendix $\mathrm{H}$ of NUREG/CR-7046 provides a summary of those combinations. The combinations outlined in the guidance documents include coincident combinations of flood mechanisms (e.g., a seismically induced dam failure coinciding with a river flood event), concurrent correlated flood mechanisms (e.g., concurrent river flooding and storm surge induced by a hurricane in estuary environments), and induced correlated flood mechanisms (e.g., precipitation leading to large inflow into a reservoir and subsequent hydrologic dam failure). For example, current NRC guidance specifies consideration of scenarios involving a probable maximum storm surge occurring along with a 25-year river flood. Although phenomenological origins are not explicitly specified in the guidance, such surge-river flooding scenarios may result from what the terminology of this report refers to as "coincident mechanisms" (e.g., the storm surge results from a hurricane, and the river flood results from an unrelated antecedent rain event) or "concurrent correlated mechanisms" (e.g., a hurricane leads to storm surge as well as precipitation-induced river flooding). Another example of a scenario considered in current NRC guidance is seismically induced dam 
failure coinciding with a 25 -year river flood. Given the necessarily independent nature of the floodforcing phenomena (i.e., earthquake and meteorological events), such scenarios result in coincident mechanisms. Although the combinations specific in these design basis guidance documents were thought to have a sufficiently small frequency of occurrence or exceedance, this conclusion had been based on judgement rather than rigorous quantitative assessment.

\section{A.1.2 INTERNATIONAL GUIDANCE AND STANDARDS}

The International Atomic Energy Agency (IAEA) standards for the siting of nuclear installations are in Safety Requirements Standard No. NS-R-3 (IAEA 2016a). General Criterion 2.5 specifies that proposed sites "shall be evaluated with regard to the frequency and severity of external natural and human induced events, and potential combinations of such events, that could affect the safety of the installation." Furthermore, Criteria 2.7 and 2.8 reference combinations of external hazard events in the context of selecting external hazard-specific parameters and ambient conditions for use in facility design. In the context of flooding, Criterion 3.20 specifies that combinations of effects from several causes (e.g., a combination of high tide, wind effects, and wave action) shall be assessed.

In addition to the criteria outlined in IAEA Safety Requirements Standard NS-R-3, Specific Safety Guide No. SSG-18 (IAEA 2011) outlines standards for the evaluation of meteorological and hydrologic hazards for nuclear installations. The document includes considerations associated with individual and combinations of flood mechanisms. Specific Safety Guide No. SSG-18 specifies that "combined events should be considered as well as the single events" in deriving the design-basis flood for a nuclear facility. Although the document provides limited commentary on the need to consider combinations of events, explicit guidance for performance of quantitative assessments is not provided. For example, the document notes that in considering combinations of events, although treating "all input parameters as random processes, with given autocorrelation and cross-correlation functions" is "desirable," simplified approaches may be used. The IAEA document discusses deterministic, probabilistic, and hybrid approaches at a high level but provides limited guidance relative to the quantitative assessment of combinations of flood mechanisms. For example, the document specifies that reasonable conservative values of the frequency of exceedance for a given level of severity, for a specific effect resulting from individual or combinations of events, should be estimated by considering the annual frequency of exceedance of the separate events and the likelihood that the events may occur together in combination.

Along with guidance related to siting and selecting plant design bases, combinations of flood mechanisms are also relevant in the context of probabilistic risk assessment (PRA), which is also referred to as probabilistic safety assessment (PSA). The ASME/ANS RA-S-2008 Standard for Level I PRA (ASME/ANS 2009) provides limited requirements related to considering combinations of external hazard events. Regarding combinations of flood mechanisms, no specific requirements address the topic in Part 8 (which addresses external flooding PRA) of the current version of the standard. However, the external flooding PRA scope specifies, "It is also important to consider rational probabilistic-based combinations of [flooding-causing] phenomena."

IAEA (2010) provides "recommendations for meeting the requirements of [the IAEA 2009 'Safety Assessment for Facilities and Activities,' IAEA Safety Standards Series No. GSR Part 4; revised as IAEA (2016b) ] in performing or managing a Level 1 PSA project for a nuclear power plant and using it to support its safe design and operation." IAEA (2010) specifies the need for assessing combined effects from extreme natural hazards and provides recommendations for identifying and screening combined hazards (see Section 6 of the IAEA report). Additionally, the report provides recommendations for considering combinations of hazards involving flooding, wind, and other hazards (see Section 8 of the IAEA report). IAEA (1995) provides guidance on conduct of a PSA for events leading to core damage with particular emphasis on treatment of external hazards. No specific procedural steps are provided in 
the document. The report discusses combined effects in the context of high-wind hazards combined with temperatures, precipitation, and flooding (see Section 2.2.3 of the IAEA report). IAEA Safety Report Series Standard No. 92 (IAEA 2018) provides standards for consideration of external hazards in a PSA. High-level considerations are provided for treatment of combinations of external hazards. The document refers to NUREG/CR-7046 (USNRC 2011) as providing guidance for selecting combinations of natural hazards and external artificial hazards. Furthermore, the document refers to ASME/ANS RA-S-2008 for further requirements applicable to external hazards PSA.

IAEA Safety Report Series Standard No. 92 explicitly discusses correlated hazards, which include hazards of two types: induced hazards and combined hazards. Induced hazards result when the occurrence of an initial hazard creates conditions that result in a second hazard soon after (e.g., earthquake followed by seismically induced flood). Combined hazards occur when a hazard has multiple manifestations such that a secondary effect often accompanies the primary effect (e.g., hurricane-induced high winds, precipitation, and storm surge). The document specifies that "there are no published examples of treatment of correlated hazards" in a PSA and that "procedures for identifying correlated hazards have not been formalized in the nuclear industry." Instead, the identification is left to the analyst and peer review team. However, the document does provide guidance for screening correlated hazards.

In EPRI (2015), the Electrical Power Research Institute (EPRI) reviews the current state of nuclear industry practice for identifying and screening external hazards. Although the report is broad in scope, it includes a section focused on multiple or combined hazards, which the report groups into three types:

- Consequential hazards - "one or more hazards that affect the plant and occur as the result of a separate event that also affects the plant"

- Correlated hazards - "one or more hazards that affect the plant in the same time-frame due to persistence or similar causal factors"

- Coincidental hazards - "realistic combinations of randomly occurring independent events affecting the plant simultaneously"

The report considers a range of hazards in addition to flooding hazards. In the context of combined hazards, the report identifies several IAEA documents of relevance (which are included in the previously provided summary), as well as the ASME/ANS combined PRA Standard (also previously summarized). Additionally, the EPRI report includes high-level summaries of methods used for screening or other treatment of combined events in France, Sweden, ${ }^{23}$ Finland, Germany, and Switzerland. The EPRI report also summarizes other international experiences, including outcomes of an IAEA-sponsored technical meeting in 2014 (for which a separate report was not identified), which noted some of the challenges related to assessment of combined hazards (e.g., lack of detailed guidance, reliance on expert judgement, challenges associated with development of joint distributions, and the need for practical guidance). Finally, the EPRI report includes a high-level framework for identifying and screening combinations of hazards; however, the report does not explicitly address flooding hazards or details of implementation.

\footnotetext{
${ }^{23}$ The Swedish report (Knochenhauer and Louko 2003) provides guidance for external event analysis, with specific adaptations for hazards in the country.
} 


\section{A.2 NONNUCLEAR APPLICATIONS}

Various US federal agencies provide guidance and other resources relevant to assessing flood hazards for nonnuclear applications. The following subsections summarize some relevant flood hazard literature among US federal agencies for nonnuclear flood hazard assessment applications.

\section{A.2.1 FEDERAL EMERGENCY MANAGEMENT AGENCY}

The Federal Emergency Management Agency (FEMA) is an agency within the US Department of Homeland Security responsible for developing, implementing, and supporting policies and programs for emergency management at the national, state, and local levels. FEMA also has the lead responsibility for coordinating federal efforts in dam safety and assisting states in improving their dam safety regulatory programs. Regarding floods, FEMA manages the National Flood Insurance Program, which aims to reduce "the socio-economic impact of disasters by promoting the purchase and retention of general risk insurance, but also of flood insurance, specifically" (FEMA 2018a).

FEMA provides guidelines and standards for flood risk analysis and mapping through its Risk Mapping, Assessment, and Planning (Risk MAP) program (FEMA 2018b). The program provides guidance for estimating flood scenarios of a particular frequency (typically 1 and $0.2 \% \mathrm{AEP}$, or commonly known as a 100- and 500-year return period), although the methods described could be used for evaluating alternative scenarios. Each existing Risk MAP guidance document focuses on a single flood hazard with limited or no combinations of flood mechanisms.

FEMA (2016a) includes Risk MAP guidance for estimating coastal water levels, including linear and nonlinear methods for combining tidal effects and storm surge effects. Linear interaction is assumed if it can be shown that neither effect physically alters the other. Linear methods proposed in the guidance include adding a storm surge peak and high tide, simplifying the tidal PDF to only represent a low tide and a high tide (or another representation), and linearly summing the storm surge and tidal PDFs. More complex nonlinear tidal interactions include an integrated joint probability method approach, a regression-based approach, a random timing approach, and a hybrid random timing approach. Additional physical parameters that are documented for modeling consideration include tidal, wind, and pressure boundary conditions; wind and bottom drag effects; land cover characteristics; and wave setup.

Considerations for seiche effects are included for enclosed or semi-enclosed waterbodies. Additional Risk MAP guidance is provided for coastal flooding mechanisms, including coastal wave setup (FEMA 2015) and coastal wave runup and overtopping (FEMA 2018c).

Risk MAP guidance for fluvial flooding along inland waterways is covered in multiple guidance documents on general hydrologic considerations (FEMA 2018d), general hydraulics considerations (FEMA 2016b), 1D and 2D analysis (FEMA 2016c; 2016d), ice jams (FEMA 2018e), and floodway analysis and mapping (FEMA 2016e), among others.

\section{A.2.2 US BUREAU OF RECLAMATION AND US ARMY CORPS OF ENGINEERS}

The US Bureau of Reclamation (USBR) is a federal water resource management and development agency operating in 17 western states as a part of the US Department of the Interior. USACE is a federal agency within the US Department of Defense consisting of civilian and military personnel operating across the United States and in multiple international locations. Both USBR and USACE own and operate dams across the United States, with USBR owning 474 dams and USACE owning 709 dams (FEMA 2016f).

Together, USBR and USACE play significant roles in shaping federal dam safety in the US and have developed joint documentation on best practices in dam and levee safety risk analysis (USBR and USACE 2017). USBR pioneered risk-informed dam safety techniques in the United States, and most 
USBR practices have been adopted by USACE. Current dam risk assessment practice in the United States typically requires detailed, site-specific analysis of hazards, vulnerability (fragility), and consequences, with the vulnerability estimation often involving expert elicitation.

According to USBR (2017), "manuals, guidelines, standards, and practical reference material on how to perform risk analysis for dam safety applications are lacking." To fill this gap, the Dam Safety Risk Analysis Best Practices Training Manual (USBR and USACE 2017) describes practices currently in use for estimating dam safety risks. The manual includes methods for performing probabilistic hydrologic hazard analysis (Ch. II-2) and seismic hazard analysis (Ch. II-3), both of which rely on probabilistic approaches to establish loading conditions as input to dam failure analysis. Methods for combining dam failure risk are also discussed (Ch. I-8).

In addition to ensuring dam safety and operations, the USACE is also responsible for broader flood control, response, and reduction for interior and coastal waterways under their jurisdiction, including providing disaster preparedness and response services. The USACE National Flood Risk Management Program (NFRMP) ${ }^{24}$ was established in 2006 with two primary purposes: (1) to focus USACE policies, programs, and expertise toward reducing overall flood risk; and (2) to develop a national vision for flood risk management with support at all levels of government. In its current guidance (updated in April 2018), NFRMP mentions the use of flooding probability and consequences (exposure and vulnerability) as important aspects of integrated management (USACE 2008). Current USACE guidance related to coincident and probabilistic flooding include the engineering and design manuals on "Hydrologic Analysis of Interior Areas" "Hydrologic Frequency Analysis" (USACE 2018), and "Hydrologic Engineering Requirements for Flood Damage Reduction Studies" (USACE 1995). A coincident frequency analysis editor designed based on USACE (1993) is also included in HEC-SSP for computing the exceedance frequency relationship for a variable (e.g., flow, stage, precipitation, wind) that is a function of two other variables.

\section{A.2.3 FEDERAL ENERGY REGULATORY COMMISSION}

The Federal Energy Regulatory Commission (FERC) is an independent agency within the US Department of Energy and is responsible for, among other activities, regulating the interstate transmission of electricity, natural gas, and oil; overseeing environmental matters related to natural gas and hydropower projects (including regulating nonfederal hydropower dams); and monitoring and investigating energy markets. Since it regulates hydropower projects, many of which contain dams, FERC is integrally involved in reviewing and approving hydropower licenses and in inspecting hydropower projects during and after construction. Therefore, FERC maintains responsibility for overseeing dam safety for some 2,525 dams in the United States (FEMA 2016f). Similar to USACE, FERC has adopted most USBR dam safety practices and provides relevant dam safety guidelines on its website. ${ }^{25}$

\section{A.2.4 US GEOLOGICAL SURVEY}

USGS is a science agency within the US Department of the Interior and provides science expertise about natural resource conditions and monitoring. Related to flooding, USGS is responsible for monitoring a network of more than 9,000 stream gauges nationwide. Data collected from these gauges are highly important for forecasting and monitoring floods and for conducting hydrologic research and assessments.

Related to probabilistic flood estimation, the Advisory Committee on Water Information, Subcommittee on Hydrology, Hydrologic Frequency Analysis Workgroup published Bulletin 17C (England et al. 2018)

\footnotetext{
${ }^{24}$ https://www.iwr.usace.army.mil/Missions/Flood-Risk-Management/Flood-Risk-Management-Program/ (accessed July 2019)

${ }^{25}$ https://www.ferc.gov/industries/hydropower/safety/guidelines.asp (accessed July 2019)
} 
and its predecessor, Bulletin 17B, which have served as important guidelines for estimating flood flow frequency and are used by many hydrologic and hydraulic engineers. Although published as USGS documents, both were created by interagency committees. In particular, Bulletin 17B was created by the Interagency Advisory Committee on Water Data and Bulletin 17C was developed by the Advisory Committee on Water Information, Subcommittee on Hydrology. Within the guidelines is a discussion of the various types of meteorological events that contribute to flooding. This combination of different events is referred to as "mixed populations," in that the flood frequency data, unless otherwise separated, comprises a mixture of different flood-driving mechanisms (e.g., rainfall runoff mixed with snowmelt; ice-jam floods mixed with unobstructed floods). The report identifies a few cases in which mixedpopulation analysis is used but acknowledges the need for additional efforts to provide guidance on identifying and handling mixed distributions. 
APPENDIX B. KEY COASTAL HAZARD TERMINOLOGY 



\section{APPENDIX B. KEY COASTAL HAZARD TERMINOLOGY}

This appendix provides an introductory-level explanation of key terms used to describe hazards from coastal flood mechanisms.

\section{B.1 WATER LEVEL TERMINOLOGY}

A "tide" is a long-period wave that moves through the ocean as a result of the gravitational forces exerted on the ocean by the sun and moon. These waves move from the ocean toward the coastline and back again, resulting in the rise and fall of water observable at the coast (referred to as a "tide level"), as well as a tidal current (NOAA n.d.-a). Tide levels can be predicted by considering the positions and movement of the Earth and of the sun relative to the Earth, as well as bathymetric information (Benningfield 2018). The water levels predicted using only information related to tidal waves are referred to as "predicted water levels."

The actual water levels observed at a location (typically measured by a tidal gauge) will generally differ from the predicted water levels. This difference may be due to factors such as changes in air pressure and winds caused by storms. The actual water level measured at a gauge is referred to as the "observed water level." Figure B-1 (top) shows an example of predicted water levels (solid orange line denoted by $P_{t}$ ) and observed water levels (solid purple line denoted by $O_{t}$ ) from October 28 through November 1, 2011 for National Oceanographic and Atmospheric Administration (NOAA) Station 8518750, which is located at the Battery in New York City (NOAA n.d.-b).

The difference between the predicted and observed water levels is referred to as the "nontidal residual." It is shown by the solid blue line in Figure B-1 and denoted $\eta_{t}$. It is computed as

$$
\eta_{t}=O_{t}-P_{t}
$$

where $P_{t}$ represents the predicted water level at time $t$, and $O_{t}$ represents the observed water level at time $t$. The nontidal residual is also referred to as "sea surge" and "surge residual."

"Skew surge" is a related quantity computed as the difference between the maximum observed sea level and the maximum predicted tide during a tidal cycle. There is one skew surge value per tidal cycle (NTSLF 2019). Skew surge is shown by the dotted red line in Figure B-1 and is computed as

$$
\eta_{\max , i}=O_{\max . i}-P_{\max . i}
$$

where $P_{\text {max. } i}=\max _{t_{i} \leq t<t_{i+1}}\left[P_{t}\right]$ is the maximum predicted water level during tidal cycle $i$ (shown by the dotted orange line in Figure B-1), and $O_{\max . i}=\max _{t_{i} \leq t<t_{i+1}}\left[O_{t}\right]$ is the maximum observed water level during tidal cycle $i$ (shown by the dotted purple line in Figure B-1).

When the difference in observed water levels relative to predicted water levels can be attributed to a storm event (e.g., tropical cyclone or extratropical storm), a special set of terminology is employed. "Storm tide" refers the observed water level during a storm, considering the contributions of storm surge and tides. The observed water levels shown in Figure B-1 are, in fact, the result of a storm event (Hurricane Sandy); thus, the observed water level (solid purple line) measures the storm tide for this storm event. "Storm surge" is the observed water level minus the predicted tides. Thus, for the storm event in Figure B-1 (bottom), the storm surge is equivalent to the nontidal residual shown by the solid blue line. Figure B-2 illustrates the concept of storm tide and storm surge (simply labeled "Surge") (NOAA n.d.-c). 
Storm surge and tides are not the only contributors to the water levels experienced during a storm event. During a storm, the total water level experienced on shore is the result of tides, storm surge, and breaking waves. ${ }^{26}$ As water is pushed on shore, waves become larger and contribute to higher water levels (NOAA NHC n.d.). Breaking waves contribute to water levels through "wave runup" and "wave setup" (NOAA NHC n.d.). Wave runup occurs when a wave breaks and the waves are propelled onto the shore (NOAA NHC n.d.). It is generally represented as the height above the "stillwater level" reached by the swash (FEMA 2005a). ${ }^{27}$ Wave setup describes the "additional elevation of the water level due to the effects of transferring wave-related momentum to the surf zone" (FEMA 2005a).
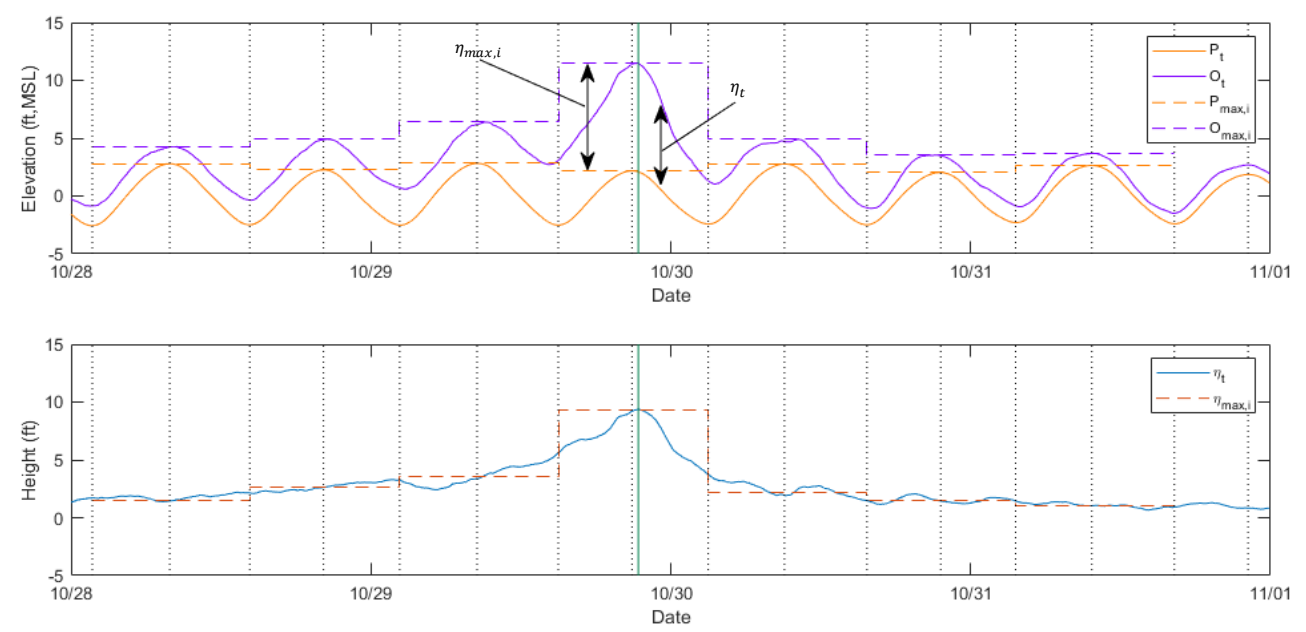

Figure B-1. (top) Example of observed water levels and predicted water levels and (bottom) example of storm surge and skew surge.

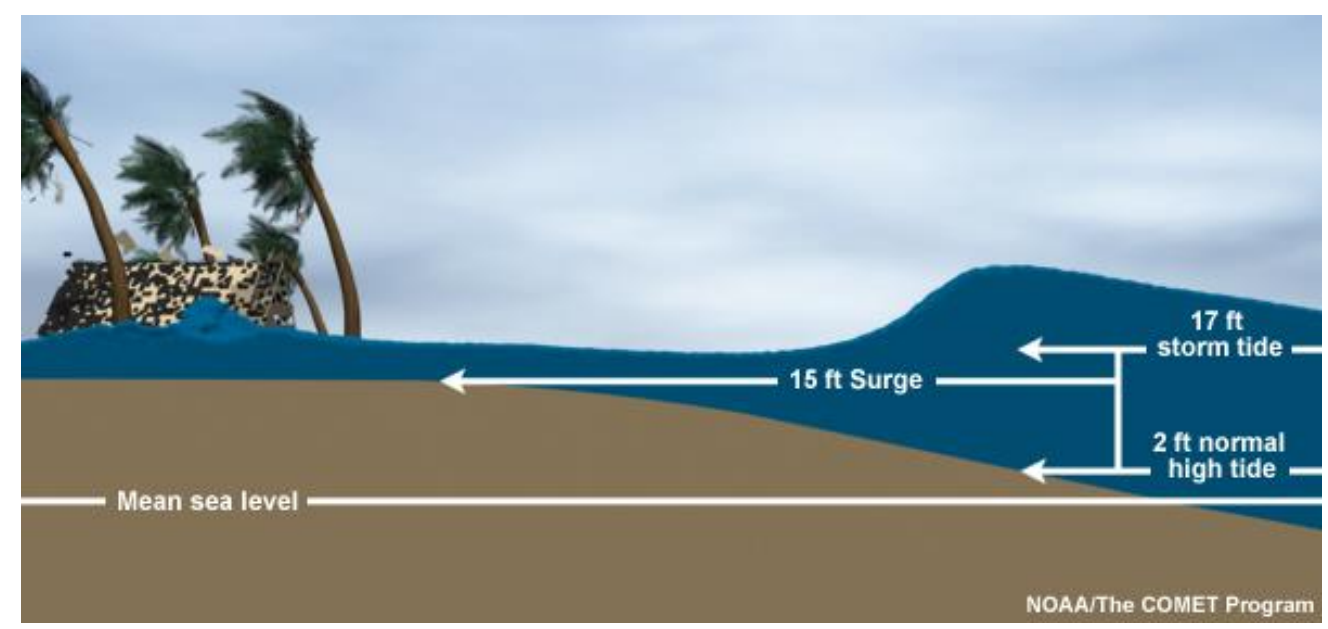

Figure B-2. Illustration of storm tide and storm surge.

\footnotetext{
${ }^{26}$ Additional contributors to total water level experienced during a storm come from the precipitation that falls during a storm event. Precipitation falling over the coastal waters can directly lead to increases in coastal water levels. Precipitation over land can also lead to rainfall runoff that discharges into the coastal environment. Contributions to water levels from these inputs are not addressed in this appendix.

${ }^{27}$ In describing the effects of coastal water levels on natural and built coastal structures, stillwater level describes a flood level not including the effect of waves. For storm-generated coastal water levels, stillwater includes the effects of storm surge and tide (FEMA 2005b). Stillwater is also used in describing hazards from a variety of flood mechanisms (e.g., river flooding) to refer to water levels in the absence of wave effects.
} 


\section{B.2 DATUMS ${ }^{28}$}

In identifying coastal water levels, the water levels need to be referenced to a vertical datum, which provides a baseline elevation from which heights and depths can be reckoned. Numerous vertical datums are used in determining coastal water levels and coastal hazards. Geodetic datums provide a reference surface whereby the Earth is represented by an ellipsoid, and water levels are provided relative to a "zero level" located on the surface of the reference ellipsoid. Examples of geodetic datums include the North American Vertical Datum of 1988 (NAVD88) and the superseded National Geodetic Vertical Datum of 1929 (NGVD 29).

Tidal datums are based on averages of tide levels over a specific time period known as a "tidal epoch." The National Tidal Datum Epoch represents the standardized time period defined by NOAA over which tidal observations are used to obtain the mean values on which tidal datums are based. Typically, a tidal epoch lasts 19 years; however, certain regions with irregular sea level changes use a shorter tidal epoch for estimating tidal datums (e.g., 5 years). Currently, the National Tidal Datum Epoch is 1983-2001. Because tidal datums are based on recordings at specific gauges, they are generally only applicable to the location for which the measurements were taken. Table 7.1 provides examples of several tidal datums (NOAA n.d.-d).

Geodetic datums provide reference points that remain consistent across large geographic regions (i.e., they provide a global reference system), whereas tidal datums provide highly localized datums. Globally referenced data provide the advantage of broad applicability; however, the idealization used to define the reference ellipsoid means that in performing assessments for small areas, local datums will generally provide higher accuracy.

Table 7.1. Examples of tidal datums.

\begin{tabular}{|l|l|}
\hline \multicolumn{1}{|c|}{ Tidal datum } & \multicolumn{1}{c|}{ Explanation } \\
\hline Highest astronomical tide & $\begin{array}{l}\text { The elevation of the highest predicted astronomical tide expected to occur at a specific tide station } \\
\text { over the National Tidal Datum Epoch }\end{array}$ \\
\hline Mean higher high water & $\begin{array}{l}\text { For any given day, "higher high water" refers to the higher of the two tides per day (if applicable). } \\
\text { "Mean higher high water" is the average of the higher high water height of each tidal day } \\
\text { observed over the National Tidal Datum Epoch }\end{array}$ \\
\hline Mean high water & The average of all the high water heights observed over the National Tidal Datum Epoch \\
\hline Mean tide level & The arithmetic mean of mean high water and mean low water \\
\hline Mean sea level & $\begin{array}{l}\text { The arithmetic mean of hourly heights observed over the National Tidal Datum Epoch. Shorter } \\
\text { series are specified in the name (e.g., monthly mean sea level and yearly mean sea level) }\end{array}$ \\
\hline Mean low water & The average of all the low water heights observed over the National Tidal Datum Epoch \\
\hline Mean lower low water & $\begin{array}{l}\text { For any given day, "lower low water" refers to the lower of the two tides per day (if applicable). } \\
\text { "Mean lower low water" is the average of the lower low water height of each tidal day observed } \\
\text { over the National Tidal Datum Epoch }\end{array}$ \\
\hline
\end{tabular}

${ }^{28}$ Information is this section is aggregated from several NOAA resources (NOAA 2018, 2019, n.d.-d; NOAA NHC 2016). 